\title{
DRESS, APPEARANCE, AND DIVERSITY IN U.S. SOCIETY
}

KELLY L. REDDY-BEST

ABBEY K. ELDER AND LESYA HASSALL

Iowa State University Digital Press

Ames, IA 
(ㄷ) (1)

Dress, Appearance, and Diversity in U.S. Society by Kelly Reddy-Best is licensed under a Creative Commons Attribution 4.0 International License, except where otherwise noted.

Cover photo by Daian Gan from Pexels. 


\section{CONTENTS}

Introduction vii

Contents vii

Content Course Level Objectives (CLO) vii

Soft Skills Course-Level Objective (CLO) viii

Module Level Objectives (MLO) viii

How to Use This Book xiv

Book Organization xiv

Example Chapter Case Study X xv

\section{Part I. Dress Theories and Concepts}

$\begin{array}{lr}\text { 1. Orientation and Honesty } & 2\end{array}$

Syllabus: AMD 165 Dress, Appearance, and Diversity in U.S. Society 2

Honesty 2

Academic Dishonesty at lowa State University 3

Honesty Case Study $\quad 3$

2. Dress, Appearance, and Identity $\quad 4$

$\begin{array}{lc}\text { Dress and Dressing } & 6\end{array}$

Identity

Socialization 11

Identity and Dress 12

Stigma and Identity 14

Focused Example: Quinceañera 16

$\begin{array}{ll}\text { Dress, Appearance, and Identity Case Study } & 17\end{array}$ 
$\begin{array}{lr}\text { 3. Identity, Social Justice, and Dress } & 18\end{array}$

$\begin{array}{ll}\text { Social Justice } & 18\end{array}$

$\begin{array}{ll}\text { Privilege } & 20\end{array}$

$\begin{array}{ll}\text { Stereotyping } & 21\end{array}$

Implicit Bias $\quad 22$

Empathy $\quad 23$

A Lens of Individual and Systemic Oppression 25

Focused Example: For Everyone Collective 25

Identity, Social Justice, and Dress Case Study 26

4. Social Science Theories $r$

$\begin{array}{ll}\text { Role Theory } & 27\end{array}$

Conformity

Symbolic Interactionism-Public, Intimate, and Secret Self 33

Focused Example: Prison Uniforms

$\begin{array}{ll}\text { References } & 36\end{array}$

Social Science Theories Case Study $\quad 37$

$\begin{array}{ll}\text { 5. Culture } & 38\end{array}$

$\begin{array}{ll}\text { What Is Culture? } & 38\end{array}$

Society vs. Culture $\quad 41$

Cultural Appropriation $\quad 45$

References $\quad 46$

$\begin{array}{ll}\text { Culture Case Study } & 47\end{array}$

6. Subculture and Group Membership 48

What Is a Subculture?

$\begin{array}{ll}\text { Social Groups } & 49\end{array}$

Subcultures are Dependent on Context

Subcultural Style $\quad 53$

References

Subculture and Group Membership Case Study 
7. Fashion Theories $\quad 57$

$\begin{array}{ll}\text { Fashion } & 57\end{array}$

$\begin{array}{ll}\text { Fashion Diffusion } & 59\end{array}$

$\begin{array}{ll}\text { Fashion Theories } & 61\end{array}$

$\begin{array}{ll}\text { References } & 64\end{array}$

Fashion Theories Case Study $\quad 65$

\section{Part II. Dress and Marginalized Communities}

$\begin{array}{lr}\text { 8. Sex and Gender } & 67\end{array}$

$\begin{array}{ll}\text { Sex } & 67\end{array}$

$\begin{array}{ll}\text { Gender } & 68\end{array}$

Trans, Genderqueer, and Nonbinary Identities and Dress $\quad 71$

$\begin{array}{ll}\text { References } & 75\end{array}$

$\begin{array}{ll}\text { Sex and Gender Case Study } & 76\end{array}$

$\begin{array}{ll}\text { 9. Sexuality } & 77\end{array}$

Gender Identity

$\begin{array}{ll}\text { Sexuality and Signifiers } & 79\end{array}$

Gay Identities and Dress $\quad 86$

Bisexual Identities and Dress $\quad 89$

The Fashion Industry and LGBTQIA+ Identities

$\begin{array}{ll}\text { References } & 93\end{array}$

$\begin{array}{lc}\text { Sexuality Case Study } & 98\end{array}$

10. Beauty and Attractiveness 99

“Beauty Is Good” Stereotype $\quad 99$

Symbolic Interaction Process and Body Satisfaction 102

Cultural Influences on How We Think About the Body 103

Faces and Attraction $\quad 104$

$\begin{array}{ll}\text { References } & 107\end{array}$

$\begin{array}{ll}\text { Beauty and Attractiveness Case Study } & 108\end{array}$ 
11. Disability 109

History of the Disabilities Rights Movement $\quad 110$

Hearing Devices $\quad 111$

Mobility Impairment and Dress 113

Disability Case Study $\quad 117$

$\begin{array}{ll}\text { 12. Religion } & 118\end{array}$

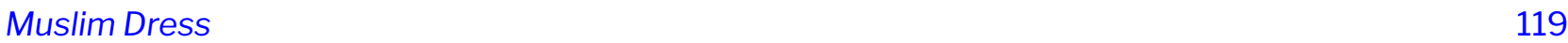

$\begin{array}{ll}\text { Jewish dress } & 122\end{array}$

$\begin{array}{ll}\text { Buddhist Dress } & 124\end{array}$

Sikh Turbans and Gucci 125

Religion Case Study 126

$\begin{array}{lr}\text { 13. Race and Ethnicity } & 127\end{array}$

$\begin{array}{ll}\text { Ethnicity versus Race } & 127\end{array}$

Roots of Ethnicity 129

Race and Ethnicity Case Study 133

$\begin{array}{ll}\text { Final Student Reflection } & 134\end{array}$

$\begin{array}{ll}\text { Book Contributors } & 141\end{array}$ 


\section{INTRODUCTION}

The book was created for use in a course at lowa State University, AMD 165 Dress, Appearance, and Diversity in US Society. The course description is below.

Examination of dress and appearance practices and experiences of marginalized identities and communities in the United States. Introduction to fashion- and dress-related theories, culture and identity concepts, and social justice concepts and issues in regards to dress, appearance, and fashion in the fashion industry. Meets US diversity requirement.

In this course, students are introduced to topics about identity, dress, and the body. We explore how individuals and communities use dress to communicate (i.e., "negotiate," in fashion studies) their various identities. There is heightened attention to social justice, power, privilege, and oppression. That is, we focus on the experiences of historically marginalized communities and the ways they navigate dress and dressing their bodies in different contexts.

An increased awareness of appearances and fashions of individuals historically experiencing oppression and marginalization can aid in developing a more socially just environment and reject past perpetuations of white supremacy, ableism, homophobia, transphobia, fat phobia, and xenophobia. As students enter the workforce with a social justice background, they will better understand and work with others who are different from them. Additionally, a better understanding of diverse consumers could help provide these consumers with the products they desire, in addition to avoiding public diversity issues that are far too common in the fashion industry.

\section{Contents}

The book contains two distinct parts.

Part 1: Dress Theories and Concepts introduces readers to concepts and theories related to fashion, clothing, dress, and/or accessories.

Part 2: Dress and Marginalized Communities asks readers to examine the role fashion, clothing, dress, and/ or accessories play in identity development for individuals in marginalized communities in the United States.

\section{Content Course Level Objectives (CLO)}

- CLO 1 Analyze foundational concepts and theories related to dress, identity, fashion, and culture and how they intersect with sex, gender, sexuality, beauty, attractiveness, disability, religion, race, and ethnicity, 
with heightened attention to marginalized communities in the United States.

- CLO 2: Analyze the experiences and the role of fashion, clothing, dress, and/or accessories for identity development with heightened attention to marginalized communities within social contexts in the United States.

- CLO 3: Critique social justice issues within the fashion system in the United States for marginalized communities.

- CLO 4: Deconstruct your own personal values and positionalities in relation to fashion, clothing, dress, and/or accessories with heightened attention to marginalized communities in US society to be able to live in and collaborate with others in the United States.

- CLO 5: Identify the driving forces of transformative social justice change in the fashion system.

\section{Soft Skills Course-Level Objective (CLO)}

- CLO 6: Analyze what academic honesty means, your experiences with academic honesty, and your related future goals.

\section{Module Level Objectives (MLO)}

\section{Part 1: Dress Theories and Concepts}

\section{Orientation and Honesty}

- MLO 1.1. Identify the policies in the syllabus.

- MLO 1.2 Meet other students to create a sense of community.

- MLO 1.3 Identify concepts related to academic honesty and dishonesty. [CLO 6]

- MLO 1.4 Explain ways to engage in honest behaviors in the course. [CLO 6]

- MLO 1.5 Explain ways to engage in dishonest behaviors in the course and the related consequences. [CLO 6]

- MLO 1.6 Articulate your past perspectives and experiences with honesty in college courses. [CLO 6]

- MLO 1.7 Articulate your perspectives, approaches, and plans for honesty in this course. [CLO 6]

\section{Dress, Appearance, and Identity}

- MLO 2.1 Identify foundational concepts and theories related to identity and dress. [CLO 1]

- MLO 2.2 Identify pioneering scholars in the identity and dress discipline [CLO 1]

- MLO 2.3 Identify the sources of information and research for the course content. [CLO 1]

- MLO 2.4 Summarize the role of dress in identity development. [CLO 1]

- MLO 2.5 Explain the ways individuals learn about how to dress. [CLO 1]

- MLO 2.6 Explain various motivations for dress. [CLO 1] 
- MLO 2.7 Analyze the relationships among stigma, stigma management, identity, and dress. [CLO 1]

- MLO 2.8 Deconstruct your own perspectives and approaches to understanding the dress of others. [CLO 4]\

\section{Social Justice}

- MLO 3.1 Identify foundational concepts related to social justice, identity, and dress. [CLO 1]

- MLO 3.2 Identify driving forces of transformative social change. [CLO 5]

- MLO 3.3 Articulate your own positionalities. [CLO 4]

- MLO 3.4 Reflect on your progress towards development of empathy related to social justice issues, identity, and dress. [CLO 4]

- MLO 3.5 Examine social justice issues in the fashion industry. [CLO 3]

\section{Social Science Theories}

- MLO 4.1 Identify foundational concepts and theories related to identity and dress. [CLO 1]

- MLO 4.2 Summarize the role of dress in identity development. [CLO 1]

- MLO 4.3 Analyze identity and dress with social science theories and concepts. [CLO 2]

- MLO 4.4 Analyze the norms that influence your own identities and dress. [CLO 4]

\section{Culture}

- MLO 5.1 Identify foundational concepts and theories related to culture, identity, and dress. [CLO 1]

- MLO 5.2 Identify the factors that influence different cultural aspects of dress. [CLO 1]

- MLO 5.3 Identify the different cultural perspectives an individual can take to approach understanding the dress and identity of others. [CLO 1]

- MLO 5.4 Explain the role of dress in identity development. [CLO 1]

- MLO 5.5 Examine how marginalized communities in the United States use dress and appearance to negotiate their identities. [CLO 2]

- MLO 5.6 Deconstruct your own perspectives and approach to understanding the dress of others. [CLO 4]

\section{Subculture and Group Membership}

- MLO 6.1 Identify foundational concepts and theories related to subcultures, identity, appearance, and dress. [CLO 1]

- MLO 6.2 Identify the factors that influence different aspects of subcultural dress. [CLO 1]

- MLO 6.3 Explain the role of dress and appearance in identity development for different subcultures. [CLO 1]

- MLO 6.4 Examine how marginalized communities in the United States use dress and appearance to negotiate their identities. [CLO 2] 
- MLO 6.5 Deconstruct your own perspectives and approach to understanding the dress of subcultures. [CLO 4]

\section{Fashion Theories}

- MLO 7.1 Identify foundational concepts and theories related to fashion, identity, appearance, and dress. [CLO 1]

- MLO 7.2 Identify the basic tenets of fashion theories and how they help explain dress and appearance. [CLO 2]

- MLO 7.3 Explain how marginalized communities in the United States use dress and appearance to express their identities. [CLO 2]

- MLO 7.4 Examine how dress and appearance of marginalized communities in the United States are represented in the fashion system (e.g., advertisements or retailers). [CLO 3]

- MLO 7.5 Examine social justice issues related to dress and appearance of marginalized communities in the United States. [CLO 3]

- MLO 7.6 Deconstruct your own perspectives and approach to understanding the dress of others. [CLO 4]

\section{Part 2: Dress and Marginalized Communities}

\section{Sex and Gender}

- MLO 8.1 Identify foundational concepts and theories related to sex and gender, fashion, identity, appearance, and dress. [CLO 1]

- MLO 8.2 Identify the numerous aspects of transition for individuals in the transgender and nonbinary communities in the United States. [CLO 1]

- MLO 8.3 Identify different types of dress worn by the transgender and nonbinary communities in the United States to affirm their gender identities. [CLO 1]

- MLO 8.4 Identify trans and nonbinary people's experiences in the United States wearing different dress objects reflecting their trans and nonbinary identity. [CLO 1]

- MLO 8.5 Identify different fashion brands that produce and sell dress objects for the transgender and nonbinary communities in the United States to affirm their gender identities. [CLO 3]

- MLO 8.6 Identity how gender expressions and norms have shifted and changed over time and across different cultures. [CLO 2]

- MLO 8.7 Explain the role of dress and appearance in the development of one's sex assigned at birth and their gender. [CLO1]

- MLO 8.8 Examine social justice issues related to dress and appearance of the transgender and nonbinary communities in the United States. [CLO 3]

- MLO 8.9 Deconstruct your own perspectives and approach to understanding the dress and appearance of the transgender and nonbinary communities in the United States. [CLO 4]

- MLO 8.10 Identify the driving forces of transformative social justice change in the fashion system related 
to transgender and nonbinary identities in the United States. [CLO 5]

\section{Sexuality}

- MLO 9.1 Identify foundational concepts related to sexuality, fashion, identity, appearance, and dress. [CLO 1]

- MLO 9.2 Identify different types of dress worn by queer communities in the United States to express their sexual identities. [CLO 1]

- MLO 9.3 Identify queer people's experiences in the United States wearing different dress object reflecting their queer identities. [CLO 2]

- MLO 9.4 Identify different fashion brands that produce and sell dress objects for the queer community in the United States to affirm their sexual identities. [CLO 1]

- MLO 9.5 Explain the role of dress and appearance in the development of one's queer identity in the United States. [CLO 1]

- MLO 9.6 Examine how dress and appearance of queer communities in the United States are represented in the fashion system (e.g., advertisements or retailers). [CLO 3]

- MLO 9.7 Examine social justice issues related to dress and appearance of the queer community in the United States. [CLO 3]

- MLO 9.8 Deconstruct your own perspectives and approach to understanding the dress and appearance of queer communities in the United States. [CLO 4]

- MLO 9.9 Identify the driving forces of transformative social justice change in the fashion system related to queer identities in the United States. [CLO 5]

\section{Beauty and Attractiveness}

- MLO 10.1 Identify foundational concepts related to beauty, attractiveness, identity, appearance, and dress. [CLO 1]

- MLO 10.2 Identify the ways beauty and perceptions of attractiveness influence people's experiences. [CLO 1]

- MLO 10.3 Identify the aspects of facial appearance that contribute to perceptions of attractiveness. [CLO 1]

- MLO 10.4 Identify how people alter their bodies when they do not think they are attractive or meet cultural beauty ideals. [CLO 1]

- MLO 10.5 Identify factors that influence why people alter their bodies when they do not think they are attractive or meet a specific beauty ideal. [CLO 1]

- MLO 10.6 Identify people's experiences related to meeting the ideals of beauty or perceptions of attractiveness. [CLO 2]

- MLO 10.7 Examine social justice issues related to dress appearance, and interpretations of beauty and attractiveness in the United States. [CLO 3]

- MLO 10.8 Analyze how dress, appearance, and concepts of beauty and attractiveness in the United States are represented in the fashion system (e.g., advertisements or retailers). [CLO 3] 
- MLO 10.9 Deconstruct your own perspectives and approaches to understanding dress, appearance, beauty, and attractiveness in the United States. [CLO 4]

- MLO 10.10 Identify the driving forces of transformative social justice change in the fashion system related to beauty and attractiveness in the United States. [CLO 5]

(Dis)ability

- MLO 11.1 Identify foundational concepts related to disability, fashion, identity, appearance, and dress. [CLO 1]

- MLO 11.2 Identify different types of dress worn by people with disabilities in the United States. [CLO 1]

- MLO 11.3 Identify the experiences of people with disabilities in the United States wearing different dress objects reflecting their disability identities. [CLO 2]

- MLO 11.4 Identify different fashion brands that produce and sell dress objects for people with disabilities in the United States. [CLO 2]

- MLO 11.5 Explain the role of dress and appearance in the development of one's disability identity. [CLO 2]

- MLO 11.6 Examine how dress and appearance of people with disabilities in the United States are represented in the fashion system (e.g., advertisements or retailers). [CLO 3]

- MLO 11.7 Examine social justice issues related to dress and appearance for people with disabilities in the United States. [CLO 3]

- MLO 11.8 Deconstruct your own perspectives and approach to understanding the dress and appearance of people with disabilities in the United States. [CLO 4]

- MLO 11.9 Identify the driving forces of transformative social justice change in the fashion system related to disabilities in the United States. [CLO 5]

\section{Religion}

- MLO 12.1 Identify foundational concepts related to religion, fashion, identity, appearance, and dress. [CLO 1]

- MLO 12.2 Identify different types of dress worn by people following different oppressed religions in the United States. [CLO 1]

- MLO 12.3 Identify people following different oppressed religions experiences in the United States wearing different dress objects reflecting their religious identities. [CLO 1]

- MLO 12.4 Identify different fashion brands that produce and sell dress objects for people following different oppressed religions in the United States. [CLO 2]

- MLO 12.5 Explain the role of dress and appearance in the development of one's religious identity in the United States. [CLO 2]

- MLO 12.6 Examine how dress and appearance of people following different oppressed religions in the United States are represented in the fashion system (e.g., advertisements or retailers). [CLO 3]

- MLO 12.7 Examine social justice issues related to dress and appearance for people following different oppressed religions in the United States. [CLO 3]

- MLO 12.8 Deconstruct your own perspectives and approach to understanding the dress and appearance 
of people following different oppressed religions in the United States. [CLO 4]

- MLO 12.9 Identify the driving forces of transformative social justice change in the fashion system related to oppressed religious groups in the United States. [CLO 5]

\section{Race and Ethnicity}

- MLO 13.1 Identify foundational concepts related to race, ethnicity, fashion, identity, appearance, and dress. [CLO 1]

- MLO 13.2 Identify different types of dress worn by people of color in the United States. [CLO 1]

- MLO 13.3 Identify people of color's experiences wearing different dress object reflecting their race and/or ethnicity in the United States. [CLO 2]

- MLO 13.4 Identify different fashion brands that produce and sell dress objects for people of color in the United States. [CLO 2]

- MLO 13.5 Explain the role of dress and appearance in the development of one's racial and/or ethnic identity in the United States. [CLO 2]

- MLO 13.6 Examine how dress and appearance of people of color in the United States are represented in the fashion system (e.g., advertisements or retailers). [CLO 3]

- MLO 13.7 Examine social justice issues related to dress and appearance for people of color in the United States. [CLO 3]

- MLO 13.8 Deconstruct your own perspectives and approach to understanding the dress and appearance of people of color in the United States. [CLO 4]

- MLO 13.9 Identify the driving forces of transformative social justice change in the fashion system related to people of color in the United States. [CLO 5] 


\section{HOW TO USE THIS BOOK}

This is a free textbook geared toward college-level courses about dress and identity. The book was written to help students learn about dress and identity and how these topics intersect with marginalized communities. Everyone interacts with different people in their day-to-day lives; a greater understanding of others can lead to a more equitable, just society.

This textbook was funded by the Miller Open Education Mini-Grant Program at lowa State University. Extra care and effort were involved to give you high-quality, affordable course materials. I am interested in your experience using these materials and welcome your feedback. If you find any issues or missing areas in this text or want to offer positive feedback, email me at klrb@iastate.edu.

\section{Book Organization}

Each chapter within this book contains

- Learning objectives: a list of major topics covered in the chapter and what you should expect to learn more about as you read.

- Content: the bulk of the chapter, including original text, summaries of peer-reviewed scholarship, and media to demonstrate examples from the text.

- Interactive questions: review questions are embedded in each chapter; use these to check your understanding of what you've learned.

- Case study: Each case study assignment is related to the chapter's content. You will recognize the case study in its callout box at the end of each chapter. The downloadable Word document provided outlines the tasks and evaluation criteria for the assignment and provides a template for submissions. 


\section{Example Chapter Case Study}

ค. จ

The case study attached below is a Word document and can be downloaded. It includes the task, evaluation, and template for the case study:

[Example Word Document would be linked here]

\section{How to Navigate our Book}

One or more interactive elements has been excluded from this version of the text. You can view them online here:

㚇 https://iastate.pressbooks.pub/dressappearancediversity/?p=238\#oembed-1 
PART I

DRESS THEORIES AND CONCEPTS 


\section{1. \\ ORIENTATION AND HONESTY}

\section{Module Learning Objectives (MLO)}

In this chapter, you will

- MLO 1.1. Identify the policies in the syllabus.

- MLO 1.2 Meet other students to create a sense of community.

- MLO 1.3 Identify concepts related to academic honesty and dishonesty. [CLO 6]

- MLO 1.4 Explain ways to engage in honest behaviors in the course. [CLO 6]

- MLO 1.5 Explain ways to engage in dishonest behaviors in the course and the related consequences. [CLO 6]

- MLO 1.6 Articulate your past perspectives and experiences with honesty in college courses. [CLO 6]

\section{Syllabus: AMD 165 Dress, Appearance, and Diversity in U.S. Society}

You can download the syllabus for our class as a Word document by clicking the link below:

AMD_165_Syllabus_Spring_2022 [DOC]

\section{Honesty}

In this course, honesty is an important value. Before beginning with the course content, read this short article on the Philosophy of Honesty:

Borghini, A. (2020, February 1). "The Philosophy of Honesty." ThoughtCo. Retrieved from https://www.thoughtco.com/philosophy-of-honesty-2670612. 


\section{Academic Dishonesty at lowa State University}

lowa State University has policies regarding academic honesty. Review the updated policies on the $\underline{\text { Academic }}$ Conduct website.

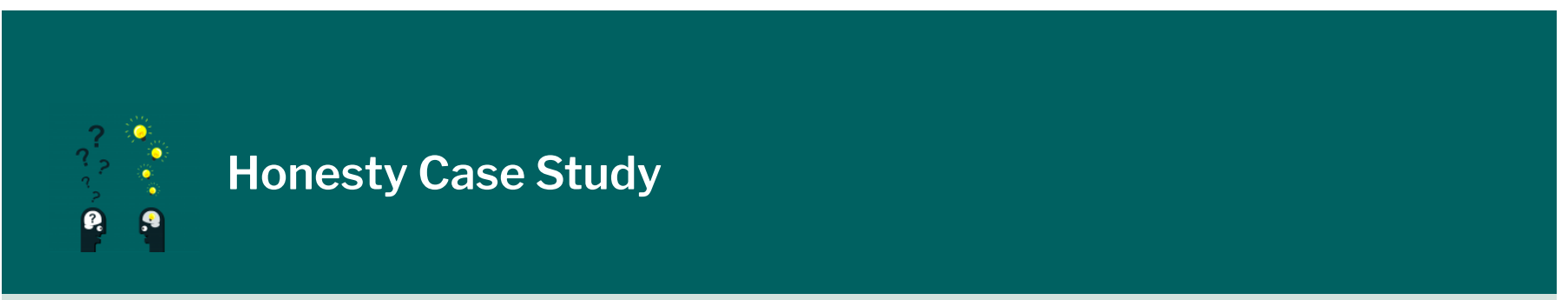

Step One: Become familiar with the case study.

1. The case study attached below is a Word document and can be downloaded. It includes the task, evaluation, and template for the case study:

Honesty Case Study [DOC]

Step Two: Submit your complete assignment on Canvas.

1. Format your document.

2. Remember to check the submission against the rubric. 


\section{2. \\ DRESS, APPEARANCE, AND IDENTITY}

\section{Module Learning Objectives (MLO)}

In this chapter, you will

- MLO 2.1 Identify foundational concepts and theories related to identity and dress. [CLO 1]

- MLO 2.2 Identify pioneering scholars in the identity and dress discipline. [CLO 1]

- MLO 2.3 Identify the sources of the information and research for the course content. [CLO 1]

- MLO 2.4 Summarize the role of dress in identity development. [CLO 1]

- MLO 2.5 Explain the ways individuals learn about how to dress. [CLO 1]

- MLO 2.6 Explain various motivations for dress. [CLO 1]

- MLO 2.7 Analyze the relationships among stigma, stigma management, identity, and dress. [CLO 1]

- MLO 2.8 Deconstruct your own perspectives and approaches to understanding the dress of others. [CLO 4]

The material presented in this book comes from studies or research in various fields of inquiry, or disciplines. Some of the fields that relate to the topics covered in this book include those listed below:

- psychology

- social psychology

- anthropology

- cultural studies

- women's studies

- fashion studies

Scholars and researchers (e.g., professors, government agencies, and nonprofits) do systematic inquiry through studies, research, and anonymous peer review prior to their work being published.

\section{What Is Peer Review?}

Peer review is a really important part of publishing scholarship. Much of the work discussed in this book is from 
peer-reviewed research. Peer-reviewed research, the lengthy process outlined below, can take anywhere from six months to multiple years.

1. Researcher(s) conducts a study and write(s) up their results in a paper.

2. The researcher(s) submit(s) their paper to an editor.

3. Keeping the author(s) name(s) anonymous, the editor sends the paper out to two or more reviewers who evaluate it for content and rigor.

4. The reviewers decide whether the paper should be published also suggest changes (often, a significant number of changes).

5. The researcher/author(s) edit(s) their paper based on the reviewers' feedback (sometimes over multiple rounds).

6. Finally, the paper is published.

\section{Types of Inquiry}

There are many ways to study dress, appearance, and identity. The following are a few examples:

- observation: ethnography, prolonged engagement with community; today there are both in-person and online ethnographic methods.

- material culture: study of objects such as at a museum or in an archive.

- historical investigation: examination of documents, garments, and other primary sources to tell the story of the past.

- survey: fill in the blank, check a box.

- interviews: both individual and focus groups (multiple people).

\section{Example of a peer-reviewed research paper}

Below is an example of a published peer-reviewed paper. Scholars at Cornell University conducted the research and then published it in an academic journal.

Study: Negotiating Identities in the Furry Fandom through Costuming (Satinsky \& Green, 2016)

Method: The authors used various methods to investigate how individuals negotiate their varying identities through costume at furry conventions.

- Drawing on ethnography, the scholars attended and observed two furry fandom conventions. They also conducted in-depth interviews and asked questions of attendees. Watch this short video to see a visual of a furry convention. 
To view a transcript for this video, download this file: Anthrocon 2017 Brings Furry Fandom to Pittsburgh Video Transcript [DOC]

This video example uses anecdotal evidence, or evidence based on or consisting usually of reports or observations of unscientific observers. That is, this video was not peer-reviewed and published in an academic forum. While anecdotal evidence can be important and cannot be discounted, much of the work in this book is from peer-reviewed literature.

\section{Dress and Dressing}

Dress is not just this yellow garment:

Dress is an intentional and unintentional modification of appearance, what people do to their bodies to maintain, manage, and alter appearance. This includes

- objects worn on or around the body

- modifications to the body (e.g., plastic surgery).

Dressing is the behavior related to dress or actions related to how one appears.

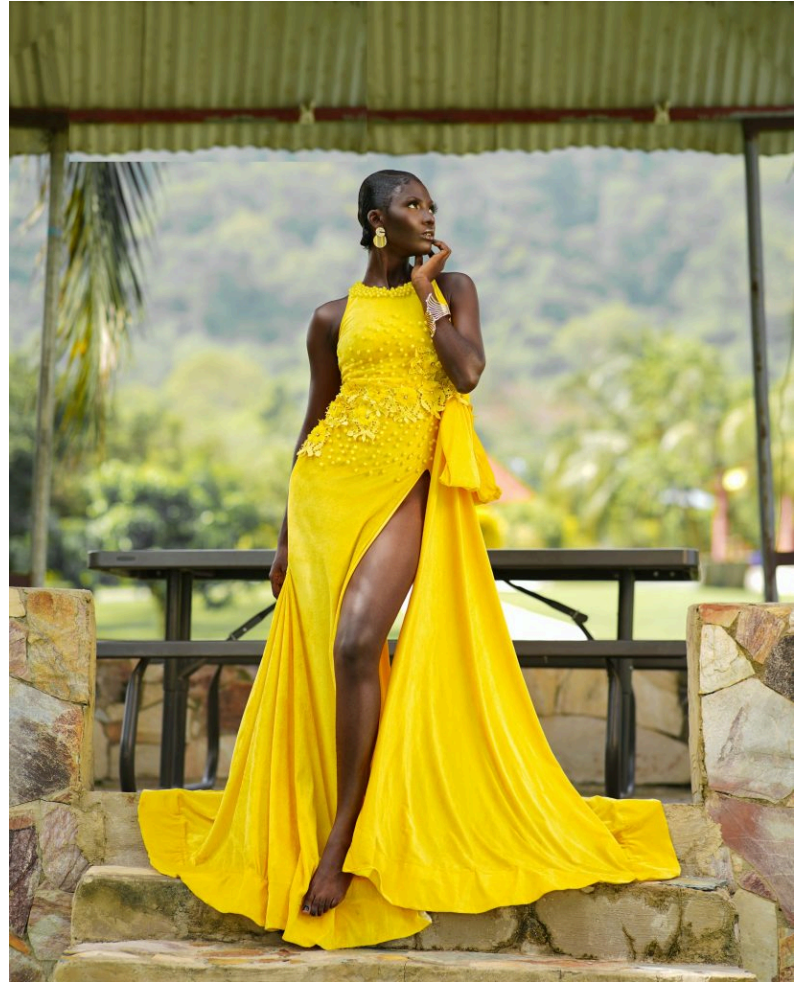

This person is wearing a yellow dress. However, in fashion studies dress refers to much more than the composition of an object such as this yellow garment. Image Source: Built by King 


\section{Pioneering Scholars in Fashion Studies}

- Susan Kaiser

- Elizabeth Way

- Darnell-Jamal Lisby

- Ben Barry

- Phyllis Bell Miller

- Gwendolyn O’Neal

- Min-ha T. Pham

- Jasmine Helm

- Christina Moon

- Amanda Muhammad

- Eulanda Sanders

- Lauren Downing Peters

- Regan de Loggans
- Mary Ellen Roach-Higgins

- Kim Johnson

- Sharron Lennon

- Nancy Rudd

- Joanne Entwistle

- Fred Davis

- Christopher Breward

- Denise Nicole Green

- Tameka Ellington

- Carol Tulloch

- Kim Jenkins

- Dyese Matthews

- Tanisha Ford

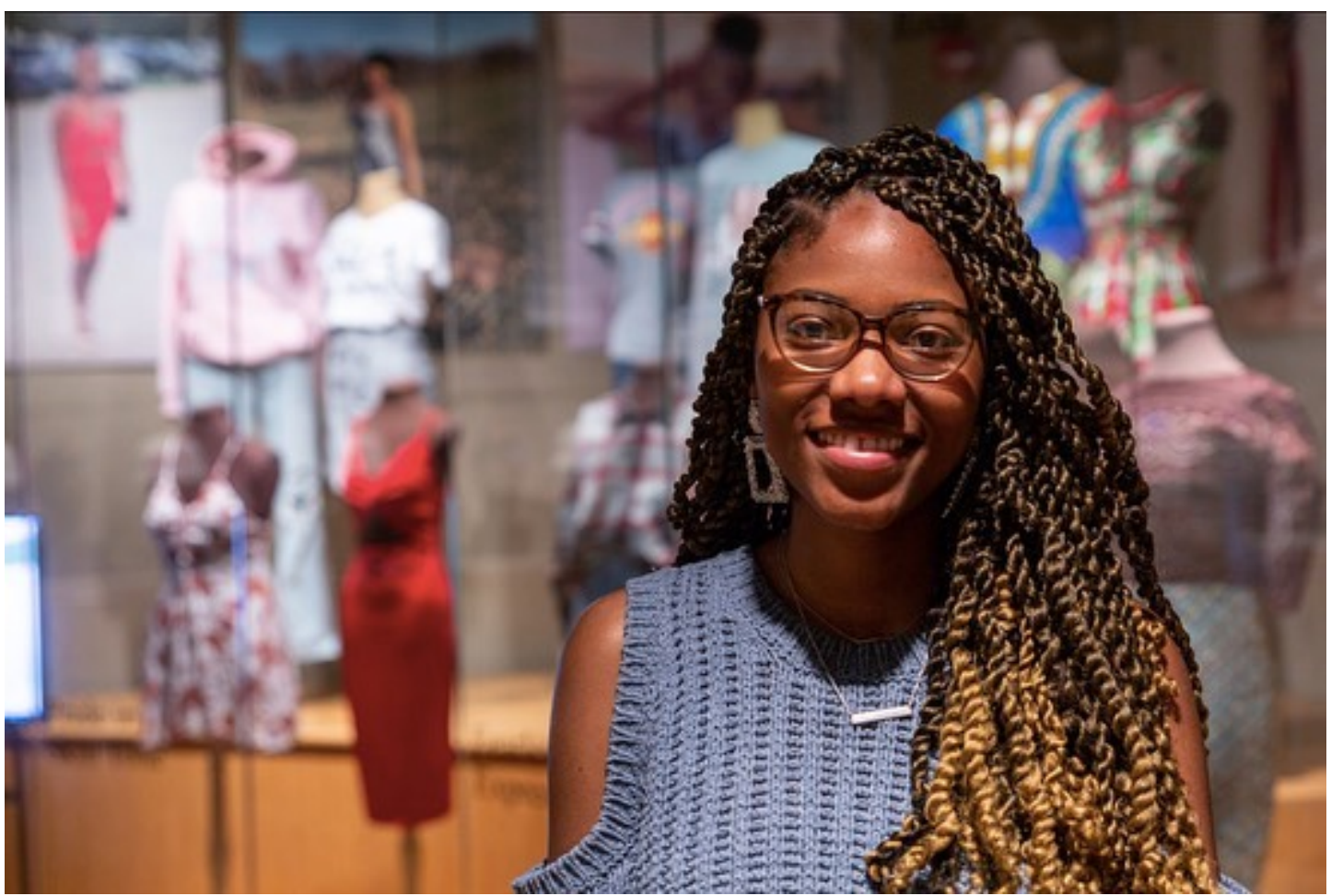

Dyese Matthews, one of the pioneering scholars in fashion studies. Image Source Dyese Matthews. 


\section{Objects}

Clothing is an example of an object worn on or around the body and refers to 3-dimensional objects that enclose and envelop the body in some way. They may be

- wrapped around the body

- suspended from the body

- fitted to the body

- preshaped to the body.

These are examples of clothing:

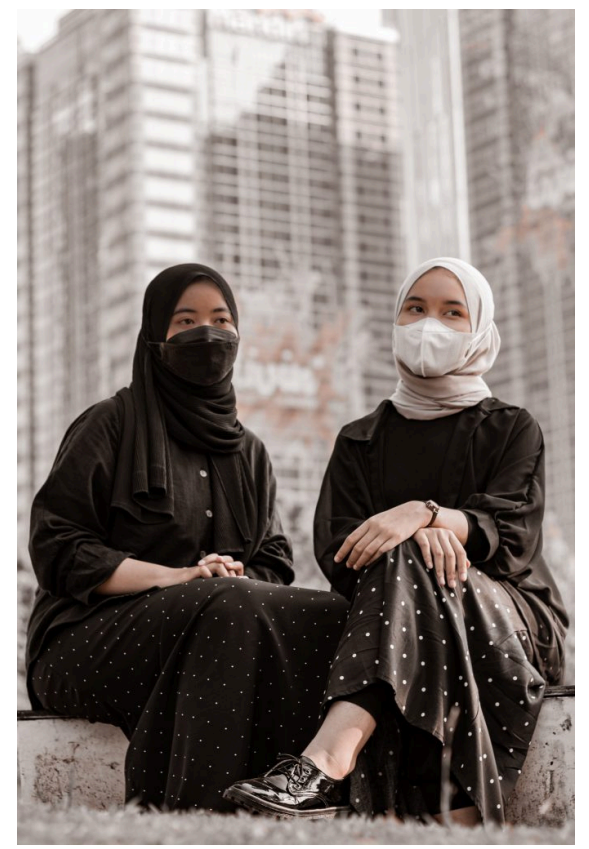

The head covering, also called a hijab, is an example of clothing. The top and skirt are also examples of clothing. Image Source: Rifki Atalla

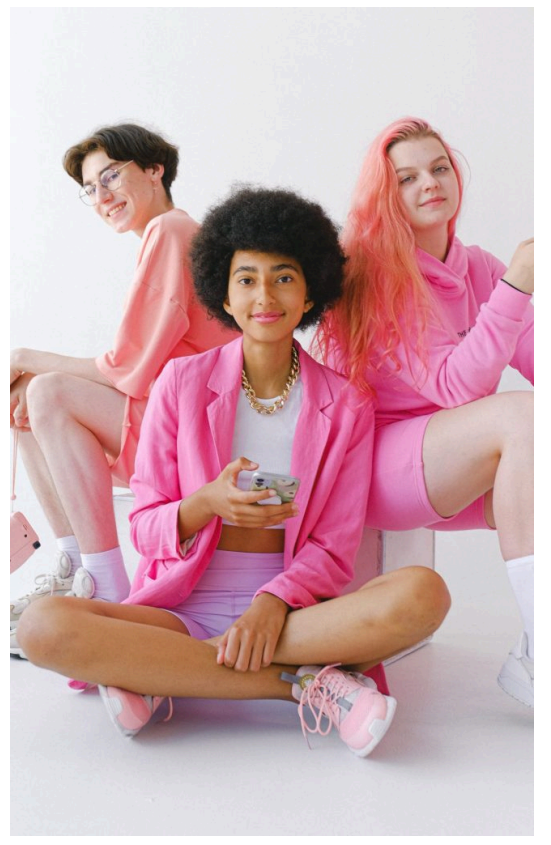

The individuals in this image are wearing different dress objects, including a blazer, shorts, sneakers, and jewelry. Image Source: Anna Shvets

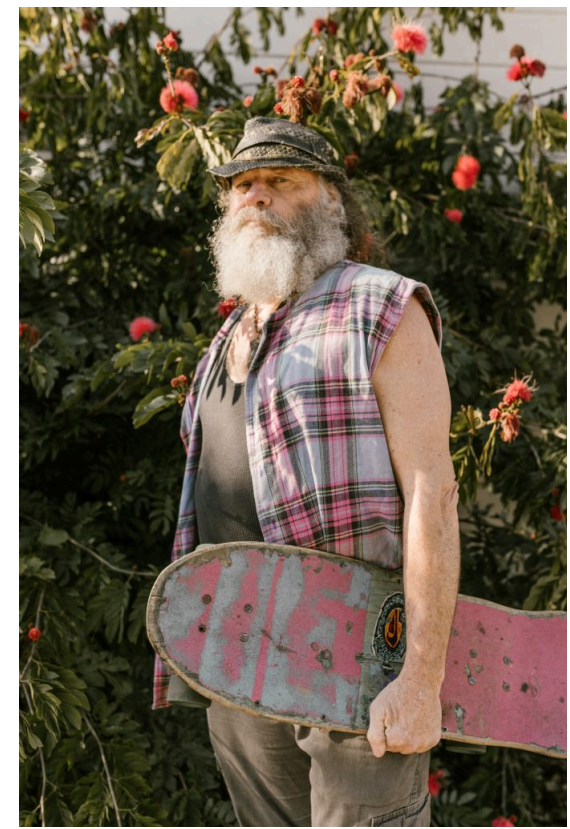

This individual is wearing various dress objects, including a hat, flannel sleeveless top, and pants. Arguably, the skateboard could be a dress object, since it is around or next to the body. Image Source: RODNAE Productions

Other examples of dress objects include accessories, shoes, and other objects worn on the body, such as braces attached to the teeth.

\section{Modifications}

Modifications are also a part of dress. These might include additions or reductions to the actual body, such as losing weight or hair extensions. Modifications also involve changing hair color, clipping nails, tanning, and 
straightening of teeth by wearing braces. Wearing perfume, showering, and having hair implants completed are also examples of modifications. Teeth whitening processes also fall under the category of dress, as they modify the color of tooth enamel.

Following are examples of reductions and modifications to the body:

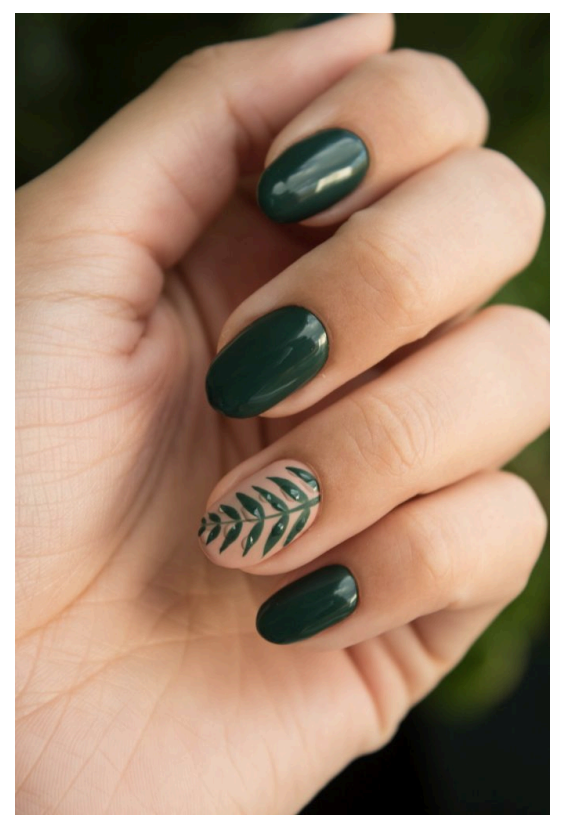

Nail polish is a example of dress modification because it alters the color of the nails. Image Source: Kristina Paukshtite

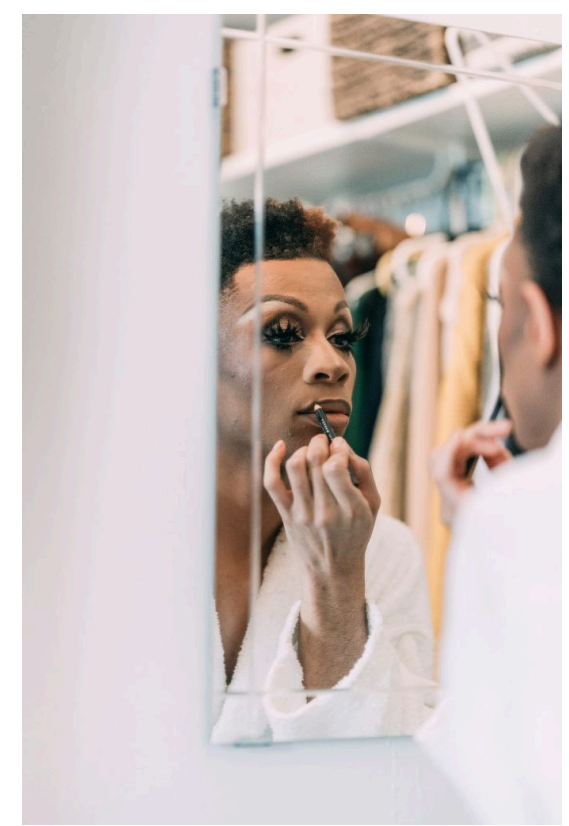

Makeup and fake eyelashes are examples of dress modification. Image Source: Greta Hoffman

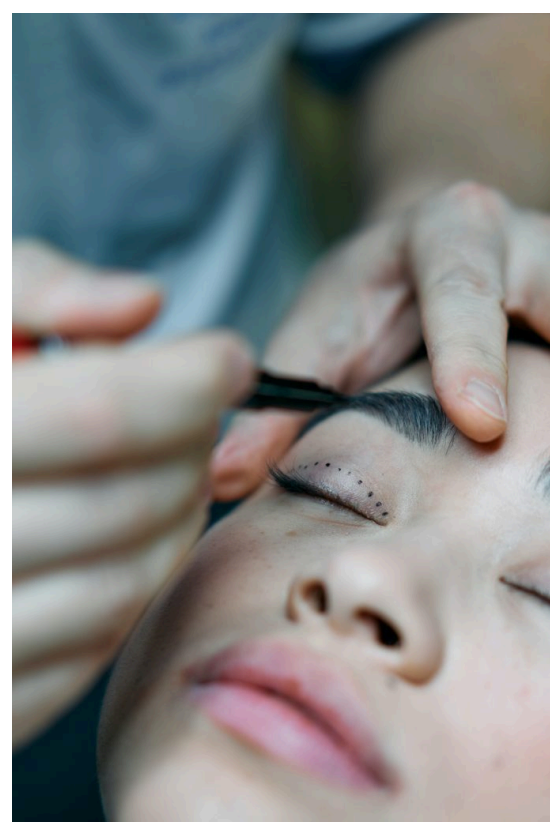

Plastic surgery, both invasive and noninvasive, is an example of dress modification. In this example, a person is being prepared to have plastic surgery on their eyelid. Image Source: $\underline{\text { Cottonbro }}$ 


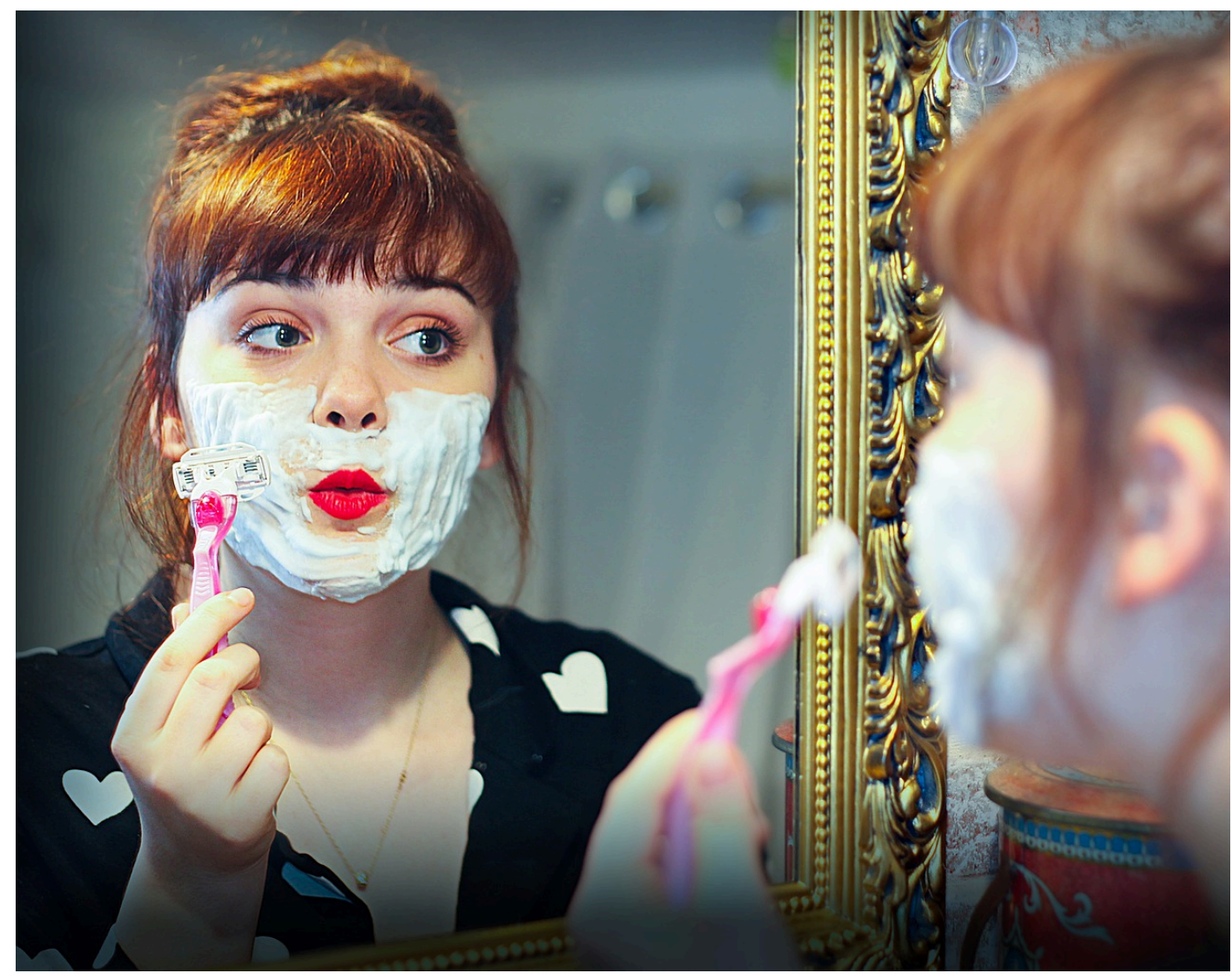

Shaving one's face with a razor is a form of dress reduction. Image Source: John Ondreasz

An interactive H5P element has been excluded from this version of the text. You can view it online here: https://iastate.pressbooks.pub/dressappearancediversity/?p=67\#h5p-1

\section{Motivations for dress}

There are four larger motivations for how and why people dress. These do not capture every single nuance, but they are the four most prominent themes.

- protection: for example, from natural elements

- modesty: avoids indecency

- communication: highlights various identities (e.g. age, gender, race, religion, sexuality, socio-economic status, etc.)

- adornment: emphasizes decorative or aesthetic function 
Dress and dressing are complex. Dress is more than just objects. It is laden with meaning. The dressed and undressed body is a project of both conscious and subconscious continual construction.

\section{Identity}

Identity has numerous definitions. In general, identity refers to an organized set of characteristics that express various aspects of who you are. Dress is used to communicate our identities, such as

- race

- religion

- sex

- gender

- sexuality

- ability

- body size

\section{The Situated Self}

Contexts or situations influence individuals to dress and act differently, depending on which identity is salient. The concept of the situated self (Kaiser, 1997) refers to the idea that given any context, a person may dress or act differently depending upon which identity is most salient at the time. This is part of what are called identity negotiation processes. This means that identities are negotiated, or, in other words, continually in flux, not static. This is especially true for individuals who occupy more than one marginalized identity. For example, Black gay men have explained that their Black identities might be more salient in Black spaces, yet within queer spaces they have to choose to whether their Black identities or gay identities might be more salient, depending on the composition of any given group (Cole, 2019). This isn't necessarily always true for Black people, as there are varied experiences of being both Black and queer (Johnson, 2019).

The identity negotiation process is the continual process of shifting and changing appearance and dress depending on the development of identity. It is often thought of as a knot: as one knot loosens, another tightens. This similar to how we as humans experience our different identities. One identity becomes more prominent in any given situation.

\section{Socialization}

Socialization refers to learning about how to behave and

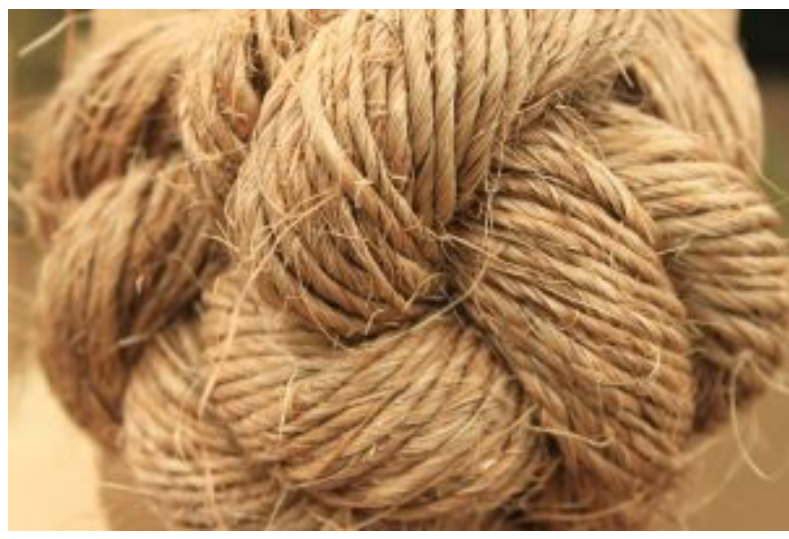
appear. This is often passed on through agents, individuals 
who teach us norms and values of our society through modeling or direct instruction. Some of these agents include

- parents

- peers

- media

- professionals (teachers, coaches, doctors, et cetera)

- cultural beliefs (written or unwritten norms)

- personal shoppers

- retailers or manufacturers

\section{Identity and Dress}

Identities are communicated through how we appear and what we wear (Kaiser, 2012). Identities are also communicated through objects around us, including the places we live and the transportation we use, among many many other examples. Dress and appearance practices, though, announce who we are depending on which identity we are communicating at any one time. For example, while on campus, you might wear a T-shirt from your university, announcing your connection to it and demonstrating that you identify as a part of that community as a student, fan, or perhaps alumnus (Lennon, Johnson, \& Rudd, 2017). This university community identity might not be important to communicate if, for example, you are attending a wedding.

There are different types of identities. For instance, a collective or social identity comes from being a part of a group or from having group membership. For example, membership in a particular year in school is a collective identity. Therefore, you could identify as a first-year student in college. Another collective identity could be tied to race. For example, a person of African descent may identify as part of the Black community due to their ties to their race (Lennon, Johnson, \& Rudd, 2017). Many people have numerous collective identities surrounding their race, gender, sexuality, sex, religion, body size and shape, ability, and/or ethnicity.

A second example of an identity is personal identity. Personal identities concern individual traits. Individual traits can include, for instance, being funny, open, conscientious, agreeable, adventurous, or closed off (Lennon, Johnson, \& Rudd, 2017). Numerous parts of one's identity reflect personal traits. Therefore, while you might identify as an outdoors person, the adventurous part of your identity is called the personal identity, whereas the outdoors person could reflect your membership in the group, or your collective identity.

Relational identities are a third example. These refer to relationships, such as father-son or wife-wife. Dress can reflect relational identities, just it can the other types of identities. For instance, sometimes when families go together to Disney World they wear matching outfits or T-shirts. And two women who are married may wear wedding rings to signify their relational identity. 


\section{Body work}

One part of identity negotiations and dress modification is referred to as body work. Body work includes managing the body through physical activity or exercise, dieting or watching what one eats, using make-up, undergoing cosmetic surgery, and many other activities.

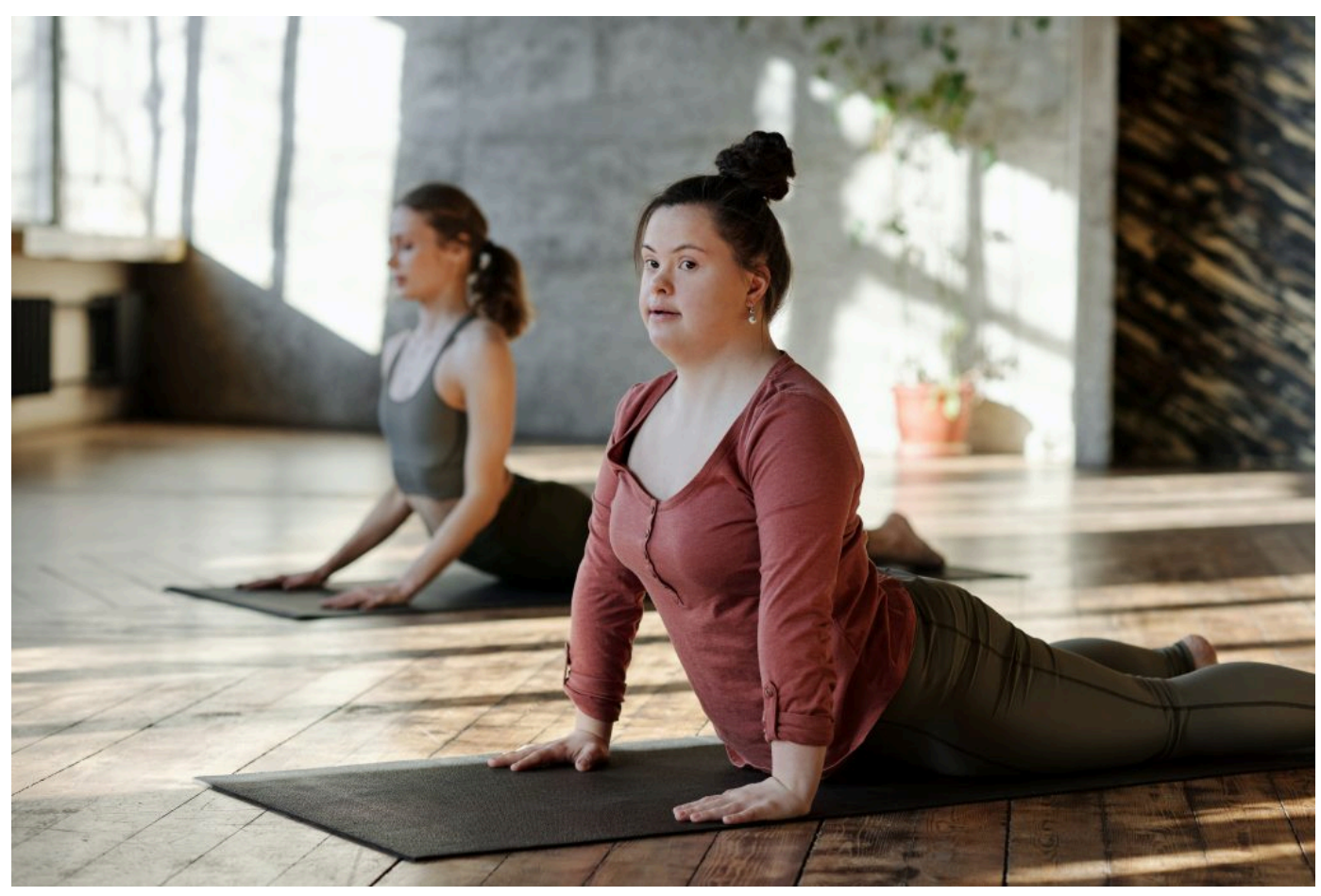

Image Source: Cliff Booth

A person might also wear a certain style of clothes to change the shape of the body, perhaps hiding or emphasizing parts of the body. One might hide parts of the body by wearing baggy clothes, whereas they might reveal parts of the with tight or low-coverage clothing (e.g., crop tops). People of all genders do body work (Lennon, Johnson, \& Rudd, 2017).

\section{Identity Development Online}

In the twenty-first century, thanks to advances in and increased usage of technology, many people develop their identities online. You might use a virtual community to try out different identities; for instance, in virtual reality chat, you can "put on" an identity within an anonymous space. Online spaces help users anonymously normalize identities and behaviors anonymously (e.g., people who have anorexia, Trekkies, moms, et cetera). 


\section{Stigma and Identity}

Stigma refers to a mark of shame or of disapproval, or a stain on one's reputation (Goffman, 1963). Stigmatized identities are those identities that violate a societal norm for a particular time or space. Numerous identities are stigmatized. For example, fat people often experience stigma related to their body size and shape (Sherman, 2011). Fat stigma, which is very common, can significantly influence people's experiences (Meadows, 2018). Here are just a few identities that experience severe stigmatization:

- people who are fat

- people of color

- members of the LGBTQIA+ community

- people with disabled bodies

Table 1. Stigma management communication strategies, based on Meisenbach, 2010

Accept that stigma applies to self

Accepting stigma

Evading responsibility for stigma

Challenge the public understanding of stigma (change)
Challenge that stigma applies to self

Avoiding stigma

Denying stigma

Reducing the offensiveness of stigma Ignoring stigma

Meisenbach (2010) further expands on each of these behaviors:

An individual accepting a stigma may passively accept the status quo, apologize for their stigma, use humor as a source of comfort, blame the stigma for negative outcomes in one's life, isolate themselves, or bond with other stigmatized people. 


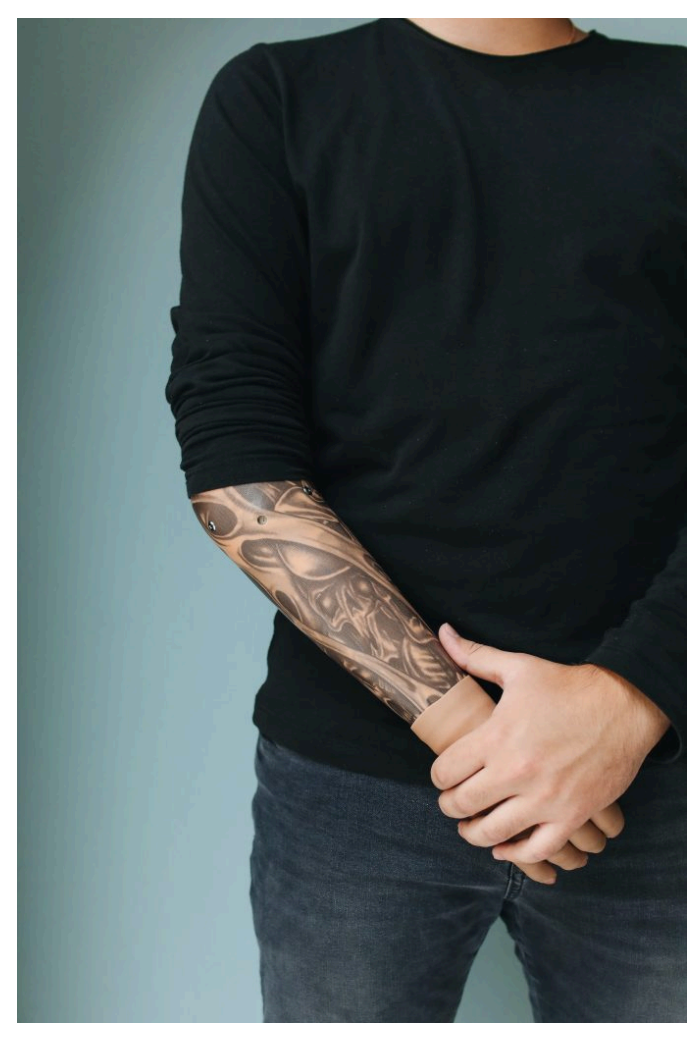

Image Source: Polina Tankilevitch

An individual avoiding a stigma might hide or deny their stigmatized attribute, avoid situations where this attribute is notable, stop the behavior that stigmatizes them, distance themselves from the stigma, or criticize others in an attempt to make themselves seem favorable by comparison.

An individual evading responsibility for a stigma may accept that they display stigmatized attributes but challenge the ways those attributes are perceived by the public. For example, the individual may argue that they were born with the stigmatized attribute, that it was inflicted upon them, or that they cannot change the way the public perceives them.

An individual reducing the offensiveness of a stigma may attempt to reclaim the stigma by reinforcing the positive aspects of their stigmatized attribute, to minimize the damage of the stigma by arguing that their stigmatized attribute is not as severe or harmful as it is depicted by the public, or to transcend the stigma by explaining how their stigmatized attribute can be a positive one.

An individual denying a stigma may attempt to prove that the attributes they are stigmatized for should not be stigmatized, providing evidence for why the public perception of their attribute needs to change or highlighting logical fallacies in the way the attribute is addressed. Alternatively, the individual may deny that their attributes are stigmatized at all.

An individual who wishes to decrease a stigma may ignore or display the stigmatized attribute by normalizing it or accepting it as a part of their identity. An individual using this communication strategy might flaunt their stigmatized attribute through dress or behavior or forgo means of dress that minimize or hide the stigmatized characteristic.

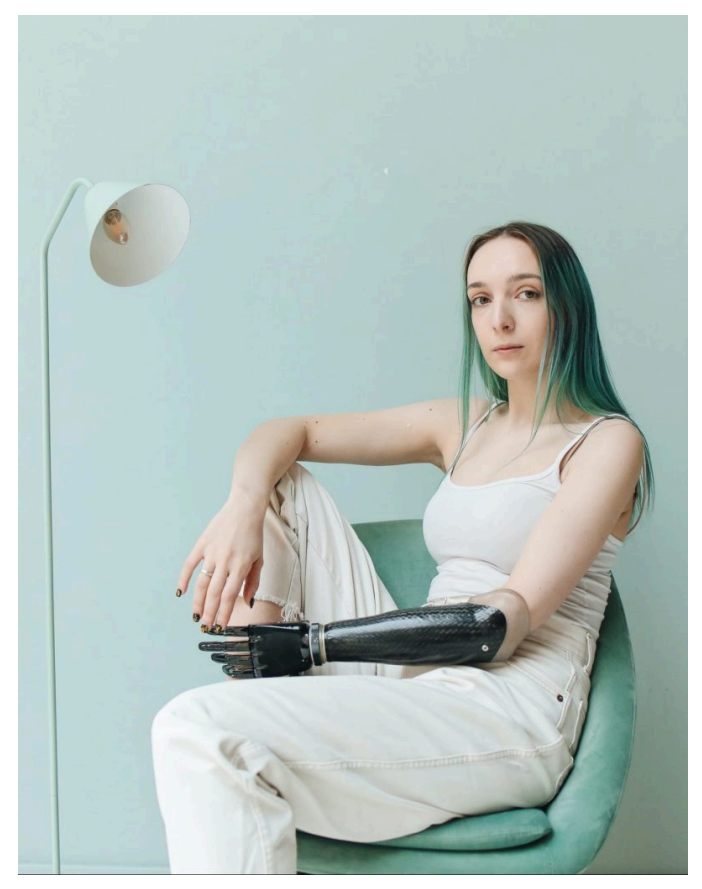

Image Source: Polina Tankilevitch

An interactive H5P element has been excluded from this version of the text. You can view it online here:

https://iastate.pressbooks.pub/dressappearancediversity/?p=67\#h5p-2 


\section{Focused Example: Quinceañera}

A quinceañera is a celebration in Latinx culture in which girls, on their 15th birthdays, celebrate the transition from a childhood to womanhood. Central to the event is the formal, full-length gown the girl wears. According to Lennon, Johnson, and Rudd (2017), these are consumption events: they are "a commercial opportunity (a) to buy products and experiences, (b) that impact identity, (c) that involve wearing special clothing and accessories which are used as props in identity assumption, and (d) in which product consumption and experience consumption reinforce the identity" (249).

A quinceañera is one of the many ways people in different stages of life, cultures, communities, ages, and thus identities negotiate their identity through dress.

Watch this short film about quinceañera:

To view a transcript for this video, download this file: What is a Quincenera Video Transcript [DOC]

\section{References}

Cole. S. (2019). The difference is in the detail. Negotiating Black gay male style in the twenty-first century. Dress, 45(1), 39-54.

Goffman, E. (1963). Stigma: Notes on the management of spoiled identity. New York: Touchstone.

Kaiser, S. B. (1997). The social psychology of clothing: Symbolic appearances in context. New York: Fairchild.

Kaiser, S. B. (2012). Fashion and cultural studies. London: Bloomsbury.

Lennon, S., Johnson, K. K. P., \& Rudd, N. (2017). Social psychology of dress. London: Bloomsbury. 


\section{Dress, Appearance, and Identity Case Study}

\section{Step One: Become familiar with the case study.}

1. The case study attached below is a Word document and can be downloaded. It includes the task, evaluation, and template for the case study:

Dress Appearance and Identity Case Study [DOC]

Step Two: Submit your complete assignment on Canvas.

1. Format your document.

2. Remember to check the submission against the rubric. 


\section{3. \\ IDENTITY, SOCIAL JUSTICE, AND DRESS}

\section{Module Learning Objectives (MLO)}

In this chapter, you will

- MLO 3.1 Identify foundational concepts related to social justice, identity, and dress. [CLO 1]

- MLO 3.2 Identify driving forces of transformative social change. [CLO 5]

- MLO 3.3 Articulate your own positionalities. [CLO 4]

- MLO 3.4 Reflect on your progress toward development of empathy related to social justice issues, identity, and dress. [CLO 4]

- MLO 3.5 Examine social justice issues in the fashion industry.

\section{Social Justice}

Social justice is the equal distribution of privilege, opportunities, and wealth. Social injustice, then, occurs when there is unequal distribution of privilege, opportunities, and wealth. In the current US society, there is a significant imbalance in the distribution of privilege, opportunities, and wealth.

Required Reading:

Ornstein, A. C. (2017) Social Justice: History, Purpose and Meaning. Society 54,541-548 https://doi.org/10.1007/ s12115-017-0188-8. 


\section{Inequity and the United States}

The gender pay gap is one example of inequity in the United States. Studies have demonstrated that when women and men perform the same jobs, women, on average, are paid less. The gender pay gap varies across industries, but women who are financial managers, physicians, accountants, retail sales workers, registered nurses, lawyers, education administrators, and chief executives earn between 65 and $92 \%$ of what men earn for performing the same job responsibilities (AAUW, 2021); the only differentiating factor is their gender. The fashion industry also suffers from gender inequality. While numerous women working in the fashion industry, recent research shows that the highest paid

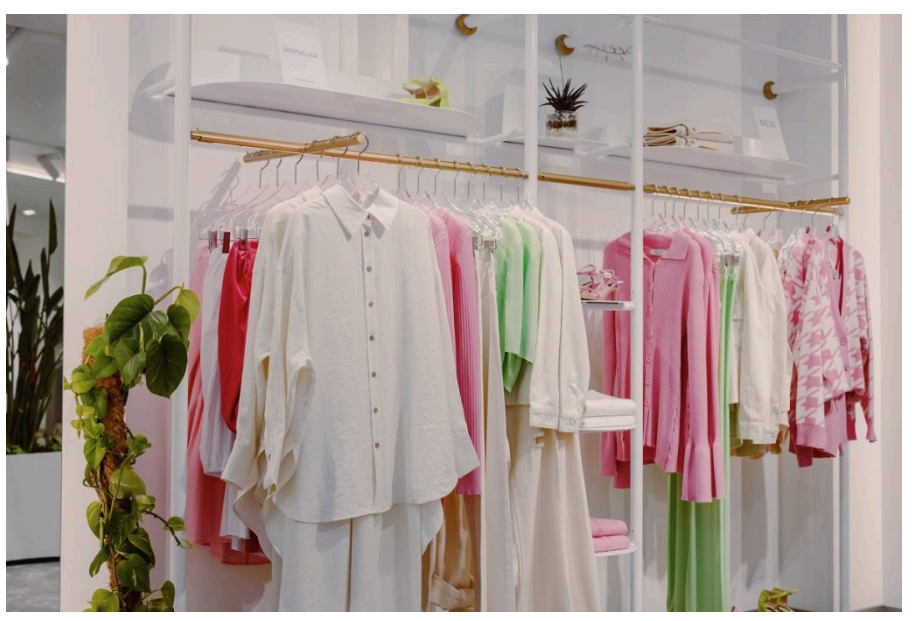

Image Source: Ron Lach employees in the fashion industry were men, and about $80 \%$ of the industry's executives were men (The Fashion

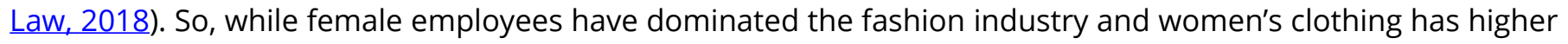
sales than men's clothing, men more often occupy the industry's higher-paying jobs (Bain, 2018).

Racial inequality, another example of the unequal distribution of privilege (Inequity.org), is still a significant issue in the United States. However, many white people feel that racism or racial inequality is not a significant issue in 2019 (Pew Research Center, 2019). 


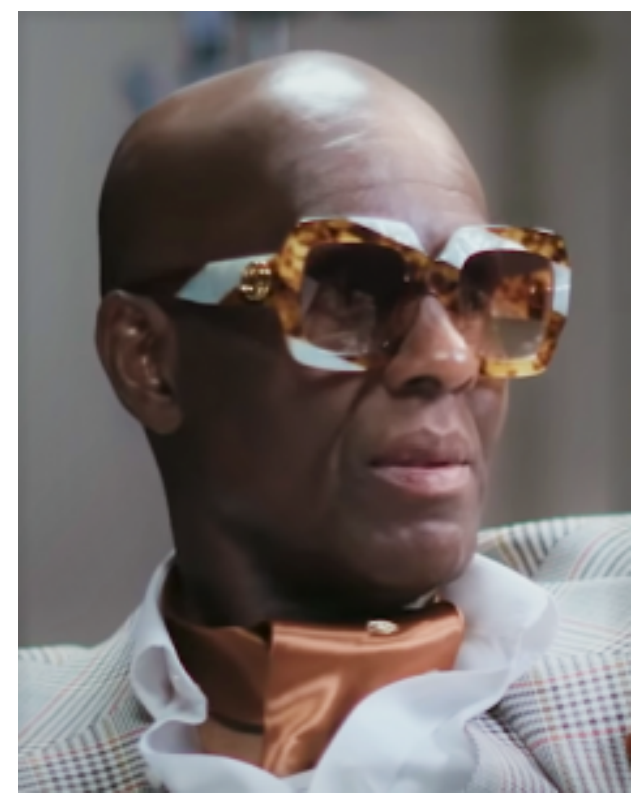

Image Source: Screenshot from 2019 Ashley Graham interview, available on YouTube

inequality is not a significant issue (Pew Research Center, 2019). 2018).

Despite the progress since the abolition of slavery and Jim Crow laws, Black people are still at significant disadvantage on many fronts (Gunn, 2018). For example, one study found that when researchers sent résumés with either African American- or white-sounding names, candidates with white-sounding names needed to send about 10 résumés to obtain a single callback, whereas candidates with African American-sounding names had to send an average of 15 resumes to obtain a single call-back (NBER, 2018).

Racial inequality can also be found within the fashion industry. While there have been numerous successful Black fashion designers, the industry also has systemic racial inequality issues (Deleon et al., 2020; Segran, 2018). For example, most fashion models are white, not people of color; while this inequality has lessened over time, the industry still most often casts white models to represent the ideal of beauty (Tai,

Racial inequality is still a significant issue in the United States and an example of the unequal distribution of privilege (Inequity.org). However, in 2019, many white people believed racism or racial

\section{Privilege}

These inequities are interconnected with the concept of privilege. The resources at the links below discuss privilege and the ways it intersects with varying identities.

- What is privilege?

- White privilege?

- Straight and cisgender privilege?

- Male privilege?

This short video explains privilege and how it relates to power and oppression.

One or more interactive elements has been excluded from this version of the text. You can view them online here: https://iastate.pressbooks.pub/dressappearancediversity/?p=74\#oembed-1

To view a transcript for this video, download this file: Power Privilege and Oppression Video Transcript [DOC] 


\section{Intersectionality}

Kimberly Crenshaw, a pioneering scholar, discussed intersectionality in the 1990s. The resource at the link below, provided by Rider University, discusses the concepts of privilege and intersectionality.

- Intersectionality

In this short film, Crenshaw discusses intersectionality and why one needs it when examining experiences of different individuals.

One or more interactive elements has been excluded from this version of the text. You can view them online here:

自 https://iastate.pressbooks.pub/dressappearancediversity/?p=74\#oembed-2

To view a transcript for the video above, download this file: The Urgency of Intersectionality Video Transcript [DOC]

In this short film, the individuals engage in a privilege walk. It is a visual of how privilege affects people differently depending on their intersectional identities.

㚇

One or more interactive elements has been excluded from this version of the text. You can view them online here:

https://iastate.pressbooks.pub/dressappearancediversity/?p=74\#oembed-3

To view a transcript for the video above, download this file: What is Privilege Video Transcript [DOC]

\section{Stereotyping}

We all stereotype. Stereotyping is a form of classification to help make sense of the complex world based on limited information. Through stereotyping, we infer a network of characteristics of a person. Stereotyping is learned through direct experience, hearsay, and cultural experience (media).

\section{Dangers of Stereotyping}

While stereotyping can help us make sense of the world, it carries significant dangers.

- Blinder effect: one cue blinds the perceiver to a person's other qualities. 
- Prejudice: one can develop a rigid use of typing in which the perceiver ignores information that conflicts with the stereotype the perceiver holds

\section{Implicit Bias}

Stereotyping can also be connected to implicit bias. According to a research center at the Ohio State University, implicit bias "refers to the attitudes or stereotypes that affect our understanding, actions, and decisions in an unconscious manner." They are enacted "without an individual's awareness or intentional control." These implicit biases have been learned over time, yet they are malleable and can be unlearned. Therefore, even if individuals have unconscious biases toward groups of people, these attitudes are able to be changed.

One fashion-related example of this bias is that the market has rarely made accessible or adaptive clothing available for people with disabilities (Schmidt, 2018). This does not necessarily mean that the fashion industry professionals do not like people with disabilities or do not think they should have clothing. It is more likely that people have an unconscious bias toward people with disabilities and are not thinking about their needs or interests as individuals. Until very recently, the fashion industry has also lacked models with visible disabilities in its fashion advertisements (Falquez, 2018).

\section{Implicit Bias Association Test}

Harvard University has an ongoing Implicit Association test (Project Implicit), which measures the strength of association between concepts (Black people, gay people) and evaluations (good, bad) or stereotypes (athletic, clumsy). One or more interactive elements has been excluded from this version of the text. You can view them online here:
https://iastate.pressbooks.pub/dressappearancediversity/?p=74\#oembed-4

To view a transcript for the video above, download this file: Implicit Bias Video Transcript [DOC]

\section{Microaggressions}

- Microaggressions are small slights that the "majority" make to members of marginalized groups without noticing, often due to their implicit biases.

- People often commit microagressions out of ignorance or surprise at being in the presence of someone who appears different than they are.

- Both individuals and institutions may perform microaggressions. Many surveys at institutions are full of microaggressions. 
Watch this short film demonstrating microaggressions. Please note that between 1:07 and 1:08 in the film, the phrase "fucking annoying" is used and a few seconds before that "goddamn it" is used.

One or more interactive elements has been excluded from this version of the text. You can view them online here:
https://iastate.pressbooks.pub/dressappearancediversity/?p=74\#oembed-5

To view a transcript for the video above, download this file: Microaggressions Video Transcript [DOC]

\section{How do we reduce implicit bias?}

There are numerous ways to reduce implicit bias. In one Psychology Today article, the authors discuss how while awareness of one's biases is a first step, it is not enough (Tropp \& Godsil, 2015). They explain that practices to significantly reduce bias should include exposing people to counter-stereotypic examples, developing an understanding of the out-group member, and engaging in positive interactions with members of the out-group. In a large-scale study, scholars reported that while interventions aimed at reducing bias had good intentions, they did not always work to reduce people's biases and that to be able to determine the best methods to reduce bias more data was needed (Gerald et al., 2019).

\section{Empathy}

Empathy refers to the ability to understand individuals who are in outgroups, or individuals who are a part of groups that we do not self-identify with or belong to (Molenberghs, 2017). That is, empathy is the ability to understand the experiences or expressions of individuals who are not like us.

Empathy

- is an approach toward greater understanding of diversity.

- involves seeking to understand others by considering their backgrounds and life situations.

- does not require liking or approving of someone.

- assists in avoiding microaggressions.

If you were in charge of selecting models for a fashion photo shoot and you knew people with disabilities feel poorly about themselves when they do not see themselves represented, would you make your hiring decisions with this in mind (Feldman, 2017)? Understanding others' experiences and listening to their stories can help increase empathy. 


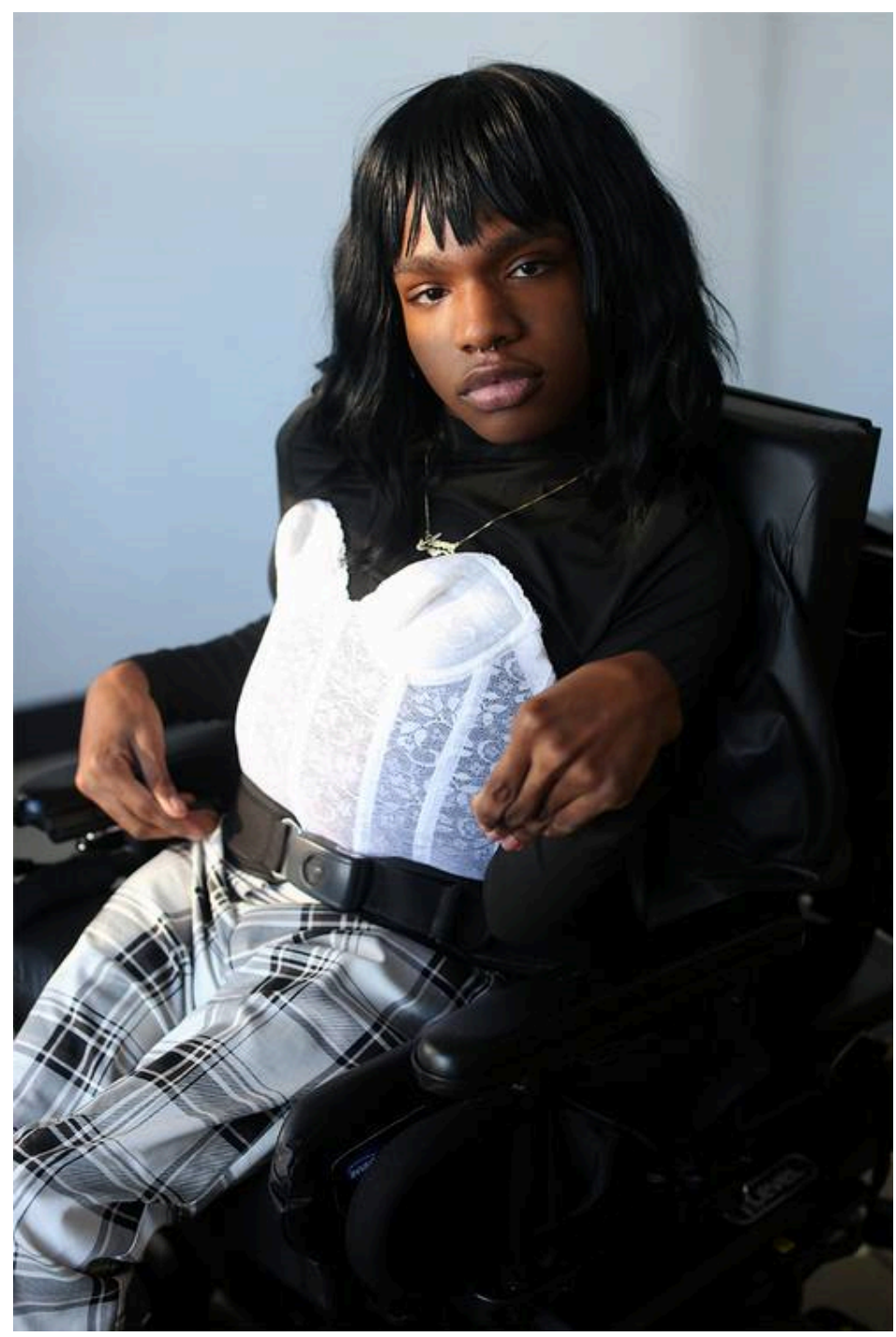

Aaron Rose Philip, an Antiguan-American model, is physically disabled and works in high fashion. She has discussed her work publicly with Who What Wear in a lineup of six models who have had to contend with ableism in the fashion industry. Image Source: Aaron Philip on Instagram 


\section{A Lens of Individual and Systemic Oppression}

A lens is a means of looking at a particular idea, event, and/or experience. In this course, we discuss oppression, and one can evaluate oppression using different lenses: individual, interpersonal, and systemic lenses.

- individual oppression in the fashion system that is conscious: A person's religion informs their beliefs that transgender people are wrong, and thus they believe that transgender people should not embrace their identity through dress. For instance, they do not think that a person assigned female at birth should wear a chest binder to affirm their gender identity as a man.

- individual oppression in the fashion system that is unconscious: A person is outwardly supportive of transgender people and the ways transgender people express their gender through fashion. However, in one instance, the person is creating a fashion line of undergarments and does not actively think about the needs of transgender people, such as producing chest binders.

- Interpersonal oppression in the fashion system: A person is outwardly supportive of transgender people and the ways they express their gender through fashion; however, this person often will stare at a transgender-appearing person because they are confused by their appearance.

- Systemic oppression in the fashion system that is institutional: A fashion brand produces undergarments, and in its practices it has have never produced garments that cater to transgender individuals. It only produces products that are for cisgender people and markets them this way.

- Systemic oppression in the fashion system that is structural: Throughout the entire fashion industry over time, there are no fashion brands that produce undergarments that cater to the needs of transgender individuals. Therefore, transgender individuals who want to affirm their gender identity through dress, such as wearing a chest binder, do not have options to do so.

Review this source on the different lenses: The Lens of Systematic Oppression (National Equity Project).

\section{Transformative Social Change}

Review these resources on how to engage in transformative social change:

- Transformative Social Change Wiki (P2PF Wiki).

- Transformative Justice, Explained in Teen Vogue (Tran, 2018).

\section{Focused Example: For Everyone Collective}

The For Everyone Collective, in Grand Rapids, Michigan, uses T-shirt activism to advocate for prison abolition. 
On its website, it describes itself as "worker owned by a multiracial group of people impacted by incarceration. Our only non-impacted employee-owner is our founder, who created Forgive Everyone to raise money for the abolitionist movement" (For Everyone Co., 2021).

This organization centers social justice philosophies in all of its processes, from its production practices, employing formerly incarcerated people, to its shared-ownership business model. Its employees earn at least $\$ 15$ an hour and are provided medical benefits, and it employs currently incarcerated artists to design T-shirts while funneling all of its profits into prison abolition education, empowerment, and justice.

In addition to requesting support for its work through product sales, the For Everyone Collective seeks to be "a central hub for advocacy and activism resources for activists in criminal justice reform, prison abolition, and transformative justice work."

ค. จ

\section{Identity, Social Justice, and Dress Case Study}

\section{Step One: Become familiar with the case study.}

1. The case study attached below is a Word document and can be downloaded. It includes the task, evaluation, and template for the case study:

Identity Social Justice and Dress Case Study [DOC]

\section{Step Two: Submit your complete assignment on Canvas.}

1. Format your document.

2. Remember to check the submission against the rubric. 


\section{4. \\ SOCIAL SCIENCE THEORIES}

\section{Module Learning Objectives (MLO)}

In this chapter, you will

- MLO 4.1 Identify foundational concepts and theories related to identity and dress. [CLO 1]

- MLO 4.2 Summarize the role of dress in identity development. [CLO 1]

- MLO 4.3 Analyze identity and dress with social science theories and concepts. [CLO 2]

- MLO 4.4 Analyze the norms that influence your own identities and dress. [CLO 4]

There are thousands of social science theories that relate to and help explain dress, appearance, and identity. This chapter describes a few of these.

\section{Role Theory}

A role is a position a person occupies in a social relationship (Biddle \& Thomas, 1966). Roles require and shape

- behavior associated with the role, including dress

- knowledge and values needed to perform the role

- status.

For example, police officers have uniforms that must be worn according to regulations, as well as codes of behavior guiding their performance of this role. They need to learn laws and procedures to perform the role. If a police officer does not value and take pride in their role, they are not likely to perform well.

Many of our roles have less specific dress regulations. University students, for example, display some variety in their dress, but the norm on campus tends to be fairly casual and comfortable. Students usually dress recognizably different from faculty and administrators.

Status: position in relation to other positions. These include 
- complementary positions within a general role type, such as

- family roles of mom, dad, child, grandma, parent

- gender roles of man, woman, nonbinary person

- positions on a continuum, where someone ranks higher than another in terms of wealth, authority, or prestige. Examples include

- owner, manager, assistant manager, salespersons in a store

- upper, middle, and lower socioeconomic classes.

Role norms are expected sets of behaviors for persons holding roles and status (Biddle \& Thomas, 1966). Role norms regulate behaviors including dress, demeanor, and expressions of politeness. For example, we expect medical doctors to dress in specific attire in a hospital or at the office. If a doctor violates these expectations (working in shorts and a T-shirt, for instance), some patients may perceive them as less competent or serious. Other patients may find the violation of expectations to be amusing in this era of lax dress rules.

\section{Purpose of Role Dress}

- learning a role

- performing a role

- identify others performing a role

- shape reactions of others

- assist in role change

Role dress helps an individual take on a role and be perceived by others as fitting that role. If a person looks like they have a role, other people are likely to assume that the person has the skills and knowledge to carry out the role. Solomon (1983) proposed that

- people who are early in their careers often dress more in accordance with role dress expectations. Responses from coworkers and clients to the role-appropriate dress help the newcomer to feel more adept in and a part of the role while learning it.

- as people become more experienced and recognized as competent, they are more likely to feel comfortable relaxing the dress rules or exploring more variety in role appearance.

Research supports these propositions for many, but not all, roles and individuals. 


\section{Some restrictions of role adoption include (Horn \& Gurel, 1981)}

Some restrictions of the ways individuals adopt rules are

- Intrinsic: An individual lacks resources to acquire role props and settings. Resources include money and time.

Example: Most of us do not have the wealth or connections to be wealthy jetsetters who attend exclusive parties with the rich and famous.

- Moral: An individual has morals or values that keep them from performing behaviors essential to a role.

Example: Due to misalignment with morals about selling sex for money, an individual does not want to dress like a prostitute and perform that role, even if it might be affordable to dress like a prostitute.

- Organic: One's body does not fit the appearance requirements of the role.

Example: Many women do not fit beauty pageant "appearance requirements."

- Cultivation and socialization: The individual lacks the knowledge and training to take on a role.

Example: A person might be able to don a lab coat and stethoscope, but most could not effectively carry off the role of a medical doctor when the time came to demonstrate expertise about medicine. In many US hospitals, physician interns are required to wear shorter, blazer-length white coats while licensed doctors wear knee-length white coats. The shorter coats indicate doctors-in-training who do not yet have full credentials to practice medicine (Coleman, 2000).

Identity is defined to a great extent by the roles we play (Kaiser, 1990). In a sense, we have multiple identities because we all have many roles.

- You may be a male student in your early twenties and have a part-time job; go on dates; and be a brother, a son, an avid bicyclist, and Latino American. Your dress may vary greatly or slightly in these roles, and it may reflect several of these role identities at one time.

- Your total identity is a composite of all your roles as well as your unique personality traits and habits. 


\section{Role Conflict}

In carrying out some roles, individuals may experience conflicts. An inter-role conflict, or a conflict between two roles, may occur when an individual finds that two sets of role demands are not always compatible. Appearance can help solve role conflicts if the individual changes clothes for each role or wears the attire for the most demanding role.

For example, a parent who is a marketing director prefers to change clothes after arriving home to spend time with their infant, who throws food around and perhaps spits up on the parent's clothes. But work stress and time limitations may require the individual to be a parent sometimes while wearing their work suit.

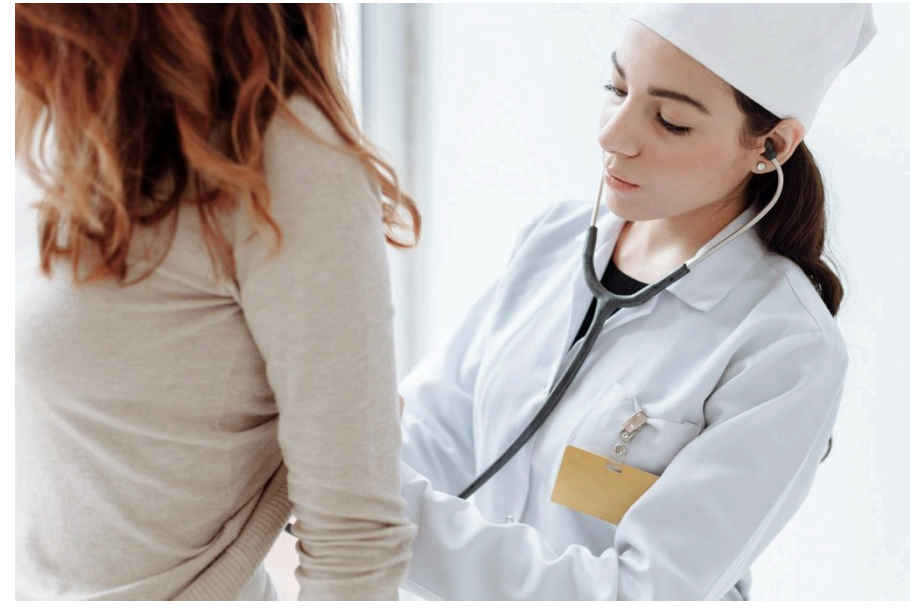

Image Source: Thirdman

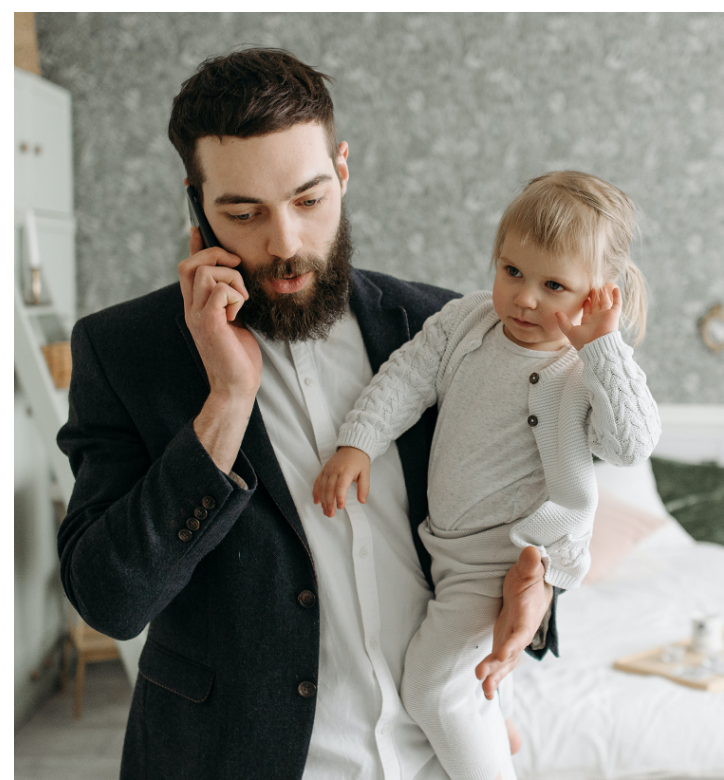

Image Source: Pavel Danilyuk

contrast, an intra-role conflict is one that conflicts within a role due to changing expectations for that role across different groups in a society. In these situations, the role player may change clothes with differing audiences or limit the audiences with access to them.

An example of intra-role conflict might be a medical doctor who prefers to wear semicasual street clothes when seeing patients at the office. They do this to seem more approachable and easier to talk to. But ome older patients expect to see the doctor in a lab coat, so the doctor may put on a traditional white doctor's coat when seeing older patients (Blumhagen, 1979). 


\section{Role embracement vs. role distance (Goffman, 1959)}

An individual who takes on a role and learns to embrace it as part of identity is more likely to accept roleappropriate clothing than an individual who has a role but feels distanced from it or from societal definitions of the roles.

\section{Conformity}

Conformity is a change in an individual's behavior or attitude to achieve consistency with real or imagined group norms (Kaiser, 1990).

Watch this short video to demonstrate the power of cultural norms

One or more interactive elements has been excluded from this version of the text. You can view them online here:
https://iastate.pressbooks.pub/dressappearancediversity/?p=5\#oembed-1

To view a transcript for the video above, download this file: Social Conformity Brain Games Video Transcript [DOC]

Dress is an outward sign of conformity. Conformity

- faciliatates a sense of identification, belonging, definition of self, role embracement

- supports safety or comfort in group acceptance

- fosters group solidarity, peer bonding; conformity through dress defines group boundaries by identifying who is in a group and who is not

- indicates similarity, which is conducive to attraction

- emphasizes social inclusion vs. social uniqueness.

Conformity has its negative outcomes. It can be boring and monotonous. Too much required conformity can stifle creativity. Some people are more prone to conformity through dress, while others are more interested in differentiating themselves from others. Some basic personality characteristics may incline individuals to be (Storm, 1987) 


\section{Prone to conformity}

- shows feelings of inadequacy or incompetence

- outer, other-directed

- passive

- less tolerant of ambiguity

- dogmatic or wants absolute rules

- demonstrates need for social acceptance

\section{Prone to differentiation}

- shows feelings of competency

- inner, self-directed

- less passive

- more tolerance for ambiguity

- less dogmatic

- demonstrates less need for social acceptance

\section{Uniforms (extreme conformity) (Joseph \& Alex, 1972)}

Check out this object video from ISU's Textiles and Clothing Museum Collection. The video features a 1930s Girl Scout uniform with patches on the sleeve demonstrating the wearer's various achievements in the program.

One or more interactive elements has been excluded from this version of the text. You can view them online here:

뭇 https://iastate.pressbooks.pub/dressappearancediversity/?p=5\#oembed-2

Uniforms

- indicate the prestige level of the wearer

- symbolize skill level attained by the wearer

- facilitate efficiency and organizational control

- suppress the expression of individuality and idiosyncrasy

- encourage group behavior and thinking rather than focus on the self.

Uniformity more likely for role dress when the role requires special expertise and extensive training (i.e., hospital surgeons) 
- involves safety or security control (i.e., armed forces, police)

- requires dress that protects the body or facilitates task performance (i.e., fire fighters)

- benefits from group or team solidarity and identification (i.e., players on sports teams)

- establishes brand or organization image (i.e., McDonald's servers, Target employees)

- enforces identity control (i.e., prisoners).

In coercive total institutions such as prisons, uniforms are used to (Goffman, 1961)

- strip personal identity to force an inmate to become part of the system

- help (i.e., force) the inmates to leave their independent

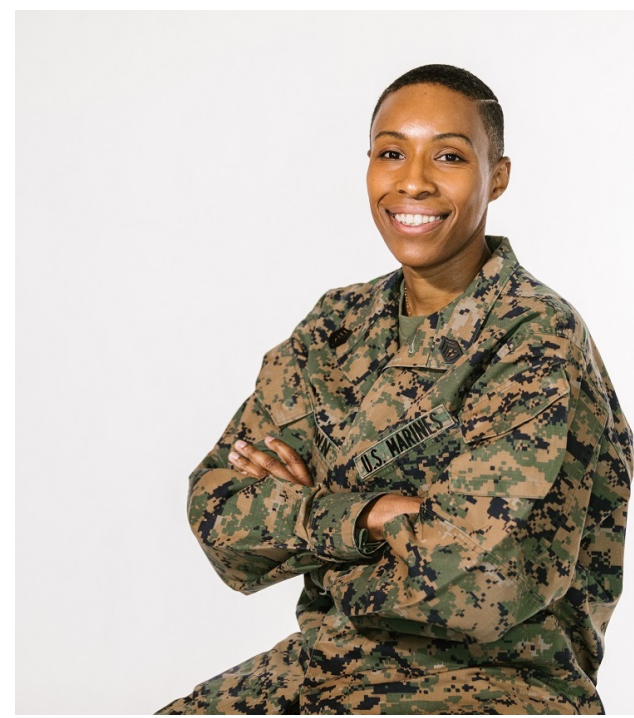

Image Source: RODNAE Productions lives outside.

\section{Symbolic Interactionism-Public, Intimate, and Secret Self}

According to Eicher (1981), there are three ways to think about the self: the public, intimate, and secret selves.

The public self is the part of a person in front of others in public, including those outside of the friend or family network. Therefore, the public self is usually a part of the self that one is comfortable sharing in a broader sense. For example, some people are comfortable sharing their occupations. That is, if an individual works as a public transportation bus driver, they might wear their uniform to the grocery store after work without feeling uncomfortable sharing this part of who they are. However, if someone has a stigmatized occupation, such as a sex worker, they may conceal this from their public self-presentation (Oselin, 2018).

The intimate self is a part of the self that individuals share only with those close to them, such as friends or family. For example, an individual might be more relaxed after work and wear casual or pajama-style garments around the house in front of their family members. 


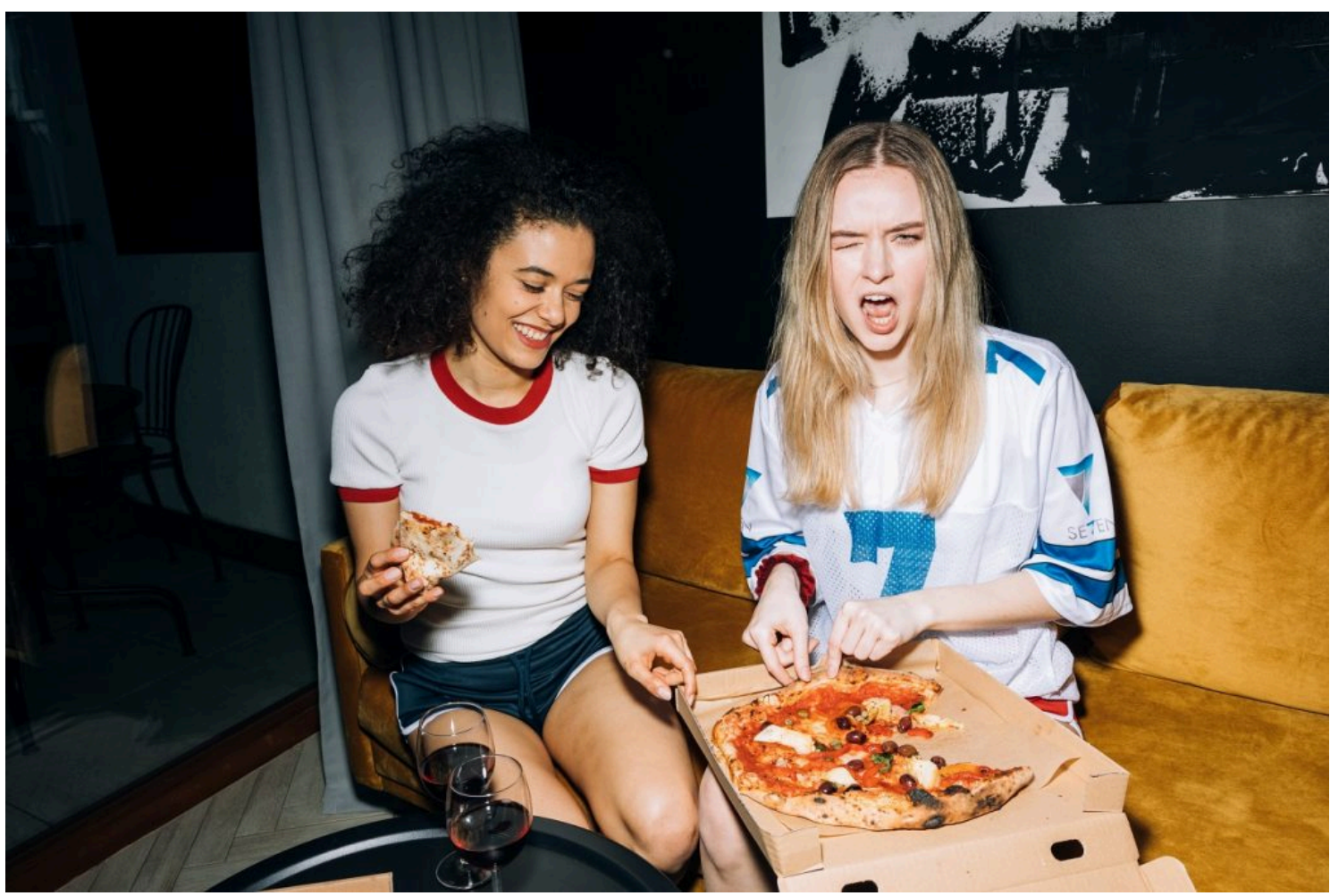

Image Source: KoolShooters

Finally, secret self refers to aspects of the self that one does not share with others. For example, one transwoman describes how she would sometimes dress in female-gendered garments without letting others know (Coates, 2016). Trans people experience significant discrimination (National Center for Transgender Equality, 2022); therefore, the transition and coming-out process for trans people is complex and may include a variety of experiences, such as experimenting in the secret-self space with different clothing styles.

According to symbolic interaction theory, individuals negotiate their appearances (and public and intimate selves) in social interactions (Goffman, 1959). In this theory, the program is a term that refers to your response to your own appearance. In the process of the program, you evaluate your own appearance based on how you look in the mirror and/or how you think others might perceive you. The concept of the generalized other is what you expect others to think of a particular identity. For example, if you are a librarian, you might wear a cardigan and glasses, as these are sometimes stereotypes associated with librarians or how individuals might assume librarians dress. In symbolic interaction theory, the review is also a part of identity negotiations in symbolic interaction theory. The review is others' evaluation of one's appearance. People can give both verbal and nonverbal reviews. Verbal examples include "Wow, I love that shirt" or "That makes you look terrible." Nonverbal reviews include, for example, a person holding their purse closer to their chest as they walk by you; Black men frequently report this experience (Lowe, 2000). 


\section{Focused Example: Prison Uniforms}

The Stanford Prison Experiment is a famous study that was conducted at Stanford University in the 1970s. Watch this short film and pay attention to how dress was used to strip inmates of their identities and to enable the guards to enact control.

One or more interactive elements has been excluded from this version of the text. You can view them online here:

益 https://iastate.pressbooks.pub/dressappearancediversity/?p=5\#oembed-3

To view a transcript for the video above, download this file: Stanford Prison Exeriment Video Transcript [DOC]

1 An interactive H5P element has been excluded from this version of the text. You can view it online here:

는 https://iastate.pressbooks.pub/dressappearancediversity/?p=5\#h5p-3 


\section{References}

Biddle, B. J., \& Thomas, E. J. (1966). Role theory: Concepts and research. New York: Wiley.

Blumhagen, D. W. (1979). The doctor's white coat: The image of the physician in modern America. Annals of Internal Medicine, 91, 111-116.

Coleman, C. (2000, February 2). Just playing doctor? Shorter coats make residents feel naked. Wall Street Journal..

Eicher, J. (1981). Influences of changing resources on clothing, textiles, and the quality of life: Dressing for reality, fun, and fantasy. Combined Proceedings, Eastern, Central, and Western Regional Meetings of Association of College Professors of Textiles and Clothing, 36-41.

Goffman, E. (1959). The presentation of self in everyday life. Garden City, NY: Doubleday Anchor Books.

Goffman, E. (1961). Asylums: Essays on the social situation of mental patients and other inmates. Garden City, NY: Doubleday.

Horn, M. J., \& Gurel, L. M. (1981). The second skin (3rd ed.). Boston: Houghton Mifflin.

Joseph, N., \& Alex, N. (1972). The uniform: A sociological perspective. American Journal of Sociology, 77, 719-730.

Kaiser, S. B. (1990). The social psychology of clothing. New York: Macmillan.

Solomon, M. R. (1983). The role of products as social stimuli: A symbolic interactionism perspective. Journal of Consumer Research, 10, 319-329.

Storm, P. (1987). Functions of dress: Tool of culture and the individual. Englewood Cliffs, NJ: Prentice-Hall. 


\section{Social Science Theories Case Study}

Step One: Become familiar with the case study.

1. The case study attached below is a Word document and can be downloaded. It includes the task, evaluation, and template for the case study:

Social Science Theories Case Study [DOC]

Step Two: Submit your complete assignment on Canvas.

1. Format your document.

2. Remember to check the submission against the rubric. 


\section{5. \\ CULTURE}

\section{Module Learning Objectives (MLO)}

In this chapter, you will

- MLO 5.1 Identify foundational concepts and theories related to culture, identity, and dress. [CLO 1]

- MLO 5.2 Identify the factors that influence different cultural aspects of dress. [CLO 1]

- MLO 5.3 Identify the different cultural perspectives an individual can take to approach understanding the dress and identity of others. [CLO 1]

- MLO 5.4 Explain the role of dress in identity development. [CLO 1]

- MLO 5.5 Examine how marginalized communities in the United States use dress and appearance to negotiate their identities. [CLO 2]

- MLO 5.6 Deconstruct your own perspectives and approach to understanding the dress of others. [CLO 4]

\section{What Is Culture?}

Culture refers to aspects of human-made elements, including tools, dress, and media, in addition to values, attitudes, and norms. Dress is a significant part of almost every culture.

As more cultures have cross-cultural contact, people from begin to change aspects of their cultures by incorporating aspects of different cultures they come into contact with. This includes changes in dress. This process of cultural change is often referred to as cultural authentication. It should be noted though, that there is a long history of forced assimilation, especially for Native or Indigenous communities in North America (Little, 2018). That is, Native communities were forced to assimilate into European culture; Native people were not interested in incorporating European cultural elements. 


\section{Culture vs. Cultured}

All people have culture. Culture is not something held only by society elites, such as only the wealthiest, most educated, or most sophisticated.

Culture is a system of learned behavior patterns that are characteristic of the members of a society (Hoebel, 1958). Note the emphasis on the learning of behaviors or ways of doing things. Culture is learned, and individuals learn culture through an ongoing process of socialization. Parents, families, schools, peers, and workplaces, for example, all socialize individuals to ways of doing things. We find differences across cultures in dress, language, food preferences, and other behaviors in part because these are learned behaviors-not knowledge that is innate, instinctual, or determined by genetic programming.

Cultural patterns are characteristic behaviors and often include a complex array of choices. A culture may afford more than one way of doing the same thing. Hence, diversity in behaviors may be found in some aspects of any culture

Culture is a complex whole that includes knowledge, belief, art, morals, law, customs, and any other capabilities and habits that members of a society acquire (Linton, 1936). Linton emphasized that culture is a complex whole-a network of behaviors related to all aspects of life. Dress is shaped by and reflects many characteristics in any culture, so dress is a complex map of cultural characteristics.

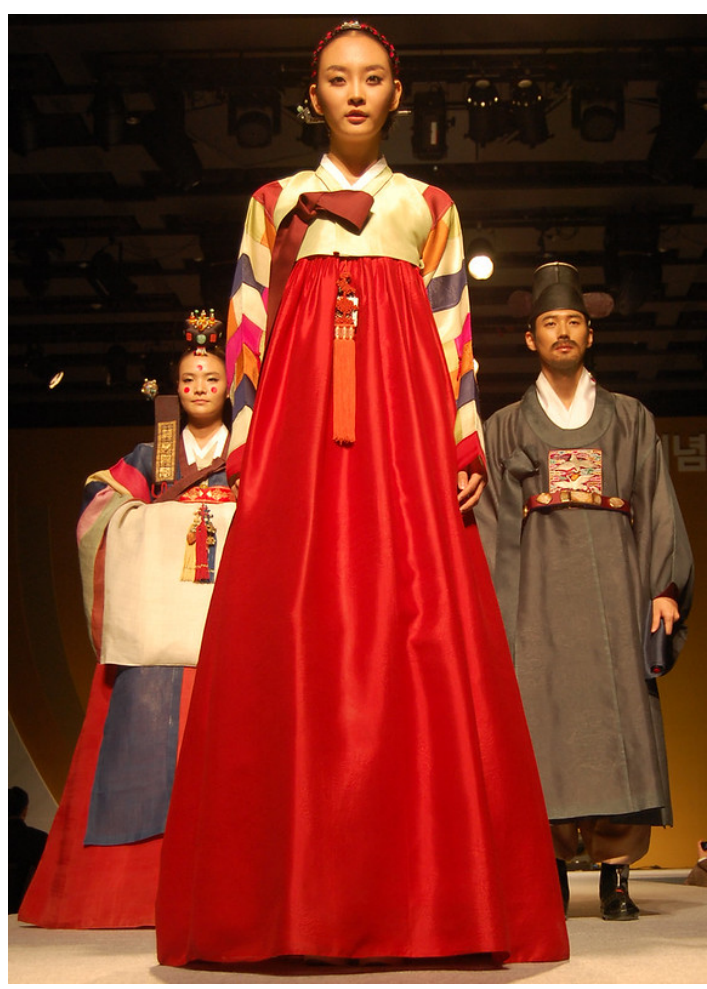

Image Source: “Hanbok fashion show” for Hanbok designer Lee Young-hee, Republic of Korea, CC BY SA

\section{Culture includes both abstract and concrete components (Scupin, 1998).}

Abstract components include the meanings of symbols, events, activities, or actions and how the meanings are created and selected. Concrete components include the forms of action, behavior, event, activity, or artifact. Dress may be a concrete object, such as a shirt, a pair of shoes, or a hairstyle, but those artifacts develop meanings in a culture. The fashion process, situations in which we use dress, and groups associated with wearing of types of dress all bring meaning to those artifacts.

Culture is mentifacts, what people know; sociofacts, what people do; and artifacts, what people make (Spradley, 1972): 


\section{Mentifacts: Ideas, Ideals, Values, Knowledge, and How We Know}

Culture shapes how people think about things. Mentifacts are the ideas, values, and knowledge that shape how we see a culture and how we know or recognize patterns. This includes stereotypes that are held about groups of people who look certain ways. Note that "how we know" also refers to educational and media systems. Fashion magazines are part of these media systems; so are television and the Internet.

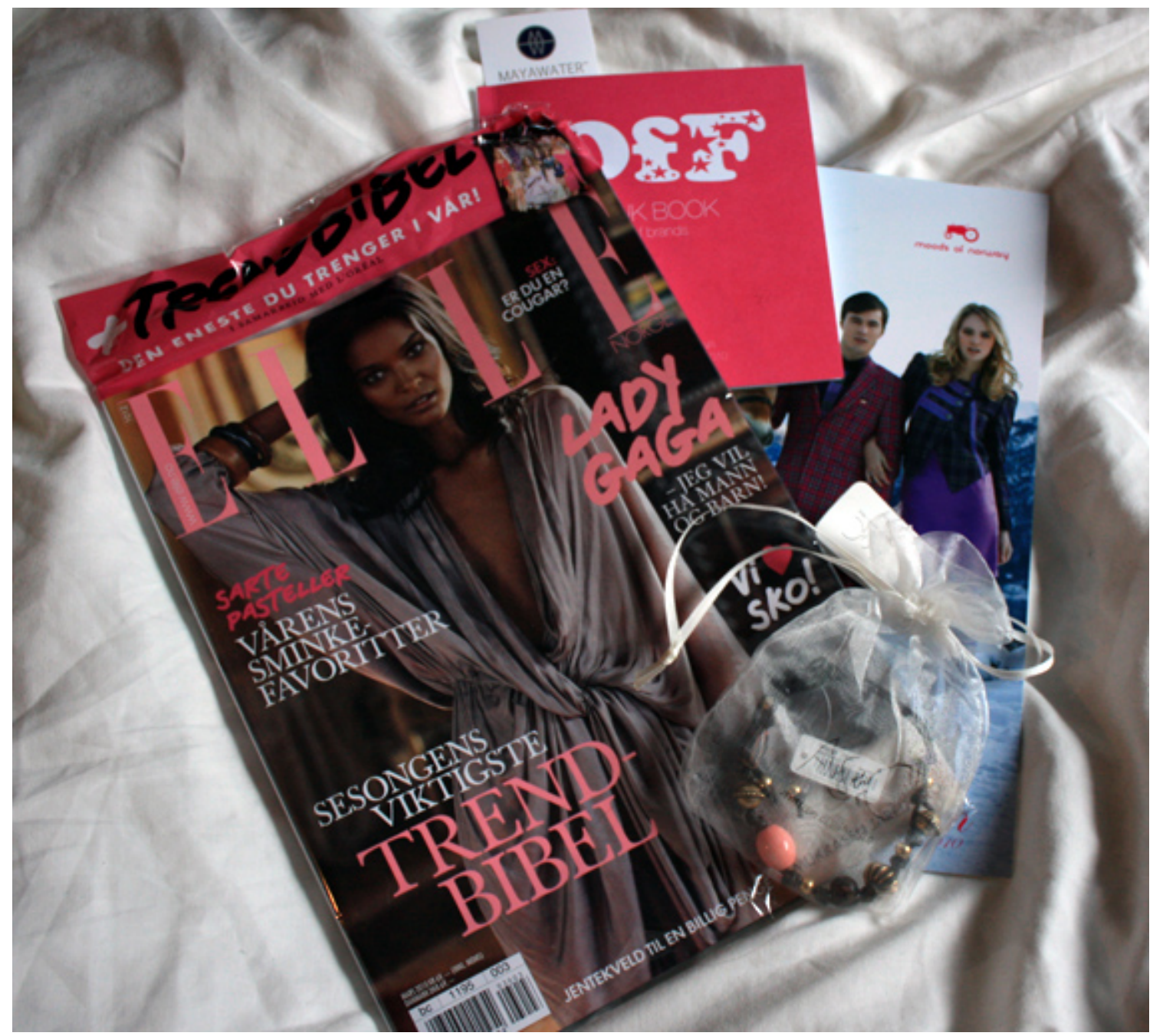

Image Source: Barbro Andersen, $\underline{\text { CC BY }}$

How people in a culture think and what they value are often reflected in dress. For example, in the United States, where we value the freedom to consume and material plenty, consumers tend to prefer large wardrobes (Sproles \& Burns, 1994). In some European countries, the average consumer has a comparatively small wardrobe that often includes several high-quality, expensive items. These few items are worn over and over during the season in which they are fashionable. 


\section{Sociofacts: Characteristics of Social Organizations and How People Organize Themselves.}

Sociofacts reflect how people behave in groups and social interactions. For example, police officers wear uniforms to indicate their occupations and rank within the police force. A store like Target has a dress code-red shirts and khaki pants-to help customers identify employees. Many individuals dress up or "clean up" when going to dinner at someone's house; this small act shows respect to the hosts and indicates participation in a social event.

Sometimes patterns of dress in the larger society reflect how people organize themselves. In the United States today, socioeconomic status is usually only vaguely communicated in our clothing. One hundred years ago, the social class of everyone passing us on the street would have been made clear by their dress.

\section{Artifacts: Things People Make and Tools and Processes for Making Them}

Dress such as clothing, makeup, tattoos, and shoes are artifacts made by people. Artifacts reflect multiple aspects of a culture, such as mentifacts, sociofacts, and the technological knowledge of a culture that shapes manufacturing processes and materials used. For example, Gore-Tex fabric, now used in high-performance sportswear, was invented through the NASA space program.

Technological advancements and economic reality may exclude some clothing options. In ready-to-wear clothing that most people in the United States buy today, only simple seams, darts, and a few gathers comprise construction. Knits and pandex rather than intricate construction details accomplish, a tight fit. During the 1940s and earlier, however, ordinary clothing often had many tucks, darts, godets, and complex seams, for example. The handwork and sewing skill required for those designs is too expensive to produce today in assembly-line factories. Complex fit through construction also requires customized fitting that is too expensive, time-consuming, and difficult for most of us. We save that expense for business suits and special-occasion garments such as wedding dresses.

\section{Society vs. Culture}

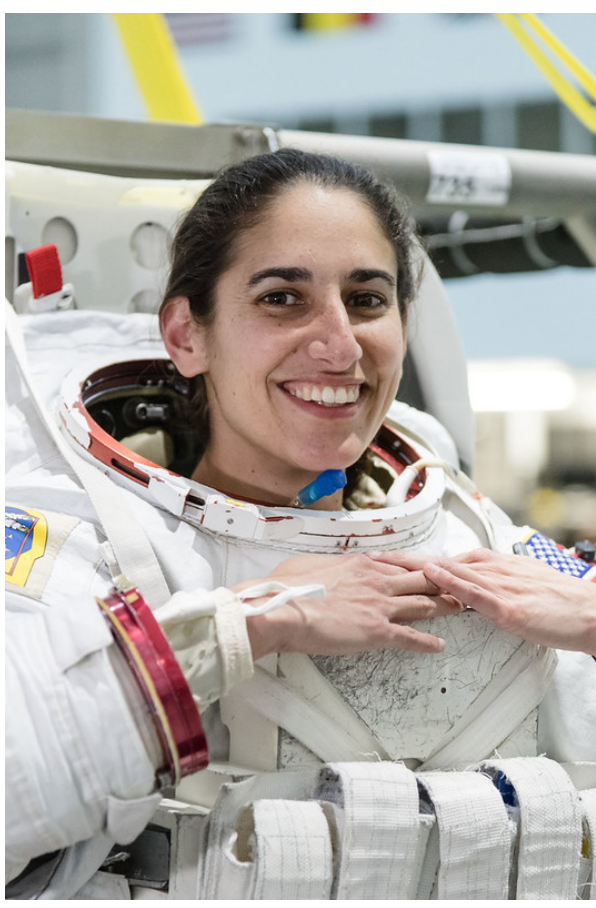

2017 NASA astronaut candidate Jasmin Moghbeli wears a spacesuit prior to underwater spacewalk training at NASA's Johnson Space Center Neutral Buoyancy Laboratory. Image Source: NASA/Josh Valcarcel, $\underline{\text { CC BY NC ND }}$

Anthropologists disagree on how to distinguish the terms culture and society. We will use the terms fairly interchangeably. One definition of society is "a group of people living and working together in a systematic way" (Mead, 1934). An important implication of this definition is that society 
requires people to coordinate their actions with each other. Each individual cannot haphazardly do their own thing with no concern for others. With no traffic laws, for example, we would run into each other fairly frequently. Indeed, with no coordination of human effort, automobiles and roads would never have been invented. Dress would have no meaning; fashions and traditions in dress would not exist. We would have no idea who anyone might be on first meeting of them. Dress is a product of systematic human interaction, and it helps us to coordinate our interactions with others.

\section{What Factors Influence Types of Dress Worn in a Culture?}

Ruth Benedict (1959) drew an "arc of human potential" to indicate that every culture makes choices from among a wide array of possibilities for any form of behavior. Each culture, then, chooses different language sounds, foods, dress materials and designs, and other behaviors.

In any culture, the following factors shape choices for dress and other behaviors:

- climate and natural resources

- religion, ideology, ritual

- technology

- culture contact and diffusion of ideas

- social and political organization

- history

- aesthetic rules.

This short film features the Korowai tribe, whose members had no contact with anyone outside of their community until the 1970s. This isolation affected their dress in numerous ways. One or more interactive elements has been excluded from this version of the text. You can view them online here:
https://iastate.pressbooks.pub/dressappearancediversity/?p=23\#oembed-1

To access a transcript for the video above, download this file: The Tree House People Korowai Video Transcript [DOC]

\section{Principles of Cultural Perspective}

Taking a cultural perspective on dress throughout the semester requires that we adopt specific some ways of thinking about people and the world: 


\section{Holistic approach}

The meaning of dress can be understood only through the study of all aspects of a culture. Dress does not mean one single thing at a time. Many meanings and aspects of a culture are embedded in any example of dress. And sometimes these meanings are difficult to read. For example, why is it that in the United States, where we value individuality so much, so many students on college campuses wear jeans and T-shirts to classes?

\section{Cultural relativism}

Seek to understand dress as it has meaning to a society "insider." What dress worn in nations outside your home country means to you, a visitor or tourist, is not necessarily related to what it means to people in that culture. We need to examine the characteristics of a culture and talk to people within that culture to find out what their dress means. Something as simple as color may have very different meanings in dress in different cultures. For example, red is a common funeral color in Zambia, Africa, and a wedding dress color in traditional China. What would it mean if someone wore a bright red dress to a close relative's funeral or a bride wore a bright red dress to her wedding in the United States today?

\section{Ethnocentrism}

Ethnocentrism is judgment of people of other cultures by one's own cultural standards and beliefs. Dress that is different from our own can be challenging to accept or appreciate.

Ethnocentricity is hard to avoid, for example, when members of other cultures or some groups within our own culture do things to the body that are harmful to the individuals. Acting to end these practices may be seen as important for humanity. It is equally important to recognize, however, that these practices may have deep meanings and roots in religious values or beauty standards previously considered good or "healthful." Simply marching in and making such practices illegal will not necessarily end them. We must take great care when we attempt to change deeply held beliefs about these practices. Change is likely to be slow.

Sometimes it can be quite difficult to avoid ethnocentrism. Here are some examples that individuals may or may not view as harmful: 
- corset wearing

- foot binding

- tanning

- web sites promoting anorexia

- female circumcision

- little people lengthening their legs

- embracing one's transgender identity

- women exposing their breasts in public

- steroid use

- scarification, or the carving of permanent designs in the skin

- practicing bondage and discipline, dominance and submission, sadochism and masochism (BDSM) or kink such as wearing dog collars, chastity belts, or other restrictive garments.

An interactive H5P element has been excluded from this version of the text. You can view it online here:

https://iastate.pressbooks.pub/dressappearancediversity/?p=23\#h5p-10
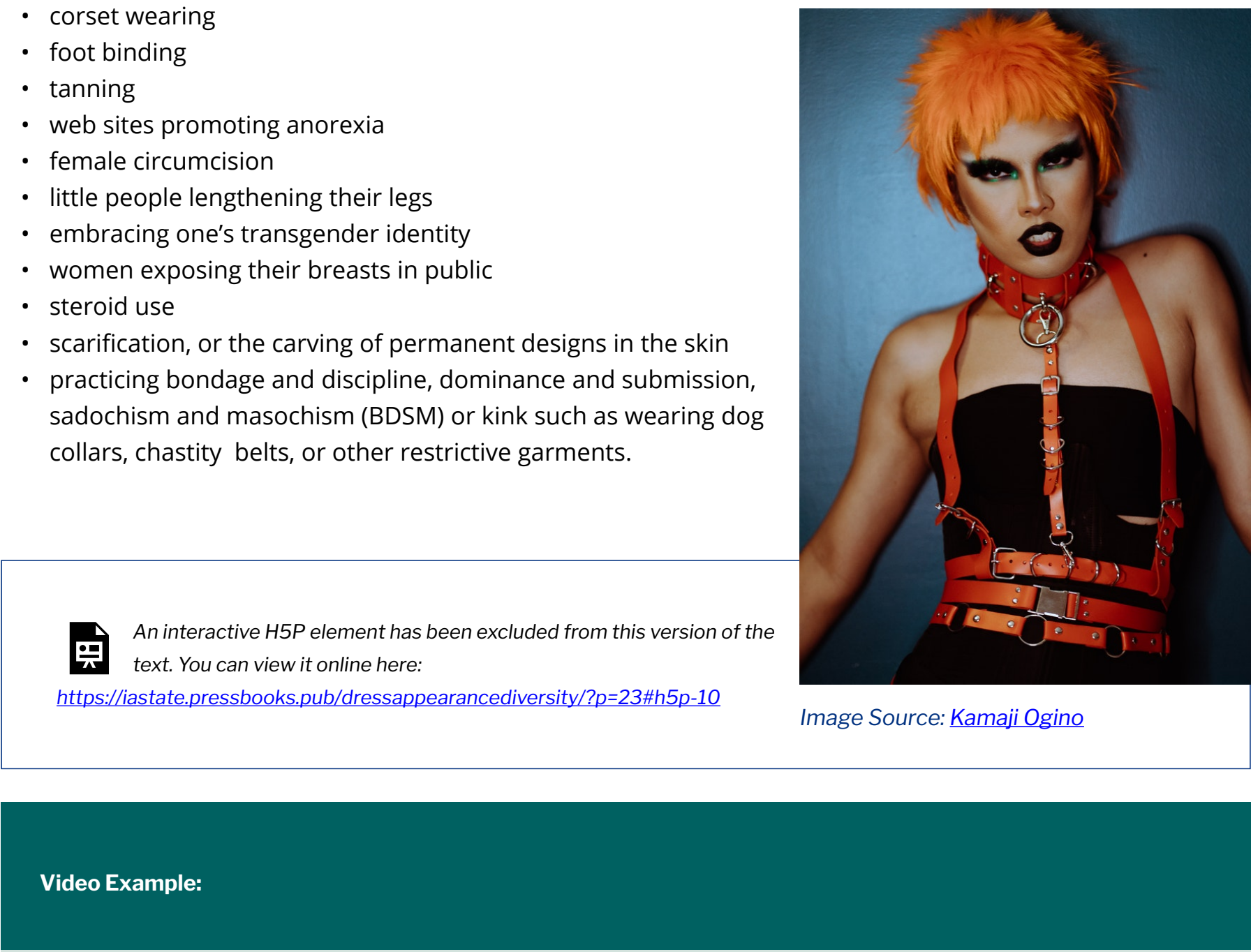

Watch this short video about BDSM dress, identity, and women's empowerment. The research presentation is titled "Paddles, Strap-Ons, Latex, and Leather: Negotiations of BDSM Women's Dress, Embodiment, and Bodies in Motion through Spatial-Temporal Dynamics."

The video highlights how these women embrace their BDSM identity when others sometimes view these practices as harmful. 


\section{Cultural Appropriation}

Another term related to changing cultural aesthetics or norms is cultural appropriation. The concept of cultural appropriation is highly debated. For example, in a video that went viral, Amandla Stenberg discusses her opinions about white people adopting Black hairstyles (2015). Stenberg discusses how the adoption of hairstyles such as braids or cornrows by white people is wrong because when Black people wear these styles, they are viewed as "thugs" or "gangsters," yet when white people adopt these styles they can be seen as "cool" or "edgy," which reinforces longstanding racial hierarchies and stereotypes of white people having power. There are also arguments such as appreciation versus appropriation, where individuals will argue that their adoption of a particular style or aesthetic is not wrong; they merely appreciate that part of another culture (Brucculieri, 2018).

In the following film, about 28 minutes long, Denise Green of Cornell University delivers a compelling lecture on cultural appropriation and the Cowichan sweater (CTV News, 2015).

One or more interactive elements has been excluded from this version of the text. You can view them online here:

https://iastate.pressbooks.pub/dressappearancediversity/?p=23\#oembed-2

To access a transcript for the video above, download this file: What is the cost of not fitting in Video Transcript [DOC]

In this short film, Bethany Yellowtail, an Indigenous designer, discusses her experiences as a fashion designer and cultural appropriation.

图

One or more interactive elements has been excluded from this version of the text. You can view them online here:

https://iastate.pressbooks.pub/dressappearancediversity/?p=23\#oembed-3

To access a transcript for the video above, download this file: Indigenous Cultural Appropriation in Fashion with Bethany Yellowtail and James St. James Video Transcript [DOC] 
Puri, S. "Ethnic fashion” obscures cultural identity. Yale Herald. (February 2, 2001). Accessed November 1, 2021, via the Internet Archive: http://www.yaleherald.com/archive/xxxi/2001.02.02/opinion/page12aethnic.html

\section{References}

Benedict, R. (1959). Patterns of culture. Boston: Houston Mifflin.

Hoebel, E. A. (1958). Man in the primitive world: An introduction to anthropology (2nd edition). New York: McGrawHill.

Linton, R. (1936). The study of man: An introduction. New York: D. Appleton-Century.

Mead, G.H. (1934). Mind, self, and society (Ed. by Charles W. Morris). Chicago: University of Chicago Press.

Scupin, R. (1998). Cultural anthropology: A global perspective (3rd ed.). Upper Saddle River, NJ: Prentice-Hall.

Spradley, J. P. (1972). Culture and cognition: Rules, maps, and plans. San Francisco: Chandler Publishing.

Sproles, G. B., \& Burns, L. D. (1994). Changing appearances. New York: Fairchild. 


\section{Culture Case Study}

?. 8

\section{Step One: Become familiar with the case study.}

1. The case study attached below is a Word document and can be downloaded. It includes the task, evaluation, and template for the case study:

Culture Case Study [DOC]

Step Two: Submit your complete assignment on Canvas.

1. Format your document.

2. Remember to check the submission against the rubric. 


\section{6. \\ SUBCULTURE AND GROUP MEMBERSHIP}

\section{Module Learning Objectives (MLO)}

\section{In this chapter, you will}

- MLO 6.1 Identify foundational concepts and theories related to subcultures, identity, appearance, and dress. [CLO 1]

- MLO 6.2 Identify the factors that influence different aspects of subcultural dress. [CLO 1]

- MLO 6.3 Explain the role of dress and appearance in identity development for different subcultures. [CLO 1]

- MLO 6.4 Examine how marginalized communities in the United States use dress and appearance to negotiate their identities. [CLO 2]

- MLO 6.5 Deconstruct your own perspective and approach to understanding the dress of subcultures. [CLO 4]

\section{What Is a Subculture?}

Subcultures are social groups, or groups of individuals who share similar lifestyles, belief systems, or other commonalities. Some subcultural groups have dress codes, whereas others do not. Sub means underneath or below; therefore, subculture refers to individuals who are a part of a group that is different from the dominant culture or dominant people in a particular part of society (Lennon, Johnson, \& Rudd, 2017, p. 292).

\section{Why Do Subcultures Exist?}

Subcultures exist because the dominant culture does not meet the needs or interests of members of the particular subculture. Therefore, these groups form to engage in lifestyles or activities that meet the needs of their interests or shared experiences related to a particular identity (Lennon, Johnson, \& Rudd, 2017, p. 292). 


\section{What are Examples of Subcultures?}

There are numerous groups of people that could be classified as subcultures, for example: hippies, antigun groups, high school jocks, environmental activists, people in the furry community, people in the cosplay community;, punks, goths, and many more (Lennon, Johnson, \& Rudd, 2017, 292). Even religious groups could be considered subcultures; for instance, Holdeman Mennonites are a group of individuals who follow a particular religion and wear a specific style (Church of God in Christ, Mennonite, 2021). All of these groups have shared interests, experiences, or identities, thus classifying them as a subcultures.

An interactive H5P element has been excluded from this version of the text. You can view it online here:

\section{Social Groups}

Individuals might identify with many types of social groups, which are defined by the connections between their members. These groups fall into two types: primary and secondary.

- Primary groups are small, informal collections of individuals who interact with each other in personal, direct, and intimate ways.

- Secondary groups are groups to which individuals feel only limited ties.

A subculture can be seen as a primary or secondary social group, depending on the type of culture and its members. Members of groups can be further categorized by their "closeness" and the extent to which they identify with their social group.

\section{In-group membership}

In-group memberships helps people feel

- Like they belong to the group

- A sense of togetherness

\section{Out-group membership}

In out-group membership, people 
- feel like they do not belong to the group

- may make conscious decisions to avoid appearing out-group

For example, gangs are self-formed associations of peers with members who may engage in illegal activities. People may avoid being out-group members of a particular gang to escape violence and/or death.

\section{Subculture membership}

Some subcultural groups have clear, distinct rules and definitions of members (among these are some gangs, biker groups, and the Amish). However, many groups are only loosely defined, and members have liminal membership. For example, members of subcultures might

- relate to some people in the subculture but not fully invest identity in one group

- have moderate to limited connections with other members of the same group

- borrow style ideas from several groups. 


\section{Subcultures are Dependent on Context}

\section{Distinct Example: The Holdeman Mennonites}

The Holdeman Mennonites live in communal groups that stay fairly separate from mainstream society.

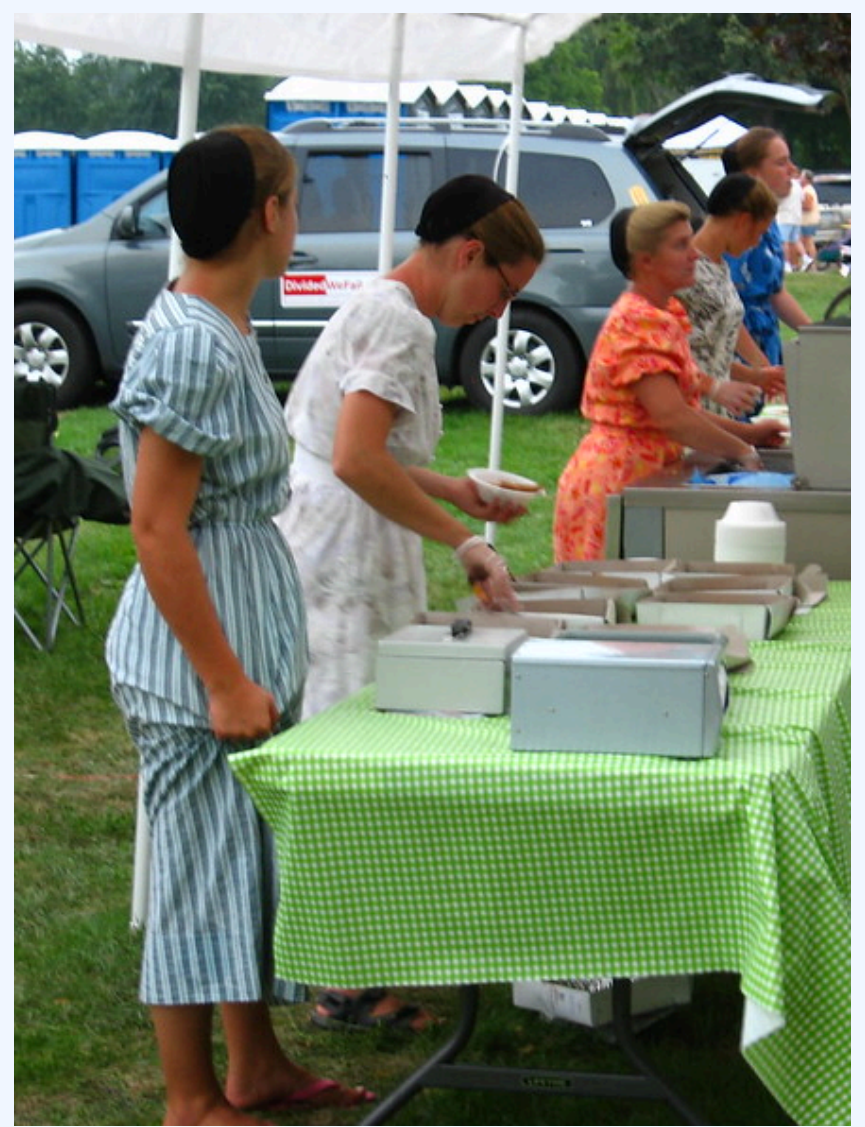

Mennonite women in Independence, lowa. Image Source: Rockman on Flickr, CC BY SA.

Women's dress is highly symbolic. Rules for acceptable prints (they change over time) are carefully approved by men and women in the community. 


\section{Liminal Example: Burning Man}

The Burning Man festival began in the 1980s on Baker Beach in San Francisco but has become a large-scale, expensive event held in the Nevada desert for 2 weeks each summer.

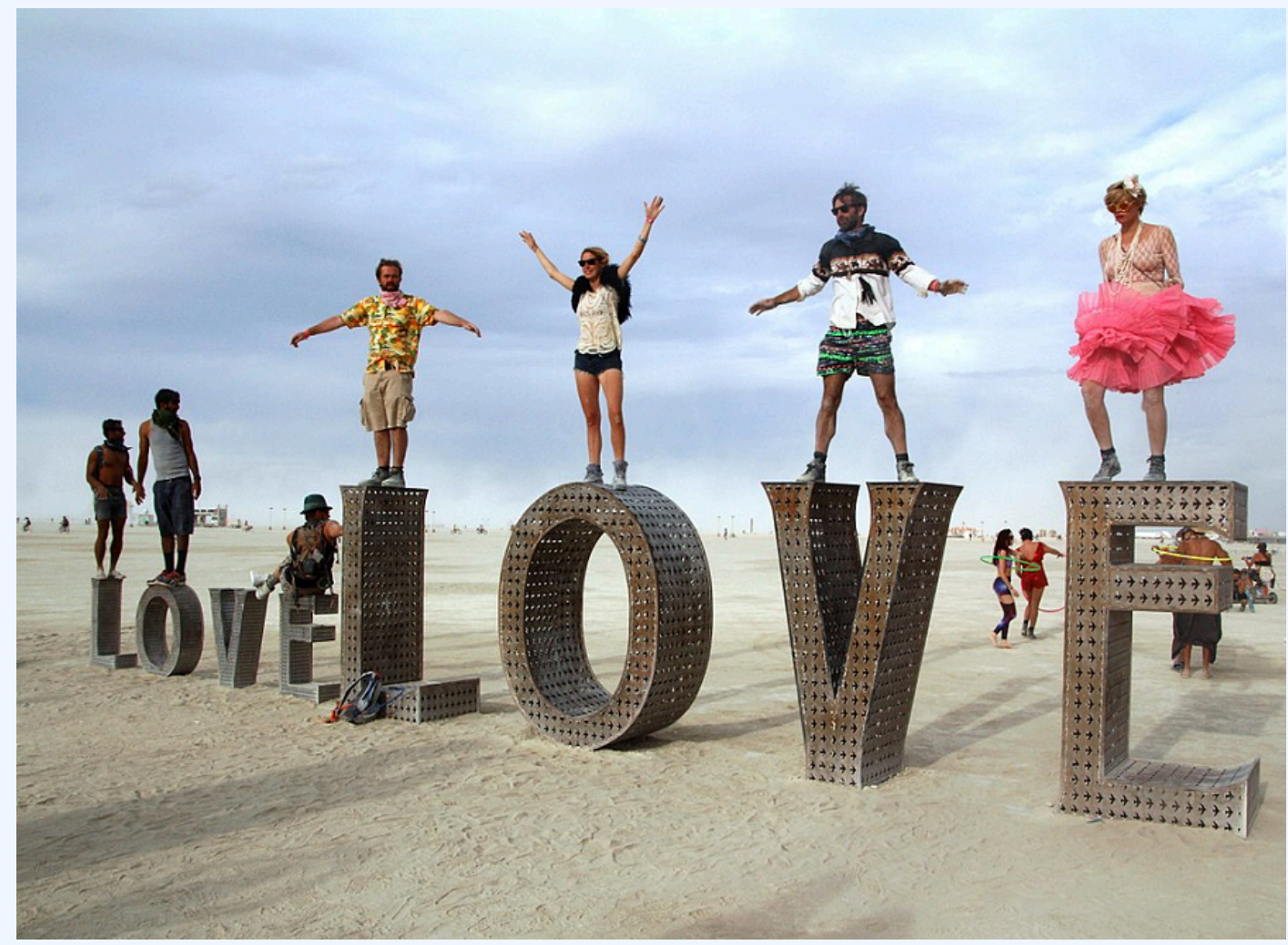

Image Source: BLM Nevada, $\underline{\text { CC BY }}$

The subculture community that forms each year is highly liminal and diverse.

Watch this short film Somewhere in Between on Burning Man, subcultural style, and shifting masculinities by Denise Green from Cornell University.

One or more interactive elements has been excluded from this version of the text. You can view them online here: https://iastate.pressbooks.pub/dressappearancediversity/?p=81\#oembed -1

To access a transcript for the video above, download this file: Somewhere in Between Video Transcript [DOC] 


\section{Subcultural Style}

Subcultures often develop or have distinct styles reflecting their membership. Mainstream culture might respond to this outward expression of a subculture in many ways, but a common process one sees $n$ public response to subculture fashion is outlined below:

- Initial response is often fear,

- Dominant culture can meet the unmet needs,

- Dominant culture assimilates the subcultural style (commodification),

- Entrepreneurs commodify the style,

- After commodification, the subculture loses its initial power.

\section{Example: Goth Subculture}

In the 1970s, British bands set the tone for Goth subculture to emerge. Siouxsie and the Banshees are considered founders of the movement, and the group typified the subculture's interest in dark, somber music. Over time, the Goth subculture was commodified and sold to a mainstream audience through stores like Hot Topic, which originally focused on selling music brands before expanding into a wider range of merchandise catering to a more vague Goth "aesthetic."

This Siouxsie and the Banshees music video for the song "Spellbound" demonstrates the group's dark, somber aesthetic.

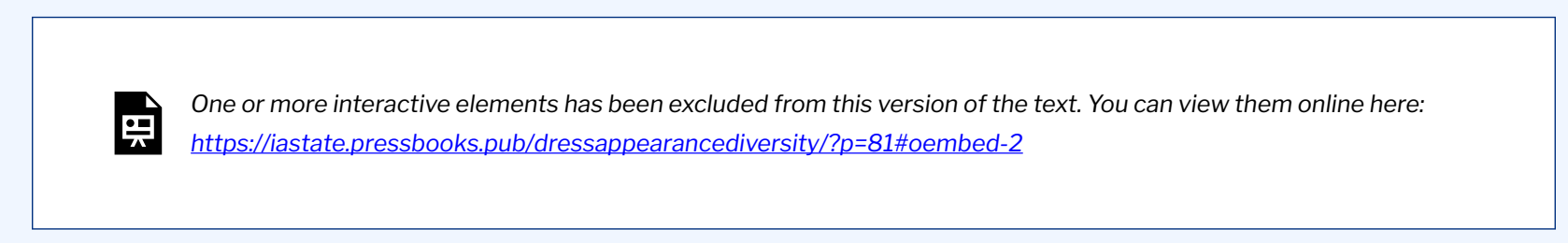

To access a transcript for the video above, download this file: Sousie and the Banshees Spellbound Video Transcript [DOC]

\section{Example: Punk subculture}

Punk is difficult to define, due to its fluidity and complexity. The punk subculture, though, has roots in the 1970s in urban areas in the United States and the United Kingdom. Individuals who self-identify as punk typically reject aspects of mainstream society, including consumer lifestyles, politics, art, and ideologies. They frequently embody antihegemonic ideologies (Sklar, 2013). 
Bricolage, or the creation from multiple and mixed things, is often described as central to punk aesthetics (Hebdige, 1979; Polhemus, 1994; Szatmary, 1996). Symbols often associated with punk aesthetics include , for instance, studded leather belts and cuffs, pins, ripped clothing, unnatural hair colors, combat boots, and many other dress and appearance practices (Bennett, 2006). Individuals mix and match multiple and varied items to create particular looks, a look influenced by the concept of bricolage. Plaids or tartans, and iconography such as band logos and subversive imagery are also patterns used frequently to signify group membership (Sklar, 2013). The popularization of tartan or plaid in the punk aesthetic dates to designers Vivienne Westwood and Malcolm McLaren (Punkflyer.com); the designers used the patterns in their early clothing lines in 1976 to signify those fighting battles or at war (Sklar, 2013). Another key concept in punk aesthetic is DIY, or do it yourself. Individuals may repurpose items or create original look through sewing, crafting, or other means (Sklar, 2013). Punk aesthetics also include distressed apparel. The notion of dirty or worn-in clothing rejects mainstream concepts of acceptable appearances, which aligns with some parts of punk ideologies.

It is important to note that there is no consistent look in a punk aesthetic for individuals who might self-identify as punk (Sklar, 2013). The media has perpetuated stereotypical images from early punk bands such as the Dead Kennedys, the Sex Pistols, and many others where band members wore garments such as leather pants, safety pins, and torn clothing. These early media representations helped define what the dominant culture or the public at large viewed and defined as definitively punk, punk aesthetics, and punk identities (Sklar, 2013). However, these media representations do not solely represent what embodying and expressing a punk identity means for everyone.

Motivations to embrace a punk style, aesthetic or identity are varied. In her book on punk style, Sklar interviewed an individual who explained that for him, punk is not expressed through his appearance but through his overall attitude. He said, "I'm older . . . so when I was a punk rocker, a lot of it was attitude. It wasn't so much the clothing. We didn't have Hot Topic, you know. There wasn't anybody that was catering to a punk aesthetic like there is now . . . you know, it was a lot more, reflected personality a lot more I think back then" (2013, pp. 67-98). This example highlights how though sometimes we express our identities through our appearance, this is not always the case.

The evolution of punk from a subcultural community to a product commodified by high fashion is evident in the Metropolitan Museum of Art's 2013 exhibition Punk: Chaos to Couture, which was mounted in 2013 (MET, 2021). In the exhibition, you can view individuals from the early punk movement, such as Paul Cook and John Lydon, members of the band the Sex Pistols and see how their styles and aesthetics influenced high fashion designers such as Martin Margiela, Gianni Versace, and Comme des Garçons.

The punk subculture and style began in the third quarter of the 20th century and continues into the 21st. Punk styles have transformed over time, yet core aspects of punk style include bricolage, appropriation, distress, DIY, subversive imagery, and/or rejections of mainstream society. These styles reflect the overall antisociety attitude that embodies punk identity.

Watch this one-hour film on afro-punk. 
One or more interactive elements has been excluded from this version of the text. You can view them online here: https://iastate.pressbooks.pub/dressappearancediversity/?p=81\#oembed -3

To access a transcript for the video above, download this file: Afropunk Video Transcript [DOC]

Watch this short film on punk, punk identity, and dress.

Watch this short film on how subcultural style and roller derby.

One or more interactive elements has been excluded from this version of the text. You can view them online here:

https://iastate.pressbooks.pub/dressappearancediversity/?p=81\#oembed-4

One or more interactive elements has been excluded from this version of the text. You can view them online here:

\section{References}

Bennett A. (2006). Punk's not dead: The continuing significance of punk rock for an older generation of fans.

Sociology, 40(2): 219-235.

Hebdige, D. (1979). Subculture: The meaning of style. London: Routledge.

Lennon, S., Johnson, K. K. P., \& Rudd, N. (2017). Social psychology of dress. London: Bloomsbury.

Polhemus, T. (1994). Street style: From sidewalk to catwalk. New York: Thames \& Hudson.

Sklar, M. (2013). Punk style. London: Bloomsbury.

Szatmary D. (1996). A time to rock: A social history of rock ' $n$ ' roll. New York: Schirmer Books. 


\section{Subculture and Group Membership Case Study}

Step One: Become familiar with the case study.

1. The case study attached below is a Word document and can be downloaded. It includes the task, evaluation, and template for the case study:

Subculture and Group Membership Case Study [DOC]

Step Two: Submit your complete assignment on Canvas.

1. Format your document.

2. Remember to check the submission against the rubric. 


\section{7. \\ FASHION THEORIES}

\section{Module Learning Objectives (MLO)}

\section{In this chapter, you will}

- MLO 7.1 Identify foundational concepts and theories related to fashion, identity, appearance, and dress. [CLO 1]

- MLO 7.2 Identify the basic tenets of fashion theories and how they help explain dress and appearance. [CLO 1]

- MLO 7.3 Explain how marginalized communities in the United States use dress and appearance to express their identities. [CLO 2]

- MLO 7.4 Examine how dress and appearance of marginalized communities in the United States are represented in the fashion system (e.g., advertisements or retailers). [CLO 3]

- MLO 7.5 Examine social justice issues related to dress and appearance of marginalized communities in the United States. [CLO 2]

- MLO 7.6 Deconstruct your own perspectives and approach to understanding the dress of others. [CLO 4]

\section{Fashion}

Fashion refers to the idea of what is popular or on trend. One can also think about fashion as what is in flux in a particular time and place. Fashion undergoes a process of dynamic change: within a fashion system, there is a continuous change in what is on trend, or in fashion, over time. It can be extremely difficult to trace the origins of a particular fashion trend such as a motif, design, or silhouette (Reilly, 2012). Because multiple cultures and communities coexist across the world and even within regions, it can be almost impossible to be certain that a style came from a specific time and place or to define a fashion trend's true origin. 


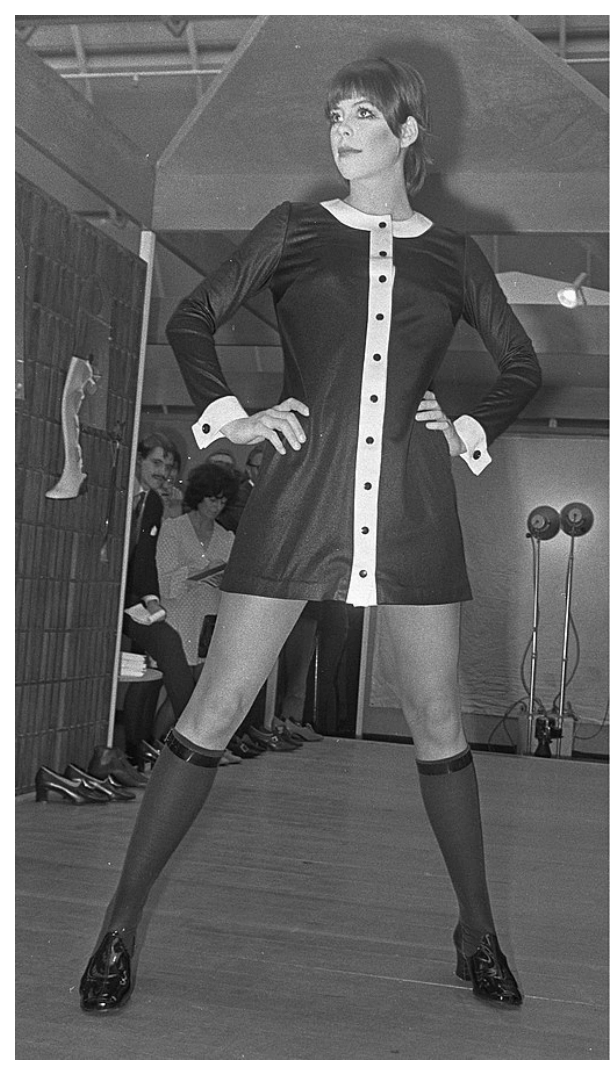

Diabolo minidress at a Mary Quant fashion show in Utrecht, March 1969. Image Source: Dutch National Archives, CCBY SA
The miniskirt is an example of a fashion trend that is thought to have developed in one place and time, yet various scholars provide conflicting evidence for some of these claimed origins. Mary Quant, a British fashion designer, is often credited for introduing the miniskirt into fashion in London in the 1960s, during the "youthquake" movement (FIT, 2021; V\&A, 2021). However, according to Ford (2015), the miniskirt developed out of Tanzania. Haya Rinoth, a South African fashion designer, argued in Drum magazine that this new style developed in Africa, not the United Kingdom, as history had recorded. This example highlights some of the social justice issues or the Eurocentric power imbalance in history, where European history often is prioritized (Pokhrel, 2021).

\section{Fashion Is a Social Process}

Fashion is not just a set of trends but a social process, a way of behaving that a discernable proportion of a social group temporarily adopts and which is perceived to be socially appropriate for a time and situation. This point is particularly important, since something that might be considered fashionable for one situation (e.g., a class lecture) might not be fashionable in another (e.g., a business office).

Taking this broader definition of fashion into perspective, there are other products that have fashion components:

- cars and car interiors

- appliances

- computers and other technological devices. 


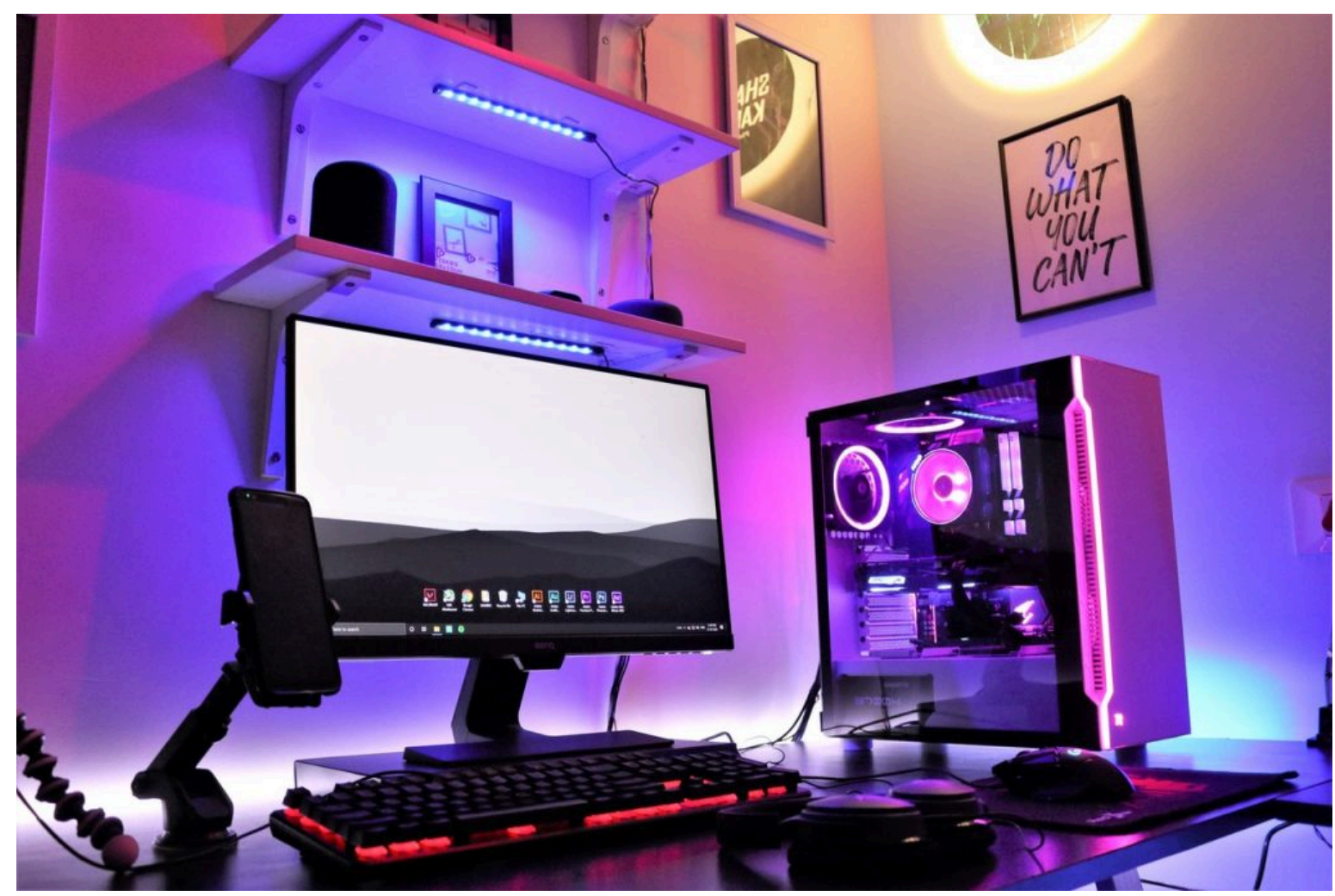

Image Source: Sharad Kachhi

\section{Style versus Fashion}

We have mentioned style throughout this chapter and will continue to do so. However, style and fashion are not synonymous. A style is a combination of lines, shapes, and forms. A type of fabric or pattern (e.g., plaid) may be a component that defines a style. Fashion, in contrast, refers to a specific style that is "popular" at some specific time.

Because its definition hinges on popular use, fashion requires an aspect of consumer acceptance. In other words, for a style to be considered fashion, there has to be an audience and consumer base. Two people wearing similar outfits is not fashion; multiple people must be wearing a look, exhibiting a collective behavior, for a style to be fashion. The reasons someone buys into a fashion can differ widely, though. Both individuality and conformity are necessary in the process, with some consumers using fashion as a way of trying something new and "stepping out of their comfort zone," while others use fashion to fit in with others.

\section{Fashion Diffusion}

As new fashions are introduced to different cultures or communities, they go in and out of style. This diffusion usually results in a bell-shaped curve. Of note is that the curve never represents $100 \%$ of consumers. In this 
bell curve, in the early innovation stage, the fashion innovators create new styles. Fashion leaders, often seen as influencers, then pick up the styles. Today, Instagram hosts a number of fashion influencers who make a tremendous impact on the industry promoting various styles (Barker, 2021). After the leaders wear a style, the style is typically worn by what are referred to as early adopters, then late adopters. Late adopters do not necessarily feel comfortable wearing new or innovative styles until they are viewed as on trend. Finally, fashion followers adopt a style when it is near obsolescence or when it is phasing out or seen as an old trend (Reilly, 2012).

Precious Lee is a highly influential fashion model who has significant following on her Instagram page (Precious Lee, 2021).

To view a transcript for the video above, download this file: Precious Lee Runway Compilation Video Transcript [DOC]

\section{Characteristics of Fashion Opinion Leaders}

Fashion opinion leaders, like the fashion influencers on Instagram and TikTok, tend to have a similar set of characteristics. They will

- communicate about dress a lot

- make themselves socially active and visible

- profess an interest in high fashion

- portray themselves as self-confident

- showcase taste and social sensitivity

- influence choices others make in their dress.

Examples of famous fashion opinion leaders include Madonna, Lady Gaga, and Beyoncé.

\section{Fashion Items That Are Not Trends:}

Fads and classics describe concepts, styles, or ideas that are different

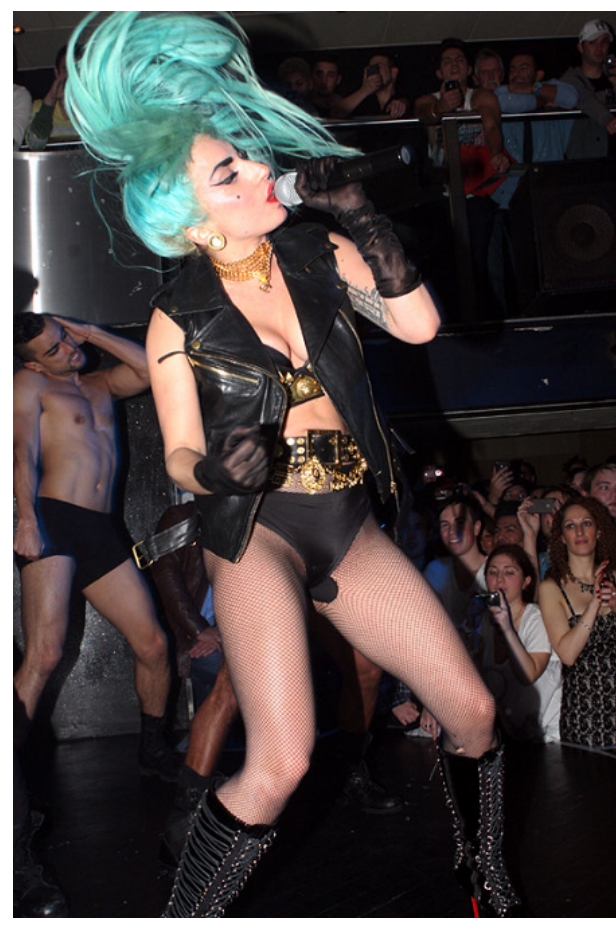

Image Source: Eva Rinaldi, CC BY SA

from fashion trends. Classics are items that have prolonged lives and do not necessarily go out of fashion. Examples of classics include the little black dress, Converse sneakers, denim jeans, black suit jackets, shift dresses, white button-down shirts, and trench coats (Reilly, 2012). Some brands, such as The Gap, are famous 
for selling classics in addition to more fashionable items. Fads, which quickly go in and out of fashion. are defined in contrast to classics. Examples of fads include the 1990s' glitter eyeshadow. Another example is the Google Glass eyewear (Doyle, 2016). It was quite popular when it came out in the 2000s, but it did not last very long at all.

An interactive H5P element has been excluded from this version of the text. You can view it online here:

https://iastate.pressbooks.pub/dressappearancediversity/?p=83\#h5p-8

\section{Who Determines What Is Fashionable?}

Gatekeepers are individuals who influence what is fashionable at a particular time. Examples include people in marketing, designers, buyers, or others in the fashion industry. In particular, the fashion industry has great control over what is available on the market and thus is considered a major gatekeeper in aesthetics, styles, and fashions that we see in communities and cultures (Reilly, 2012).

\section{Fashion Theories}

A theory is used to explain phenomena; fashion theories are used to explain how and why styles and fashions diffuse across time and across cultures.

\section{Trickle-down Theory}

Trickle-down, or upper-class theory, is one example of a fashion theory (Simmel, 1904). This theory is based on ideas related to social class. It explains that individuals of higher socioeconomic status set the trends, and then those of lower socioeconomic statuses follow these trends. 


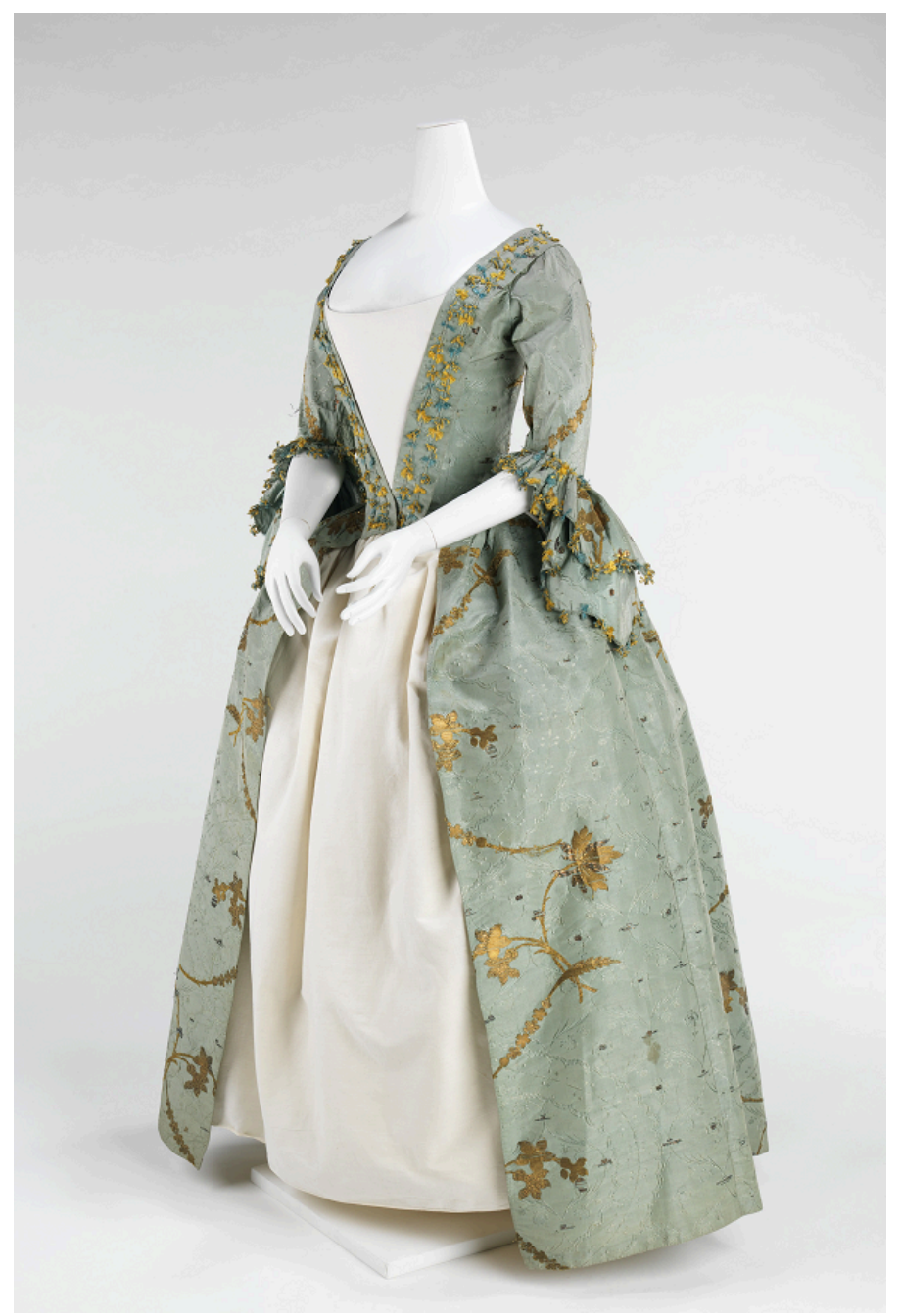

The 18th century Robe à l'Anglaise was developed by upper class French ladies after styles developed by upper-class dressmakers in England and Spain before them. Image Source: The Met Museum

The Trickle-down Theory is particularly limited in that it assumes we live in a pyramid-shaped society, one in which fashion information is initially available only to upper classes, which consume fashion in order to show off their wealth. Further, this theory assumes that fashion innovators are only found in the upper classes and that upper-class individuals do not want to look similar to those in the middle and lower classes. In reality, fashion and fashion trends are much more complex. This is especially true after the invention of the Internet.

\section{Trickle-up Theory}

A second theory is Trickle-up Theory, or the subcultural leadership model (Sproles, 1985). This theory supposes that style ideas start with "lower classes or non-prestigious groups" and are picked up by middle and 
upper classes and incorporated into mainstream fashion. For example, Lolita styles that emerged in Japan in the 1990s began on the streets of Japan and then trickled up into haute couture or high-fashions (V\&A, 2021). Harajuku street fashion continues to innovate and inspire high-fashion trends today.

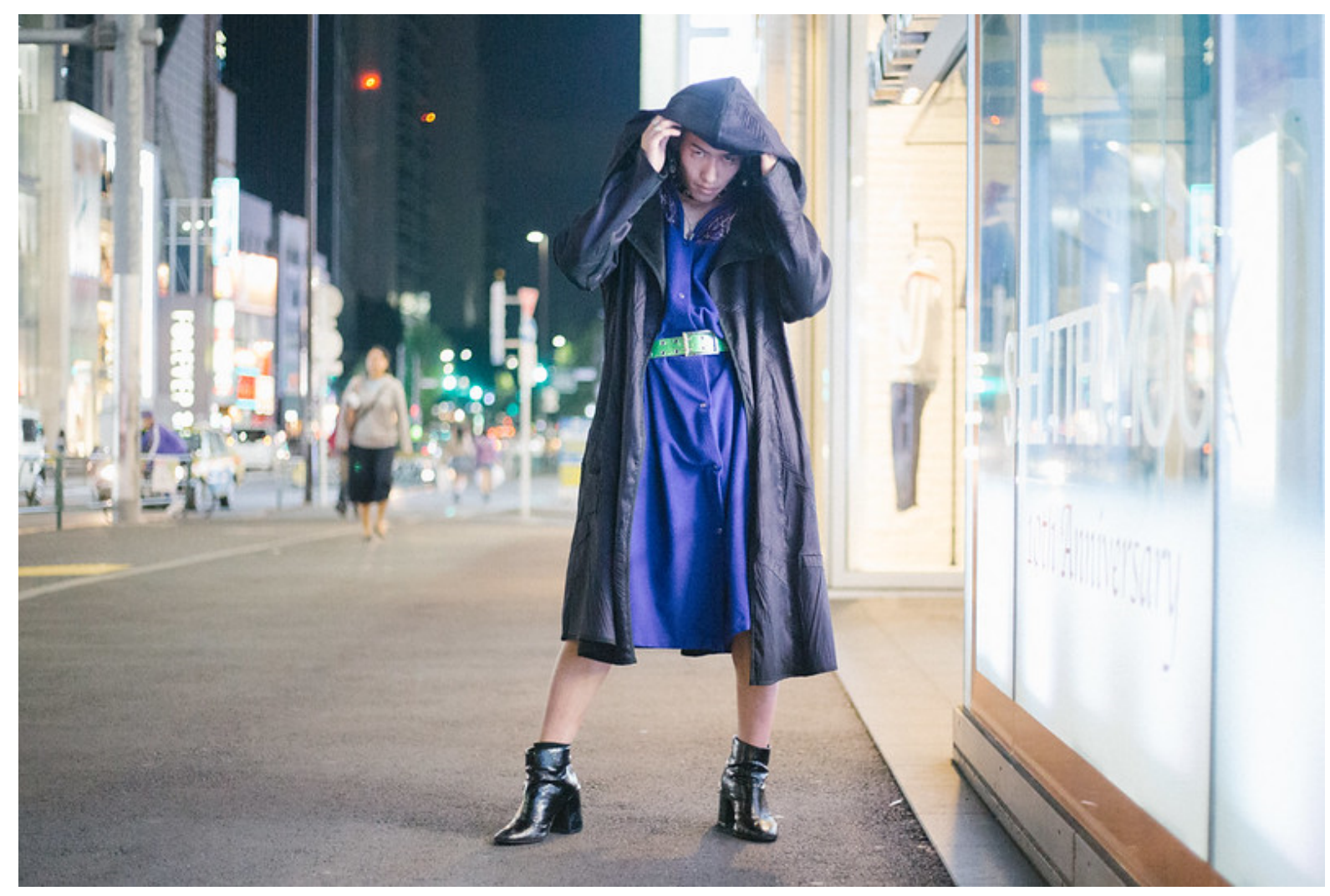

Harajuku street fashion. Image Source: Dick Thomas Johnson, CC BY

Unlike Trickle-down Theory, this does not argue that the individuals are innovating to create a trend. Instead, Trickle-up Theory states that subcultures create fashions to respond to unmet needs, and only after media legitimizes a subculture's style by featuring it and getting the public used to seeing it will a style spread (Hebdige, 1979). The originators of the style often get no monetary benefit from being featured in this way and might not be recognized as the originators of a style at all. (See chapter 6, "Subcultures" for more information.)

Finally, there is Trickle-across Theory (King, 1963). In this theory, fashion trends or styles can appear and spread across any social class.

Many theories help explain how and why styles or trends move or change, but these three theories are some of the basics. It should be noted, though, that they explain fashion at the broader societal level. Other theories help explain fashion on a more individual and micro level.

Fresh Dressed is a film that chronicles the history of hip-hop fashion and how it evolved. It demonstrates how these styles diffused throughout US society. 
One or more interactive elements has been excluded from this version of the text. You can view them online here:

To view a transcript for the video above, download this file: Fresh Dressed Trailer Video Transcript [DOC]

\section{References}

Hebdige, D. (1979). Subculture: The meaning of style. London: Methuen.

King, C. W. (1963). Fashion adoption: A rebuttal to the "trickle-down" theory. In S A. Greyser (Ed.), Towards Scientific Marketing (pp. 108-125). Chicago: American Marketing Association.

Reilly, A. (2012). Fashion as a dynamic process. In S. A. Miller-Spillman, A. Reilly, \& P. Hunt-Hurst (Eds.), The meanings of dress (pp. 43-51). London: Bloomsbury.

Simmel, G. (1904). Fashion. International Quarterly, 10, 130-155. 


\section{Fashion Theories Case Study}

\section{Step One: Become familiar with the case study.}

1. The case study attached below is a Word document and can be downloaded. It includes the task, evaluation, and template for the case study:

Fashion Theories Case Study [DOC]

Step Two: Submit your complete assignment on Canvas.

1. Format your document.

2. Remember to check the submission against the rubric. 


\section{PART II \\ DRESS AND MARGINALIZED \\ COMMUNITIES}




\section{8. \\ SEX AND GENDER}

\section{Module Learning Objectives (MLO)}

In this chapter, you will

- MLO 8.1 Identify foundational concepts and theories related to sex and gender, fashion, identity, appearance, and dress. [CLO 1]

- MLO 8.2 Identify the numerous aspects of transition for individuals in the transgender and nonbinary communities in the United States. [CLO 1]

- MLO 8.3 Identify different types of dress worn by the transgender and nonbinary communities in the United States to affirm their gender identities. [CLO 1]

- MLO 8.4 Identify trans and nonbinary people's experiences in the United States wearing different dress objects reflecting their trans and nonbinary identities. [CLO 1]

- MLO 8.5 Identify different fashion brands that produce and sell dress objects for the transgender and non binary communities in the United States to affirm their gender identities. [CLO 3]

- MLO 8.6 Identity how gender expressions and norms have shifted and changed over time and across different cultures. [CLO 2]

- MLO 8.7 Explain the role of dress and appearance in the development of one's sex assigned at birth and their gender. [CLO1]

- MLO 8.8 Examine social justice issues related to dress and appearance of the transgender and nonbinary communities in the United States. [CLO 3]

- MLO 8.9 Deconstruct your own perspectives and approach to understanding the dress and appearance of the transgender and nonbinary communities in the United States. [CLO 4]

- MLO 8.10 Identify the driving forces of transformative social justice change in the fashion system related to transgender and nonbinary identities in the United States. [CLO 5]

\section{Sex}

Sex is a way of distinguishing individuals based on a collection of biological traits. These traits include: 
- reproductive organs

- chromosomes

- hormones

- secondary sex characteristics, such as breast development.

Sex is often associated with the words male and female, and throughout much of Western culture it is presented as a binary. People who challenge the male/female binary sex system are grouped under the umbrella term intersex. Often, someone is labeled as intersex when they have ambiguous genitalia, though this term can apply to a variety of situations in which a person is born with reproductive or sexual anatomy that doesn't fit the box of "female" or "male." Intersex individuals are fairly common, and approximately $2 \%$ of the human population is intersex. Sometimes intersex individuals undergo surgical interventions during infancy, decisions made for them by their parents, caregivers, or medical practitioners, so they can more easily identify as one sex, but many intersex people view these interventions as cruel or unnecessary.

Tricky Terminology: The term hermaphrodite has been used to refer to intersex people in the past, but starting around the 2010s has been viewed as derogatory.

Required reading: Terms and Definitions for LGTBQIA+ topics [PDF]

\section{Gender}

In contrast to sex, gender is defined as the social construction of femininity and masculinity. While sex is defined by one's biological and physical traits, gender is a performance of mannerisms, posture, movement, vocal tone, word choice, and dress that serves to present a specific identity to the rest of society. Although they often overlap, a person's gender identity, their internal understanding of their own gender, might not reflect their gender expression, the behavior, actions, and style in which they express their gender. For example, a closeted trans woman might choose to present herself in more masculine clothing until she feels more comfortable presenting her gender identity to those around her. Alternatively, someone might choose to present themselves with a more intense expression of the gender they identify with (e.g., a woman might wear makeup, high heels, and pencil skirts) due to social pressures to perform one's gender within a certain environment (e.g., a business office).

\section{Cisgender}

When someone's gender identity and expression align with the social expectations of the sex they were assigned at birth, that individual is considered cisgender. The term cis is a Latin prefix meaning "on or from the same side." Most cisgender people wouldn't consider identifying with a gender other than the one they were assigned with their sex at birth. This sense of belonging is not a bad thing, but it is important to recognize it as 
an unearned and unrecognized privilege. For example, cisgender people are often catered to when it comes to the presentation of "gendered" body wash, deodorant, and shampoo options at the convenience store. While these soaps and detergents are all gender neutral in function, their packaging and presentation give them a gendered presence that could make someone who is not cisgender feel uncomfortable or uncertain about which product to purchase. Cisgender privilege becomes particularly clear when one considers the stigmatization of people who are not cisgender, known as cisgenderism or simply genderism.

\section{Transgender and Gender Nonconforming}

Transgender is an umbrella term for someone whose gender identity or gender expression does not align with social expectations based on the sex they were assigned at birth. Sometimes, transgender individuals will call themselves trans, a shorthand version of the term. A related term is transexual, which more specifically identifies those individuals who often, but not always, undergo transition processes.

Required Reading

National Center for Transgender Equality. (2018, October 5). Understanding Non-Binary People: How to Be Respectful and Supportive. Retrieved from https://transequality.org/issues/resources/understanding-non-binarypeople-how-to-be-respectful-and-supportive

National Center for Transgender Equality. (2016, July 9). Understanding Transgender People: The Basics. Retrieved from https://transequality.org/issues/resources/understanding-transgender-people-the-basics

\section{Transitioning}

Transitioning is the process of changing one's gender expression to match one's gender identity. MTF: A person transitioning from male to female, using she/her pronouns (sometimes called a transwoman or, simply, a woman). FTM: A person transitioning from female to male, using he/him pronouns (sometimes called a transman or, simply, a man). Nonbinary, genderqueer, or gender-nonconforming describes a gender identity that is neither female/woman nor male/man, often comfortable blurring gender lines.

For members of the trans and nonbinary communities, process of transition includes many elements:

- awareness

- psychological evaluations

- legal identification

- coming out or sharing 
- hormone therapy

- surgeries,

One or more interactive elements has been excluded from this version of the text. You can view them online here:

To view a transcript for the video above, download this file: Coming Out as Nonbinary, Genderqueer, or Gender Non-Conforming Video Transcript [DOC]

\section{Nonbinary genders}

In cultures outside of the United States, there are numerous examples of gender identities outside of the man/ woman binary:

- Five genders of Sulawesi, Indonesia

- Kocek of the Ottoman Empire

- Muxes of Mexico

- Kathoeys of Thailand

- Warias of Indonesia

- Hijra of India

\section{Two-Spirit of North America}

One or more interactive elements has been excluded from this version of the text. You can view them online here:
https://iastate.pressbooks.pub/dressappearancediversity/?p=87\#0embed-2

To view a transcript for the video above, download this file: Two Spirit Video Transcript [DOC]

\section{Mānūs of Hawaii}


An interactive H5P element has been excluded from this version of the text. You can view it online here:

https://iastate.pressbooks.pub/dressappearancediversity/?p=87\#h5p-12

\section{Trans, Genderqueer, and Nonbinary Identities and Dress}

Trans and nonbinary (TNB) individuals can conform to cisgender dress stereotypes in an effort to pass and/ or challenge notions of femininity and masculinity to appear visibly TNB. Appearances that challenge binary gender constructions by combining or negating feminine and masculine aesthetics are often interchangeably referred to as genderqueer, genderfuck, genderless, nonbinary, or unisex (Beemyn, 2015). Some people may want to appear more cisgender (or "passing"), and some may want to appear more TNB (Allen, 2010); however, TNB expression is less binary. Furthermore, TNB individuals continually negotiate their gender performance (Butler, 1990) and may engage in "shape shifting," or altering their appearance depending on the situation (McGuire et al., 2016). Numerous factors influence gender presentation. For example, some individuals may wish to appear cisgender because it can lead to correct gender identification by others or help them avoid dangerous situations (Garfinkel, 1967; Schrock et al., 2009; Snorton, 2009). Being visibly TNB can also allow individuals to promote visibility and challenge cultural assumptions about gender. Additionally, individuals use dress to camouflage body parts they may believe do not align with their gender identity or to highlight and reveal body parts that align with their gender identity (Corwin 2009; McGuire et al., 2016; Reilly et al., 2019).

McGuire and Reilly (2020) have developed an aesthetic identity framework using a combination of aesthetic, gender, and human development theories to study TNB clothing choices. Their model incorporates performativity and safety aspects of presentation; sensory, cognitive, and emotional aspects of clothing; exploration and commitment; scaffolding and feedback; and role-making and role-taking. They argue:

As individuals mature in their sense of transforming gender identity, they will consolidate their aesthetic identity and begin to take on gendered social roles (role taking) that they will adapt (role making). The gendered aesthetic identity will be a way of claiming and shaping an individual's placement within a gender role, as well as making meaning of that gender role for themselves and others. (n.p.)

Rahilly (2015) suggested that TNB people are often forced to wear clothing that is physically or psychologically uncomfortable. However, the majority of participants in Rahilly's study were White, so these feelings may not apply to all racial and cultural backgrounds. Still, regardless of one's background, apparel designed for cisgender bodies may not fit TNB bodies appropriately. Mass-produced (ready-to-wear) clothing often does not meet TNB individuals' functional and aesthetic needs. Reilly et al. (2019) identified three themes some TNB people associate with searching for clothing: fit, cut, and sizing issues with mainstream ready-to-wear clothing; desire to use clothing to hide body parts that reveal a TNB identity; and desire to reveal body parts "to celebrate or show pride in one's body and a design to highlight bodily changes post gender confirmation treatment" (p. 12). 
The study's participants were diverse in racial and ethnic identities, suggesting these themes reflect experiences of TNB people regardless of race. Some TNB individuals may employ tailoring services to make mass-produced apparel fit their bodies. Additionally, with the growing visibility of TNB individuals, some clothing brands are responding to consumers' needs by offering apparel designed specifically for the TNB market (e.g., FtM Detroit, Official Rebrand, Saint Harridan, and Transguy Supply).

Catalpa and McGuire (2020) found dress contributes to Serano's (2007) "mirror epiphany," or the first encounter with one's authentic self: "Dress helps transpersons make a conscious connection between how they imagined themselves and the material reality of their physical presence" (Catalpa \& McGuire, 2020, p. 57). Moreover, TNB individuals may employ tattoos as a sign of self-acceptance, to connect with their body, to mark their identity, or to celebrate physical changes to the body (McGuire et al., 2016; McGuire \& Chrisler, 2016).

\section{Trans Gear}

Trans gear, or objects worn by trans people to affirm their gender identity, is a major part trans dress.

\section{Chest Binding}

One common piece of gear among transgender men is a chest binder. Chest binding involves the compression of chest tissue for masculine gender expression among people assigned a female sex at birth.

\section{Required Reading}

Sarah Peitzmeier, Ivy Gardner, Jamie Weinand, Alexandra Corbet \& Kimberlynn Acevedo (2017) Health impact of chest binding among transgender adults: A community-engaged, cross-sectional study, Culture, Health \& Sexuality, 19:1, 64-75. Retrieved from https://queerdoc.com/wp-content/uploads/2018/05/Binding-Health-ProjectResults.pdf

The first study to review chest binding in depth, conducted in 2016, included a sample of 1,800 adults. $97.2 \%$ of the participants in the study reported at least one negative outcome they attributed to chest binding, including

- back pain (53.8\%)

- overheating (53.5\%)

- chest pain (48.8\%)

- shortness of breath (46.6\%)

- itching $(44.9 \%) \cdot$ bad posture $(40.3 \%)$ 


\section{3 | SEX AND GENDER}

- shoulder pain (38.9\%).

Despite discomfort, though, the participants also stated that binding made them feel less anxious, reduced dysphoria-related depression and suicidality, improved overall emotional well-being, and enabled them to safely go out in public with confidence. One participant said, "Binding allowed me to present my gender as I felt it to be by flattening my chest and causing it to look more male. It helped to affirm my gender by appearance."

Watch this video to learn more about how to safely use a chest binder:

To view a transcript for the video above, download this file: How to use a binder safely Video Transcript [DOC]

\section{Packing}

Another type of trans gear is a packer, padding or a phallic object placed in the pants to give the appearance of a bulge. Like chest binding, this implement of dress is used by those who prefer to present as masculine. Packing can be done in many ways: for example, people create DIY packers by bundling socks or purchase packers and packing accessories, such as packing shorts and straps made for safely securing packers.

\section{Example Video}

Watch this short video on packers and STP devices to learn more: "Show and Tell of Packers and STP Devices for Transmen."

\section{Tucking}

Finally, a trans person might choose to use tucking to feel more comfortable about their gender expression. Tucking is the practice of arranging the external genitals between the legs with clothing. Since only about $12 \%$ of transgender women might obtain a vaginoplasty (a surgical procedure that results in the construction of reconstruction of a vagina), tucking, like chest binding, can help prevent dysphoria-related depression. Trans individuals might tuck with tape or with of a gaff, a garment used to tuck the genitals inward.

You can watch the video below to learn more about DIY gaffs: 
SEX AND GENDER | 74

One or more interactive elements has been excluded from this version of the text. You can view them online here:

믓 https://iastate.pressbooks.pub/dressappearancediversity/?p=87\#oembed-5

To view a transcript for the video above, download this file: How to make a Gaff for Tucking Video Transcript [DOC] 


\section{References}

Allen, M. P. (2010). Connecting body and mind: How transgender people changed their self-image. Women \& Performance, 20(3), 267-283. https://doi.org/10.1080/0740770X.2010.529248

Butler, J. (1990). Gender trouble: Feminism and the subversion of identity. New York: Routledge.

Catalpa, J. M., \& McGuire, J. K. (2020). Mirror epiphany: Transpersons' use of dress to create and sustain their affirmed gender identities. In A. Reilly \& B. Barry (Eds.), Crossing boundaries: Fashion to deconstruct and reimagine gender (pp. 47-59). Bristol, UK: Intellect Books.

Garfinkel, H. (1967). Studies in ethnomethodology. Prentice-Hall, Inc. Geczy, A. \& Karaminas, V. (2013). Queer style. London: Bloomsbury.

McGuire, J. K., \& Chrisler, A. (2016). Body art among transgender youth: Marking social support, reclaiming the body, an creating a narrative identity. In Y. Kiuchi \& F. A. Villarruel (Eds.), The young are making their world: Essays on the power of youth culture (pp. 97-118). Jefferson, NC: McFarland.

McGuire, J. K., Doty, J. L., Catalpla, J. M., \& Ola, C. (2016). Body image in transgender young people: Findings from a qualitative, community based study. Body Image, 18, 96-107. http://dx.doi.org/10.1016/j.bodyim.2016.06.004

McGuire, J., \& Reilly, A. (online first in 2020). Aesthetic identity development among trans adolescents and young adults. Clothing and Textiles Research Journal. https://doi.org/10.1177/0887302X20975382

Rahilly, E. P. (2015). The gender binary meets the gender-variant child: Parents' negotiations with childhood gender variance. Gender \& Society, 29(3), 338-361. https://doi.org/10.1177/0891243214563069h

Reilly, A., Catalpa, J., \& McGuire, J. (2019). Clothing fit issues of trans people. Fashion Studies, 2(1), https://doi.org/ 10.38055/FS010201.

Schrock, D. P., Boyd, E. M., \& Leaf, M. (2009). Emotion work in the public performances of male-to-female transsexuals. Archives of Sexual Behavior, 38(5), 702-712. https://doi.org/10.1007/s10508-007-9280-2

Serano, J. (2007). Whipping girl: A transsexual woman on sexism and the scapegoating of femininity. Berkeley, CA: Seal Press.

Snorton, C. R. (2009). “A new hope”: The psychic life of passing. Hypatia, 24(3), 77-92. https://www.jstor.org/ stable/20618165

Worsley, H. (2011). 100 ideas that changed fashion. London: Laurence King. 


\section{Sex and Gender Case Study}

Step One: Become familiar with the case study.

1. The case study attached below is a Word document and can be downloaded. It includes the task, evaluation, and template for the case study:

Sex and Gender Case Study [DOC]

Step Two: Submit your complete assignment on Canvas.

1. Format your document.

2. Remember to check the submission against the rubric. 


\section{9. \\ SEXUALITY}

\section{Module Learning Objectives (MLO)}

In this chapter, you will

- MLO 9.1 Identify foundational concepts related to sexuality, fashion, identity, appearance, and dress. [CLO 1]

- MLO 9.2 Identify different types of dress worn by queer communities in the United States to express their sexual identities. [CLO 1]

- MLO 9.3 Identify queer people's experiences in the United States wearing different dress object reflecting their queer identities. [CLO 2]

- MLO 9.4 Identify different fashion brands that produce and sell dress objects for the queer community in the United States to affirm their sexual identities. [CLO 1]

- MLO 9.5 Explain the role of dress and appearance in the development of one's queer identity in the United States. [CLO 1]

- MLO 9.6 Examine how dress and appearance of queer communities in the United States are represented in the fashion system (e.g., by advertisements or retailers). [CLO 3]

- MLO 9.7 Examine social justice issues related to dress and appearance of the queer community in the United States. [CLO 3]

- MLO 9.8 Deconstruct your own perspectives and approach to understanding the dress and appearance of the queer community in the United States. [CLO 4]

- MLO 9.9 Identify the driving forces of transformative social justice change in the fashion system related to queer identities in the United States. [CLO 5]

In this chapter, we explore the scholarship examining the intersections of the queer community, identity negotiations, and dress. However, doing so is tricky because significant nuance lies in identity, and the scholarship is not necessarily provided in clear categories, given identity's fluidity and complexity. Therefore, while the work is presented under the stable headings outlined below, when tensions arise in the literature, they are noted. The plethora of work on these topics dissolves the idea that there is one monolithic aesthetic or style for different queer identities. 
The Center for Educational Justice \& Community Engagement's Definition of Terms is a great resource to help you understand some of the concepts that intersect with lesbian, gay, bisexual, queer, and other sexual minorities.

\section{Gender Identity}

Although the two concepts interact in many ways, gender identity is distinct from sexual orientation. Just like not all cisgender people are straight, not all transgender people are gay or lesbian.

Heterosexuality is the romantic attraction, sexual attraction, or sexual behavior between persons of the opposite sex or gender. Even though transgender people identify with the queer community, they can still be heterosexual. For example, a transgender woman and a cisgender male in a relationship are a heterosexual

I either, I would say queer or bisexual depending on who asks. I like queer better, I like the vagueness and implications but bisexual is a word people know. I'm attracted to people of all genders. couple.

There are many ways to identify in the queer community, and individuals often use various terms or switch among them.

\section{Queer sexual spectrum}

On the queer spectrum, these questions may not align with a singular sexual identity:

- Sexual identity: "Who am I?"

- Sexual orientation: "How am I attracted?"

- Sexual behavior: "How do I engage sexually?"

An interactive H5P element has been excluded from this version of the text. You can view it online here:

https://iastate.pressbooks.pub/dressappearancediversity/?p=89\#h5p-9 


\section{Sexuality and Signifiers}

Many overt symbols of sexuality are used in the LGBTQIA+ community. Often, sexuality can overtly influence appearance or dress, though this is not always the case. For all individuals in the queer community, a common theme throughout history has been the "pushing of gender boundaries." The signs and symbols of sexuality for queer individuals change and shift over time.

\section{Gaining Momentum: Stonewall}

The Stonewall Riots, in 1969, marked a period of great movement toward equality for the LGBTQIA+ community. Read what the Stonewall Riots were here: "History of the Stonewall Riots" (History.com editors, 2021).

Following these riots and the formation of numerous groups such as the Gay Liberation Front, slogan badges and T-shirts became an important signifier of support or pride. Today, these items continue to act as signifiers of belonging in the queer community.

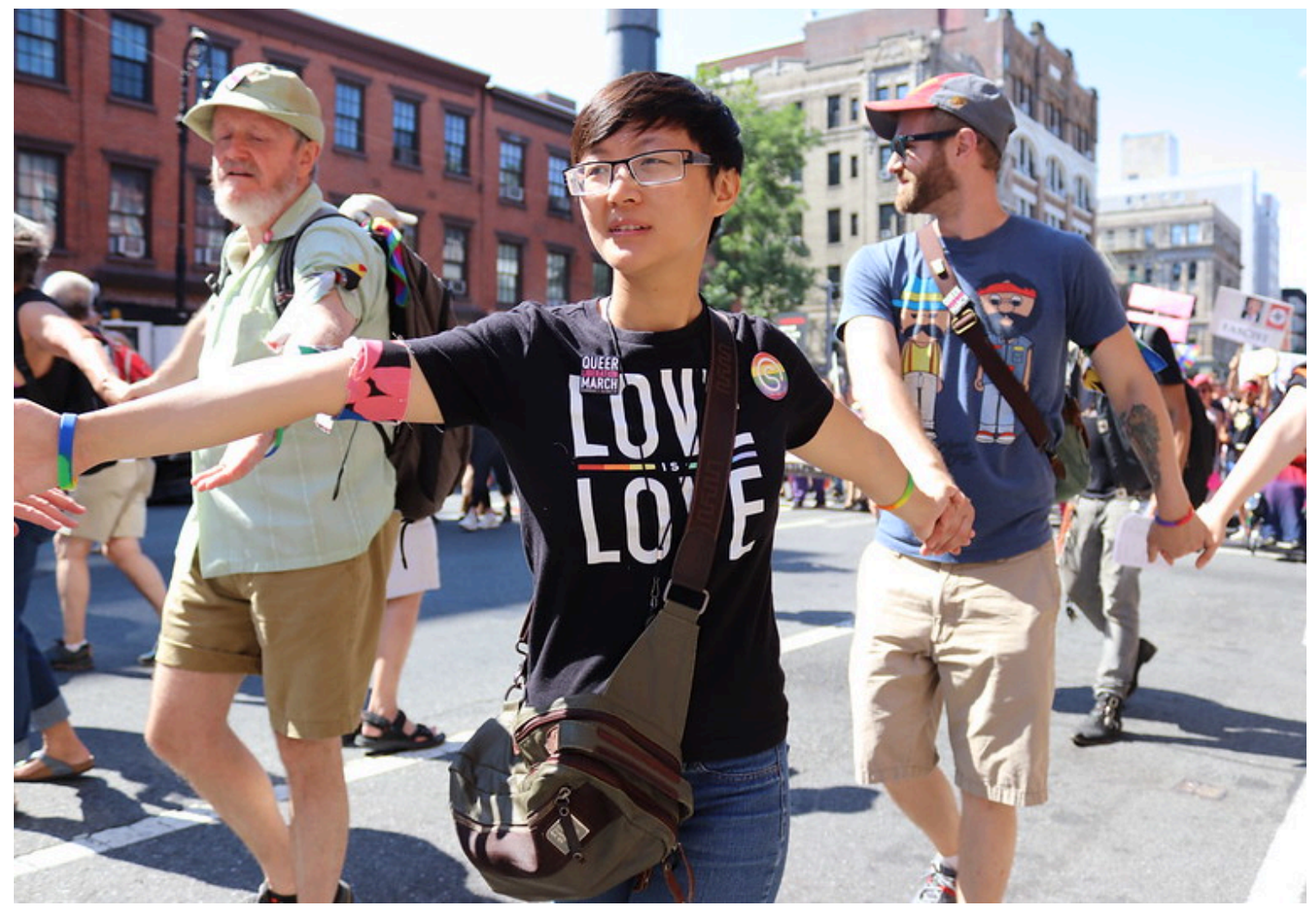

Image Source: Elvert Barnes, $\underline{\text { CC BY SA }}$ 


\section{Nazi-Occupied Germany}

Overt signifiers of LGBTQIA+ identities have sometimes been forced on members of the community. Gay men in Nazi concentration camps were forced to wear uniforms bearing pink triangles as designations of homosexuality. Similarly, women who did not conform to social roles, often believed to be lesbians, had to wear black triangles.

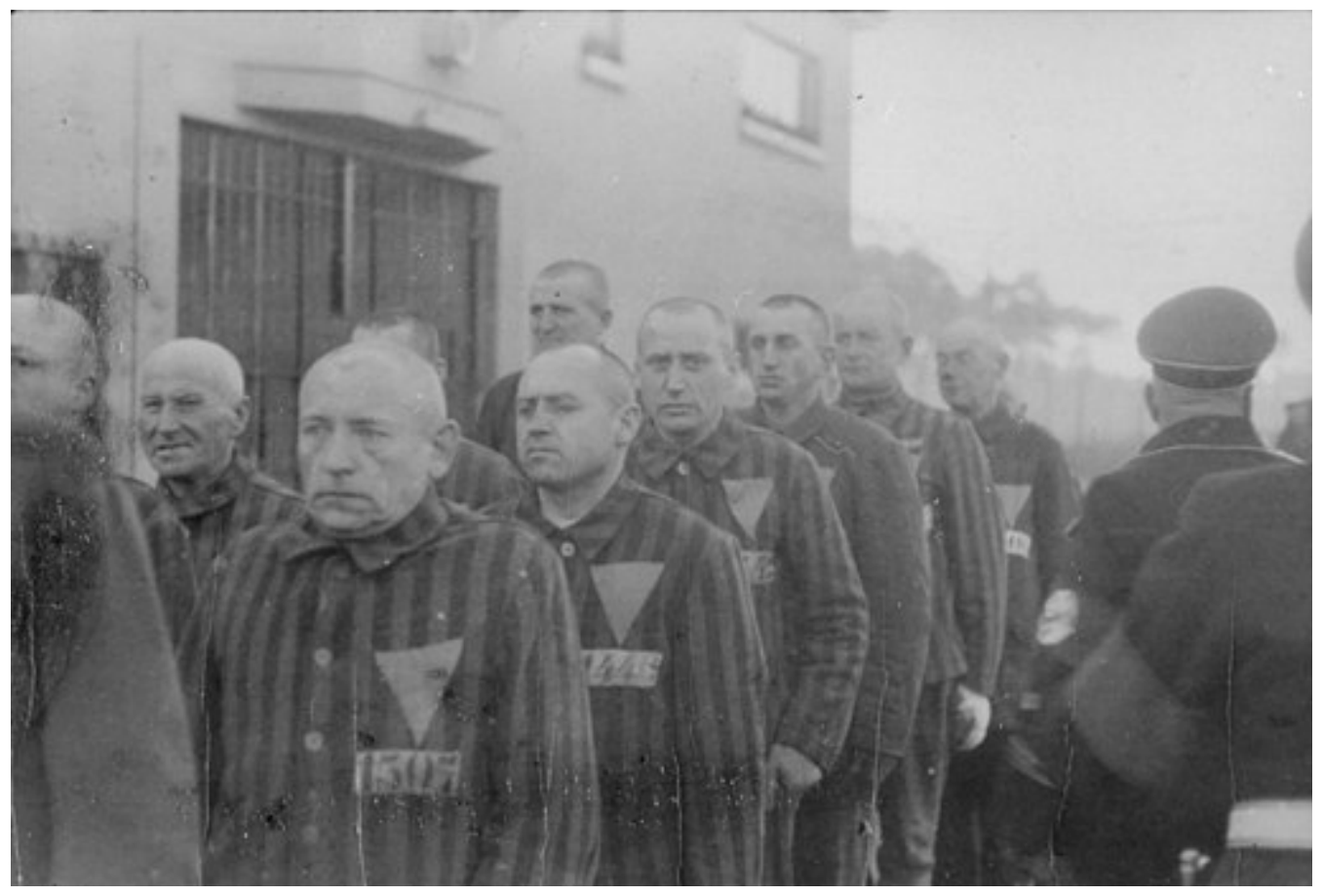

Prisoners in the concentration camp at Sachsenhausen, Germany, 1938.

Today, triangles are sometimes incorporated into clothing and accessories as symbols of freedom rather than symbols of oppression. This is an example of reclamation, wherein a member of a community who is harmed by a term, phrase, or symbol might choose to use that signifier in a positive way to challenge the stereotypes surrounding it. 


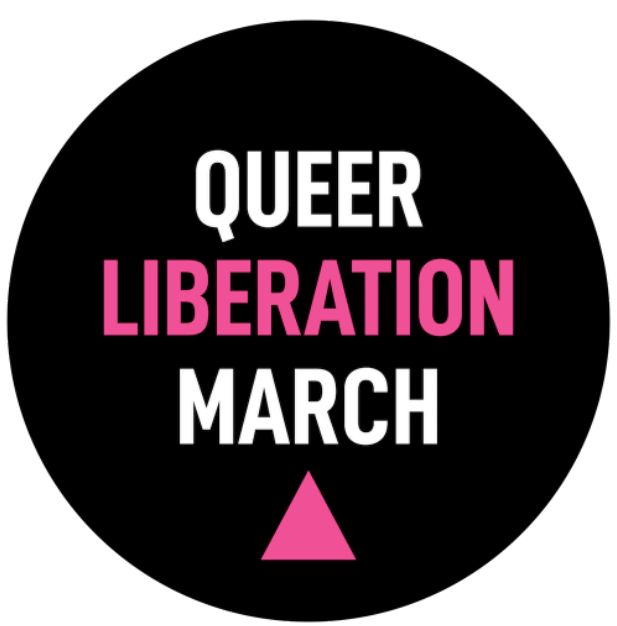

This logo was used to promote the 2019 Queer Liberation March in New York City. Image Source: Reclaim Pride Coalition

Review the Stigma and Identity section in chapter 2 for more information about how members of a stigmatized community can reclaim or refute negative stereotypes.

\section{Distinctions between Drag and Cross-Dressing}

Within discussions about the LGBTQIA+ community, newcomers often conflate the terms drag and crossdressing. However, there are some important differences between the two terms.

Drag

Drag refers to the conscious performance of femininity or masculinity, sometimes in an exaggerated manner, usually in a show or theater setting. When individuals perform femininity, they are referred to as queens, and when they perform masculinity in the same way, they are referred to as kings.

Watch this short film to learn about drag and terms related to it:

\section{Cross-Dressing}

In contrast to drag queens and kings, cross-dressers wear clothes, makeup, and other forms of dress that are 
considered by their culture to be appropriate for a gender not their own. While people generally wear drag for entertainment purposes, they cross-dress for personal reasons. The term cross-dresser falls under the umbrella term transgender, though not all cross-dressers consider themselves trans.

Not everyone who might engage in drag or cross-dressing considers themselves part of the LGBTQIA+ community.

\section{Lesbian Identities and Dress}

In a survey of mainstream popular press articles in the United States from 1960s to the 2010s, publications featured mostly White, thin, feminine lesbian aesthetics and styles (Reddy-Best \& Jones, 2020). These mainstream representations lacked the nuance, tension (Kaiser, 2012), and variety of styles that lesbianidentifying women have embraced over time. Many of these styles are intricately related to gender negotiations; however, lesbian styles expand beyond the stereotypical notions of butch and femme often perpetuated in media.

Early documented evidence of women's styles in same-gender relationships dates to the eighteenth century. Elanor Butler and Sarah Ponsonby, two Anglo-Irish aristocrats who were thought to have been in a love relationship, often adopted masculine styles of clothing; more specifically, they routinely wore riding habits, considered a subversive act because women did not customarily don the outfits they wore for riding at that time (Wilson, 2013). Anne Lister, a wealthy White woman from Yorkshire who died in the late nineteenth century, wrote in her diaries of her desires and relationships with other "mannish women," and she also embraced an eccentric, masculine style (Wilson, 2013, p. 171).

In the 1928 novel The Well of Loneliness, author Radclyffe Hall crafted a lesbian identity in a masculine aesthetic (Geczy \& Karaminas, 2013). In the same decade, photographs Albert Harlingue took of women at Le Monocle, a lesbian club in Paris, depicted White-appearing women in the popular garçonne look, a fashionable women's style in larger society (Farrell-Beck \& Parsons, 2007), "characterized by an absence of feminine curves and very short hairstyles" (Steele, 2013, pp. 26-27). Harlingue's images also featured women in highly feminine styles and wearing bias-cut dresses with form-fitting silhouettes, longer hair,

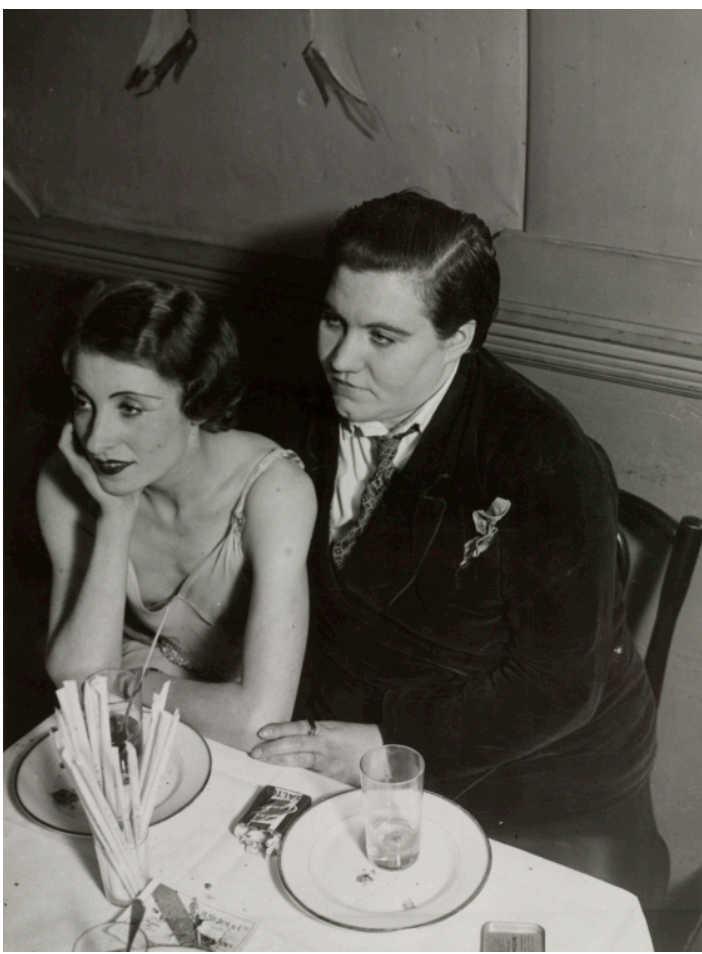

Photo from the Cleveland Museum of Art, taken by Georges Brassai at Le Monocle in 1932. Currently under copyright and used here for educational purposes only. and makeup. Georges Brassai also took similar photographs. 
Faderman (1991) discussed lesbian dress aesthetics in the early part of the 20th century and explored these recognizable masculine and feminine norms, frequently referred to as butch and femme, which she argued emerged in 1940s bar culture, where butch and femme lesbians congregated. Leslie Feinberg's popular 1993 novel Stone Butch Blues gave vivid descriptors of the mid-20th-century butches and femmes. For example, Jess, the main character, related their experience when first entering a bar in Niagara Falls: "What I saw there released tears l'd held back for years: strong, burly women wearing ties and suit coats. Their hair was slicked back. They were the handsomest women l'd ever seen. Some of them were wrapped in slow motion dances with women in tight dresses and high heels who touched them tenderly. Just watching made me ache with need" ( $p$. 28).

Rothblum (1994) argued that lesbian communities have adopted styles and aesthetics that differ from those of mainstream society. One of the ways this has manifested is through embracing and negotiating a masculine aesthetic, sometimes referred to as butch. The butch, masculine-lesbian style is often recognizable within as well as outside of the lesbian community (Maltry \& Tucker, 2002; Taylor, 2007). A butch aesthetic may include comfortable shoes, little or no makeup, tattoos and piercings, alternative-style haircuts or hair colors, and masculine-leaning garments or accessories (Clarke \& Spence, 2013; Clarke \& Turner, 2007; Esterberg, 1996; Reddy-Best \& Pedersen, 2014, 2015; Rothblum, 1994, 2010). While different lesbian styles, including those that are part of the butch aesthetic, are often considered uniform, women adopt masculine styles in complex and varied ways (Levitt \& Hiestand, 2004; McLean, 2008). For example, in Reddy-Best and Goodin's (2020) research, participant Cyndi-a White, lesbian-identifying woman-claimed her overall style was masculine-leaning but said she felt like a "delicate flower on the inside" and preferred the phrase "soft butch" (125).

In her 2019 work, Blake analyzed Black androgynous lesbians from North Carolina. Blake explained, "[l am] hesitant to essentialize Black lesbian styles of dress . . . instead of naming these gender presentations Black lesbian style, I call these articulations of Black lesbian androgyny BlaQueer Style because they represent-rather than essentialize-the racial and class politics illuminated by their dress" (p. 11). 


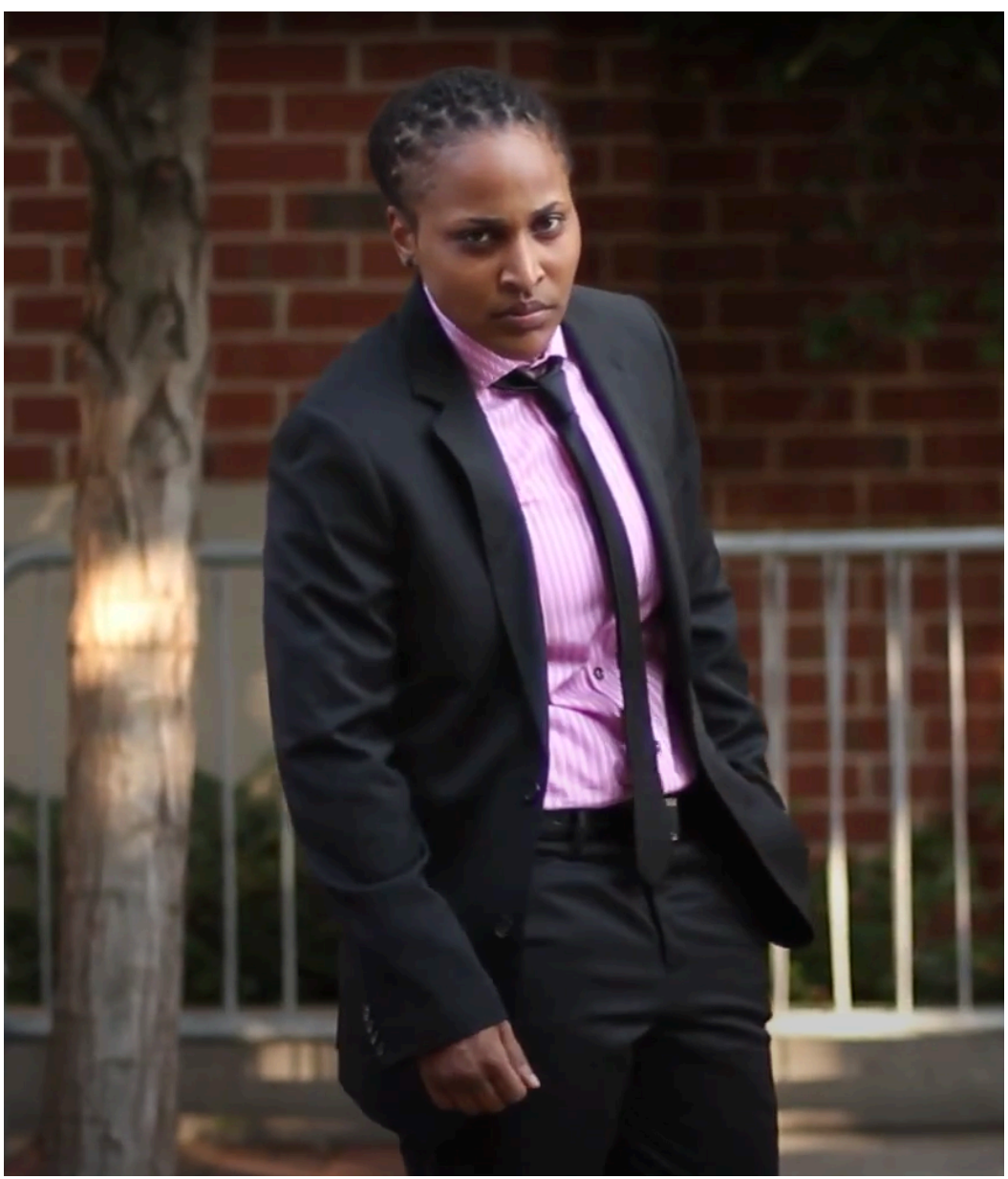

Screenshot from The Androgynous Model web series promo

Blake (2019) outlined the ways these women embraced masculinity and the tensions surrounding their multiple subjectivities, with emphasis on their Black identity. Lane-Steele's (2011) work examined studs, or Black lesbians who embrace masculinity; the studs she interviewed said they dressed similarly to their Black male peers, with "baggy pants and shirts, hats, high top shoes, Timberland boots, and fairly flashy jewelry" (p. 484). LaneSteele drew connections between these women's styles and "protest masculinity" (p. 483), which Connell and Messerschmidt (2009) defined as"[the] pattern of masculinity constructed in local working-class settings, sometimes among ethnically marginalized men, which embodies the claim to power typical of regional hegemonic masculinities in Western countries, but which lacks the economic resources and institutional authority that underpins the regional and global patterns" (p. 848). One way protest masculinity surfaces is through a hyper-masculine aesthetic-such as the one these Black lesbian women embraced.

In addition, much research has analyzed feminine-leaning aesthetics, sometimes referred to as femme, highfemme, or lipstick lesbian styles or identities. Feminine-leaning lesbians may wear long hair, makeup, and feminine-coded clothing, such as dresses or high heels (Hemmings, 1999; Levitt et al., 2003; Levitt \& Hiestand, 2004; Levitt \& Horne, 2002; Maltry \& Tucker, 2002). Because of the long-standing association between femininity 
and heterosexuality, feminine-leaning lesbians are often misread as straight (Huxley et al., 2014; Levitt et al., 2003) and can experience accusations of not being "queer enough" within the LGBTQIA+ community (ReddyBest \& Goodin, 2020). They may hide their lesbian identities until they are physically with their masculineleaning partners (Rossiter, 2016).

Watch this short film on femme identity and dress.

To view a transcript for the video above, download this file: The Femme Struggle Transcript [DOC]

While many folks adopt and embrace these stereotypical aesthetics that are thought to have developed out of the mid-20th century, there have been significant critiques and rejections of these styles altogether. As social movements gained traction in the latter part of the 20th century, some criticized these feminine- and masculineleaning aesthetics for producing a heteronormative performance (Walker, 1993). In Freitas et al.'s 1996 study, participants related that they did not want to limit themselves to one particular type of style. Additionally, Hammidi and Kaiser (1999) theorized there was no single way to imagine beauty for lesbian women, and these negotiations are intertwined with ambivalence and tensions in everyday life. This notion is evident in a recent New York Times article titled "Lesbians Invented Hipsters," in which Burton (2016) asserted, "You're all lesbians now, America. ... I'm sorry. But mostly for myself. Because it's hard to tell who's queer now."

Watch this short film on the experiences with clothing and dress of queer women who live in the Midwest.

One or more interactive elements has been excluded from this version of the text. You can view them online here:

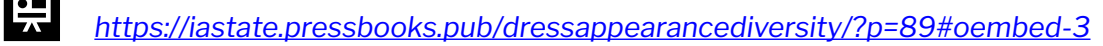

Watch this short research presentation about queer women's identity and dress.

One or more interactive elements has been excluded from this version of the text. You can view them online here: https://iastate.pressbooks.pub/dressappearancediversity/?p=89\#oembed-4 


\section{Gay Identities and Dress}

Because of the stigmatization and criminalization of homosexual behavior in much of European-American modern history, gay men have frequently adopted coded styles to display their gay identity. These symbols have included adorning one's lapel with green carnations and wearing red neckties or suede shoes.

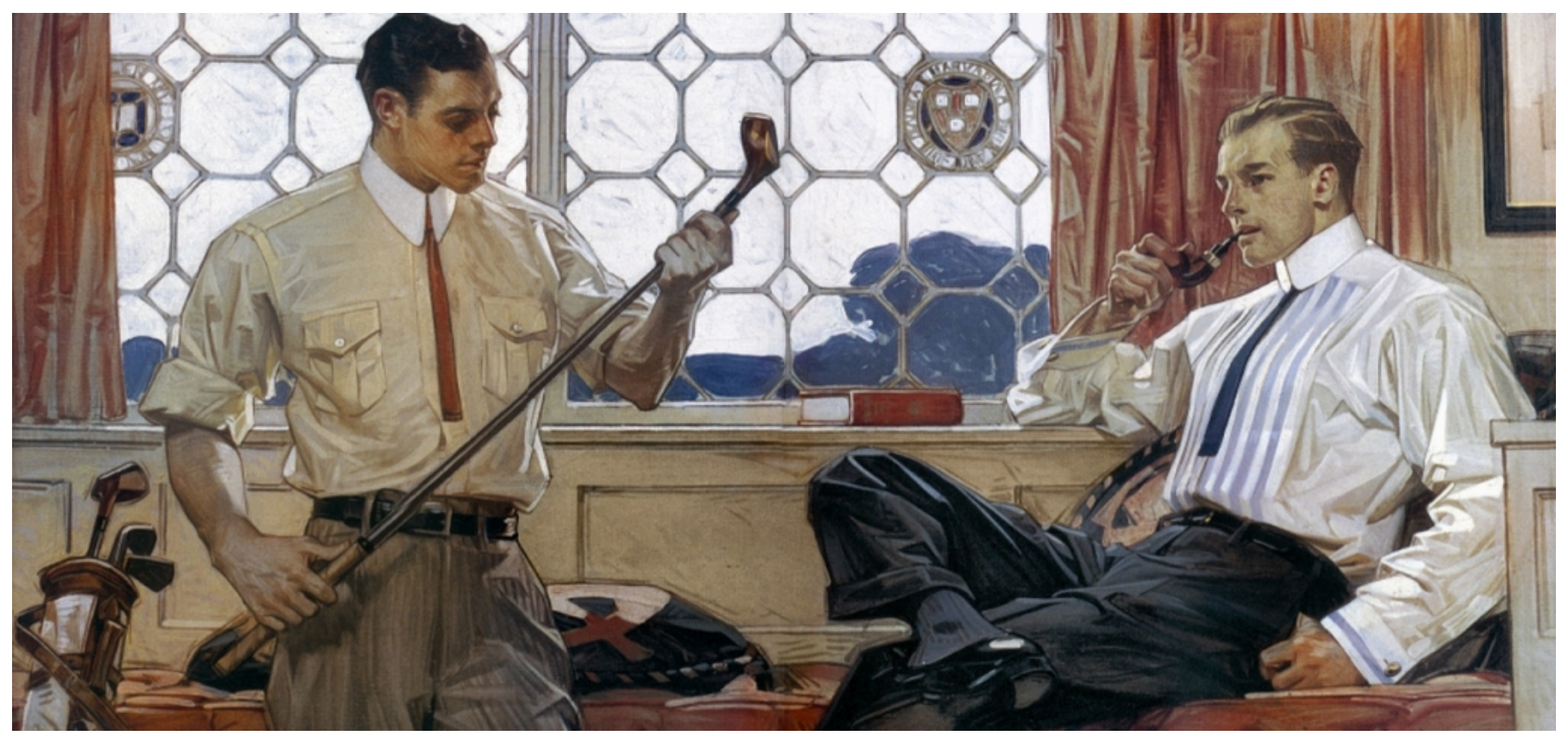

This advertisement for the Arrow shirt collar by J. C. Leyendecker features a narrow red silk necktie, a signifier that likely went unnoticed by those who weren't looking out for it. From Derek Guy's article "Straight copying: How gay fashion goes mainstream."

As legal progress has been made and the social climate for the LGBTQIA+ community has improved, the symbols shifted from knowledge among the few to commonplace, as in dress that now includes rainbow flags, the inverted pink triangle, or an earring worn in the right ear (Cole, 2000; Reilly, 2010).

During the early modern gay liberation movement, gay men were mostly divided into two ideologies regarding how to present themselves through dress: embrace traditional masculine gender presentation or subvert it (Edwards, 1994). Cole (2013) noted that the Gay Liberation Front of the 1970 s employed "genderfuck" aesthetics, combining stereotypical masculine and feminine clothes, makeup, and styling into one form to subvert Western binary gender expectations in Great Britain and the United States to combat, question, and highlight gender's artificial nature. These two philosophies and tensions-to embrace traditional Western gender presentation or to disrupt it—continue in contemporary post-postmodern forms of androgyny (Barry \& Reilly, 2020).

The conflict over how to present one's self resulted in the "butch shift," in which gay men developed dress styles based on masculine archetypes (Humphries, 1985), such as leather men, bears, and Castro clones. Bears, noted for their hirsute, either muscular or husky/large/fat and blue-collar representations of masculinity, became visible in the 1980s during the early AIDS crisis and were eroticized for their perceived health as compared to the 
emaciated appearances of those suffering in the latter stages of AIDS. Mosher et al. (2006) argued that leather identity is socially constructed and performative and both "bear and leather aesthetics can be understood as expressions of culturally valued traits and as a reconciliation of masculine and gay identities" (pp. 119-120).

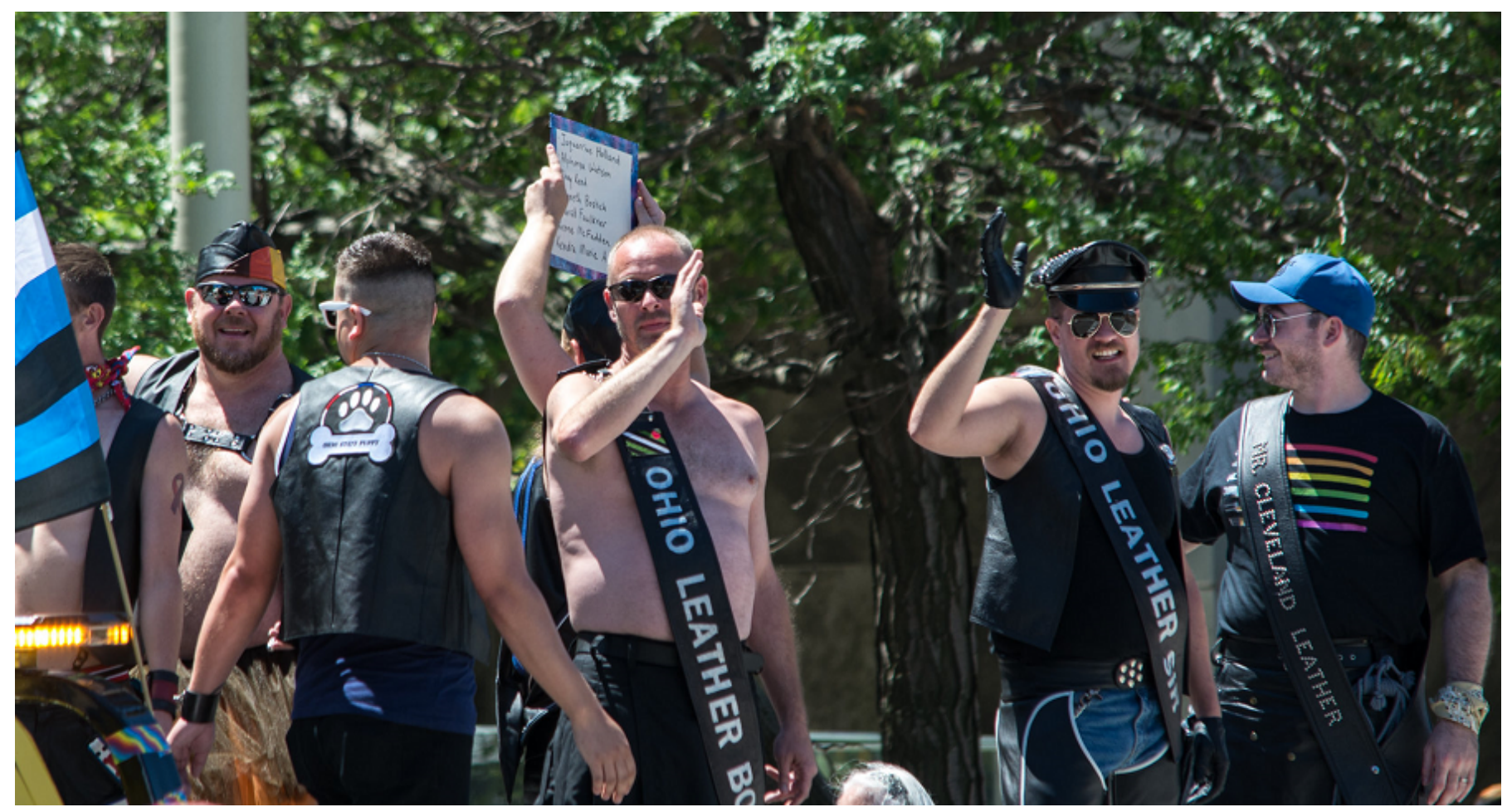

Leather Boys at Cleveland Pride 2017. Image Source: Tim Evanson, CC BY SA

Cole (2000) noted the Castro clones style emerged from American cowboy and blue-collar dress (e.g., jeans, plaid shirts, cowboy boots, construction boots, Levi's 501 button-fly jeans, T-shirts, short hair, and mustaches) and was symbolic of "toughness, virility, aggression, strength, [and] potency" (p. 128), although Levine (1998) argued the look was parody. Although clone aesthetics were patterned after heterosexual masculine styles, a knowing gay consciousness acknowledged the outfits were coordinated, perfected, and worn to show off the male physique. Cole (2000) further argued the clone image of masculinity influenced other gay men's styles, including "queer nation" and "act-up" looks (e.g., T-shirts and jeans), gay skinhead, and gay rockabilly. The clone style assisted in redefining gay men as masculine. Other gay subcultures that embrace masculine aesthetics include muscle boys, scallies, and homothugs (Cole, 2008). 
In contrast to masculine archetypes, other gay men, such as drag queens and punks, embraced camp, feminine, or androgynous aesthetics, including makeup and jewelry. Contemporarily, a result of the butch shift has been the tendency among some gay men to embrace femininity (Reilly, in press) and to incorporate apparel items marketed to both men and women into their wardrobes (Barry \& Reilly, 2020; moore, 2020). Per Barry and Martin (2015), gay men view contemporary aesthetics as more varied than previous generations, and gender identity, sexual orientation, and race intersect not only to express individuality but also to challenge binary gender norms by mixing traditionally feminine and masculine fabrics, textures, products, and other signifiers (Barry \& Martin, 2016). Clarke and Turner (2007) similarly argued that clothing is used to negotiate gay identity, but it is also used to express individuality; thus when an individual "comes out," they may feel expectations to dress a certain way, but enough room exists in the unwritten rules of gay aesthetics to show one's persona in a multitude of ways.

Gay men adopted other items, among them sailor uniforms and sneakers. In England and France between

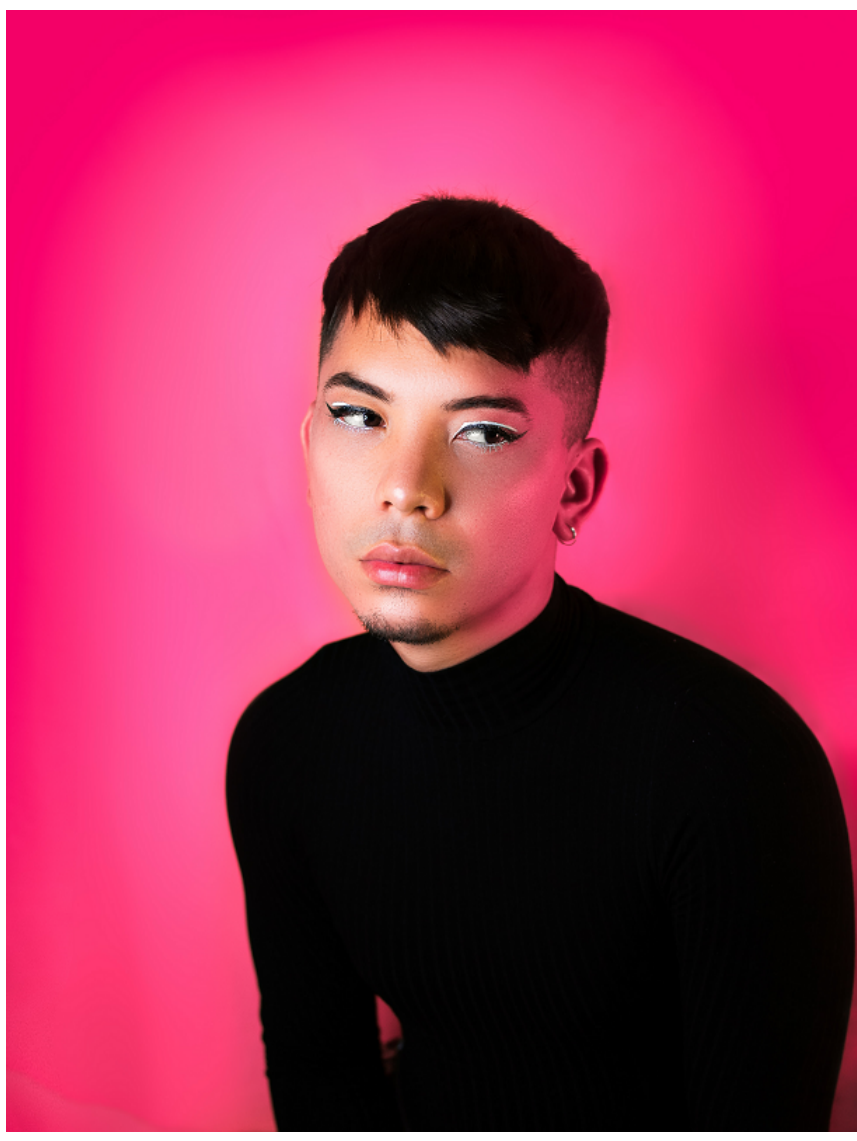

Image Source: Dhemer Gonçalves the world wars, gay and bisexual men wore the sailor uniform because it was associated with masculinity and voracious sexuality and it had a figure-revealing fit and silhouette. Use of the sailor uniform diminished when it was adapted into mainstream fashion (Stephenson, 2016). Scott (2011) proposed that sneakers were important to gay men in three ways. First, they can be viewed as feminine and are thus discouraged if one wants to appear masculine (e.g., biker and leather subcultures eschew sneakers and favor boots). Second, they can be viewed as masculine among middle-class gay men and as part of the butch shift or as gay men assimilated (e.g., jocks and straight-acting mainstream masculinity). Third, sneakers are considered masculine but fetishized, as in, for example working-class subcultures or gay skinheads.

Much of the research on gay men's dress has been conducted on White men, leaving significant opportunities for future research on other races and ethnicities. However, the research that has been conducted has yielded important findings. Cole's (2019) work on gay Black men in Britain and the United States reported that gay Black men find attention to detail important, considering age, race, class, and how one wanted to present oneself with consideration of time and place: “What constitutes gay men's style and what constitutes Black gay men's style raises questions about whether it is possible to identify gay styles broadly and Black gay styles specifically at this time" (p. 54). Drummond (2005) argued gay Asian men have different clothing styles for home, straight or mainstream, and gay spheres. 
Tan (2019) documented the dissemination of the bear style from the United States to Japan, through Northeast Asia, and into Taiwan and found bears in Taiwan cultivate their look to achieve sexual capital by using clothes-such as tank tops or bright colors on sleeves and torsos of shirts-to draw attention to their thick or beefy bodies. Last, Horton's (2020) research on the regulation of flamboyant dress, or fabulousness, in India, from within its own gay communities, argued dress has become politicized-a matter of respectability politics rather than one of enjoyment of pushing boundaries.

\section{Bisexual Identities and Dress}

Some scholars have focused specifically on the ways bisexual-identifying individuals negotiate their identities through dress. Taub (2003) surveyed mostly White, bisexual-identifying women and reported that these women fashioned their bodies in a variety of ways; in their responses, there was significant discussion of negotiating societal gender norms and stereotypical lesbian appearance norms. Some of these women rejected dominant culture's norms and created "personalized and affirming beauty ideas and practices," whereas others felt pressure to conform to lesbian norms, such as the "soft butch" aesthetic (p. 21).

Hartman (2013) conducted interviews with mostly White, bisexual-identifying women. Participants frequently relayed a desire to make themselves visible as bisexual in public settings because of their belief that society often deems them invisible, which is sometimes referred to as bi-erasure (for discussions of bisexual invisibility, see Bradford, 2004; Firestein, 1996; Fox, 1995; Tabatabai \& Linders, 2011). Participants used the terms attitude and androgyny and a hybrid of heterosexual and homosexual aesthetics to describe a bisexual display, and they placed significant emphasis on gender negotiations through style. The participants described their uses of overt pride aesthetics, such as pins or slogan T-shirts-particularly those with the bi-pride colors (pink, blue, and purple). Although Hartman's (2013) participants articulated specific aesthetics to highlight their bisexual identity, they also expressed that it was "difficult to pin down such a description" (p. 49). Similarly, other researchers found a lack of distinct dress aesthetics for bisexual individuals (Clarke \& Spence, 2013; Clarke \& Turner, 2007; Hayfield, 2011; Hayfield et al., 2013; Holliday, 1999; Huxley et al., 2014). 


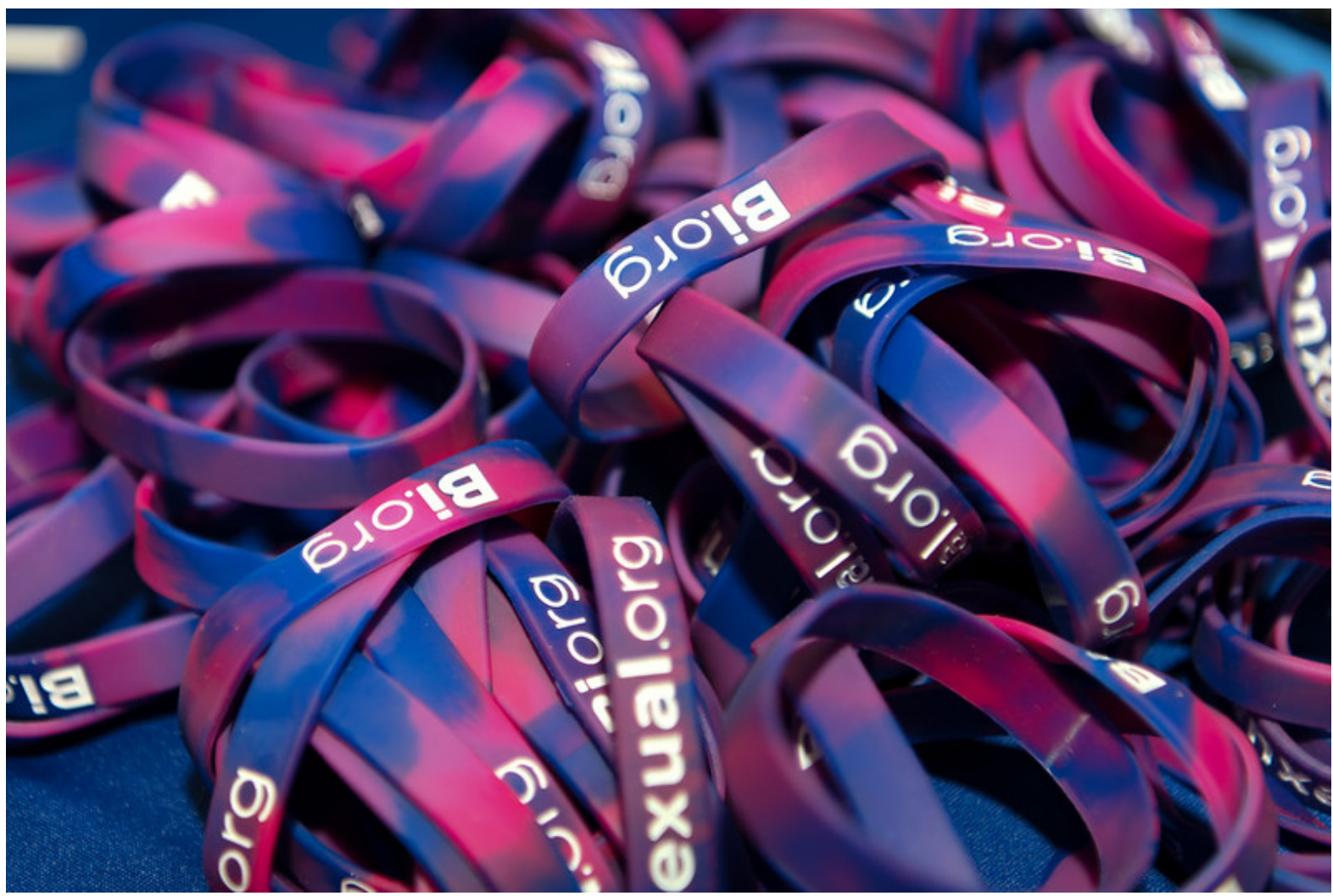

Image Source: WeHoCity, CC BY NC ND

Hartman-Linck (2014) discussed the importance of bisexual signifiers in private or intimate spaces, such as around close friends or family. Her participants also related using aesthetics of the home, such as magnets or artwork with lesbian symbols, to signify their identities. Artwork or magnets are arguably not "hand-held objects" (Roach-Higgins \& Eicher, 1992, p. 1), yet they are debatably an extension of the body in the context of these private spheres.

In a recent study, Daly et al. (2018) again examined bisexual women's appearance and dress. Similar to the aforementioned studies, the bisexual participants' appearance markers conformed to stereotypical lesbian aesthetics (or masculine-leaning styles), or they adopted mainstream gender norms by using feminine signifiers. The participants' partners' genders often motivated adoption of various styles. For example, some women in same-gender relationships adopted feminine aesthetics to avoid having others assume they identified as lesbian.

Duffin (2016) interviewed African American men who were behaviorally bisexual but identified as straight and described themselves as "on the down low" or "DL" (p. 484). The down-low phenomenon is significant in the Black community because of the stigmatization of homosexuality; the phrase, which emerged in rap music lyrics in the 1990s (Cohen, 1999), has been discussed in popular press articles (Denizet-Lewis, 2014). Dress was not the primary focus in Duffin's (2016) work, but in one part of his results, he reported that men often associated femininity with being gay. That is, these bisexually behaving men asserted their masculinity by wearing baggy or 
other stereotypically masculine styles. By contrast, one participant defined being gay as wearing "tight clothes, swish[ing] up and down the street, [and] act[ing] like a girl" (p. 499).

\section{Required reading}

Huxley, C., Clarke, V. and Halliwell, E. (2014). Resisting and Conforming to the "Lesbian Look": The Importance of Appearance Norms for Lesbian and Bisexual Women. J. Community Appl. Soc. Psychol., 24: 205-219. https://doi.org/ $10.1002 /$ casp. 2161

Kelly L. Reddy-Best \& Elaine L. Pedersen (2015). The relationship of gender expression, sexual identity, distress, appearance, and clothing choices for queer women. International Journal of Fashion Design, Technology and Education, 8:1, 54-65, DOI: $10.1080 / 17543266.2014 .958576$

To access these articles, read them on campus or look them up on the University Library website and log in with your NetID and password.

\section{The Fashion Industry and LGBTQIA+ Identities}

In the 2010s, there was a significant emergence of queer-focused brands in the fashion industry selling a variety of different products, such as suits and suit coordinates, sportswear, accessories, swimwear, shoes, and undergarments or other objects worn near or against the skin (Reddy-Best et al., 2020; Reddy-Best, 2017, 2020; Reddy-Best \& Goodin, 2018). Many of these brands garnered widespread attention in 2016 when HBO released Suited, a documentary about Bindle \& Keep-a Brooklyn, New York-based company that produces suits and suit coordinates for gender-nonconforming people. Many of Bindle \& Keep's clients described feeling-for the first time in their lives_comfortable in their suits and liking the way they looked in the mirror (Benjamin, 2016). Because many LGBTQIA+ individuals push gender boundaries in their dress, they often have difficulty shopping for clothes that fit their bodies and desired gender and/or sexual presentations (Pierre, 2020; Reddy-Best \& Pedersen, 2015); many of these queer-focused fashion brands emerged to address these issues.

Many of the entrepreneurs who started these businesses cited entering the industry because they were unable to find clothing that fit them or their partners (Benjamin, 2016; Reddy-Best, 2020; Reddy-Best et al., 2020). For example, Thúy of Thúy Custom Clothier asserted they could empathize with their clients and the inability to find masculine-leaning clothes, and this ability to empathize has created a trusting shopping environment (ReddyBest et al., 2020). Bindle \& Keep designer Rae Tutera recalled their first suit: "I just never felt so good about myself before. It was just such a powerful experience for me. I couldn't help but want to take it and adapt it to a landscape that welcomed people like me" (Benjamin, 2016, 5:14). Some brand owners may not personally 
have difficulty finding clothing, but a loved one might. For example, Abby Sugar was inspired to start Play Out because her ex-wife was unable to find masculine-style underwear (Reddy-Best et al., 2020).

The development of the Internet and the increase in LGBTQIA+ rights in the United States were catalysts for the creation of some brands. For example, Saint Harridan, now closed, developed alongside the legalization of same-sex marriage and the need for masculine-leaning wedding attire for gender-nonconforming individuals (Reddy-Best, 2020). Additionally, with the changing retail landscape and the increase in e-commerce, designers are no longer required to pitch to wholesale buyers or generate the overhead to build and sustain storefronts (Worsley, 2011). Therefore, these brands can enter the market with little to no capital investment. Social media has also allowed brands to target and attract customers (Reddy-Best et al., 2020). For example, Rebirth Garments-a company that designs garments and accessories that promote queerness, disability, and fat identities-sells products from its Etsy store and accepts orders via direct messages on social media (ReddyBest \& Goodin, 2018). These virtual spaces have also allowed brands to politicize fashion by circulating imagery that challenges larger hegemonic gender norms. For example, Saint Harridan worked with Miki Vargas, a queer-fashion photographer, to capture gender-boundary-pushing aesthetics. As these images circulated on Saint Harridan's social media, discussions often focused on "gender and identity politics," "shifting ideologies surrounding gender," and "signs of solidarity with other groups experiencing oppression," such as people of color (Reddy-Best, 2020, p. 99).

Unfortunately, several brands have since closed (e.g., Saint Harridan stopped operations only four years after its founding in 2012 because of a lack of capital investment (Reddy-Best, 2020). Overall, these brands reflect the numerous ways individuals in the LGBTQIA+ community fashion their bodies and will largely have a lasting impact as trailblazers of the queer-fashion brands movement in the early part of the 21 st century.

Watch this research presentation on the development of queer and trans fashion brands in the 21st century. 


\section{References}

Barry, B., \& Martin, D. (2015). Dapper dudes: Young men's fashion consumption and expressions of masculinity. Critical Studies in Men's Fashion, 2(1), 5-21. https://doi.org/10.1386/csmf.2.1.5 1.

Barry, B., \& Martin, D. (2016). Gender revels: Inside the wardrobes of young gay men with subversive style. Fashion, Style \& Popular Culture, 3(2), 225-250. https://doi.org/10.1386/fspc.3.2.225_1.

Barry, B., \& Reilly, A. (2020). Gender more: An intersectional perspective on men's transgression of the gender dress binary. In A. Reilly \& B. Barry (Eds.), Crossing boundaries: Fashion to deconstruct and reimagine gender (pp. 122-136). London: Intellect Books.

Benjamin, J. (Director). (2016). Suited [Film]. A Casual Romance Productions.

Blake, D. A. (2019). “It ain't he, it ain't she, it's we." Dress: The Journal of the Costume Society of America, 45(1), 1-21, https://doi.org/10.1080/03612112.2019.1559529.

Bradford, M. (2004). The bisexual experience: Living in a dichotomous culture. Journal of Bisexuality, 4(1/2), 7-23. https://doi.org/10.1300/J159v04n01_02.

Burton, K. (2016, December 31). Lesbians invented hipsters. New York Times. https://www.nytimes.com/ 2016/12/ 31/opinion/sunday/hipsters-broke-my-gaydar.html.

Clarke, V., \& Spence, K. (2013). Will the real lesbian please stand up? Constructing and resisting visible nonheterosexual identities through dress and appearance. Psychology of Sexuality, 4(1), 25-33. https://doi.org/ 10.1080/19419899.2013.748240.

Clarke, V., \& Turner, K. (2007). Clothes maketh the queer? Dress, appearance and the construction of lesbian, gay and bisexual identities. Feminism \& Psychology, 17(2), 267-276. https://doi.org/10.1177/0959353507076561.

Cohen, C. J. (1999). Boundaries of blackness: AIDS and the breakdown of Black politics. Chicago: University of Chicago Press.

Cole, S. (2000). Don we now our gay apparel: Gay men's dress in the twentieth century. Oxford: Berg.

Cole, S. (2008). Butch queens in macho drag: Gay men, dress, and subcultural identity. In A. Reilly \& S. Cosbey (Eds.), Men's fashion reader (pp. 279-294). New York: Fairchild.

Cole, S. (2013). Queerly visible: Gay men's dress and style 1960-2012. In V. Steele (Ed.), A queer history of fashion: From the closet to the catwalk (pp. 135-166). New Haven: Yale University Press.

Cole, S. (2019). The difference is in the detail: Negotiation black gay male style in the twenty-first century. Dress: The Journal of the Costume Society of America, 45(1), 39-54. https://doi.org/10.1080/03612112.2019.1557833.

Connell, R. W., \& Messerschmidt, J. (2009). Hegemonic masculinity: Rethinking the concept. Gender \& Society, 19(6), 829-859. https://doi.org/10.1177/0891243205278639.

Daly, S. J., King, N., \& Yeadon-Lee, T. (2018). ‘Femme it up or dress it down’: Appearance and bisexual women 
in monogamous relationships. Journal of Bisexuality, 18(3), 257-277, https://doi.org/10.1080/ 15299716.2018.1485071.

Denizet-Lewis, B. (2014, March 20). The scientific quest to prove bisexuality exists. New York Times. http://www.nytimes.com/2014/03/23/magazine/the-scientific-questto-prove-bisexuality-exists.html? $r=0$.

Drummond, M. fJ. N. (2005). Asian gay men's bodies. Journal of Men's Studies, 13(3), 291-300. https://doi.org/ 10.3149/jms.1303.291.

Duffin, T. P. (2016). The lowdown on the down low: Why some bisexually active men choose to self-identify as straight. Journal of Bisexuality, 16(4), 484-506. https://doi.org/10.1080/15299716.2016.1252301.

Edwards, T. (1994). Erotics and politics: Gay male sexuality, masculinity, and feminism. New York: Routledge.

Esterberg, K. G. (1996). “A certain swagger when I walk”: Performing lesbian identity. In S. Seidman (Ed.), Queer theory/sociology (pp. 259-279). London: Blackwell.

Faderman, L. (1991). Odd girls and twilight lovers: A history of lesbian life in the twentieth century. New York Penguin Books.

Farrell-Beck, J., \& Parsons, J. (2007). Twentieth century dress in the United States. New York: Fairchild.

Feinberg, L. (1993). Stone butch blues. Ithaca: Firebrand.

Firestein, B. A. (1996). Bisexuality as a paradigm shift: Transforming our disciplines. In B. A. Firestein (Ed.), Bisexuality: The psychology and politics of an invisible minority (pp. 263-291). London: Sage.

Fox, R. C. (1995). Bisexual identities. In A. R. D’Augelli \& C. J. Patterson (Eds.), Lesbian, gay, and bisexual identities over the lifespan (pp. 48-86). New York: Oxford University Press.

Freitas, A., Kaiser, S. B., \& Hammidi, T. (1996). Communities, commodities, cultural space, and style. In D. L. Wardlow (Ed.), Gays, lesbian, and consumer behavior: Theory, practice, and research issues in marketing (pp. 83-107). New York: Haworth Press.

Geczy, A., \& Karaminas, V. (2013). Queer style. New York: Bloomsbury.

Hammidi, T. N., \& Kaiser, S. B. (1999). Doing beauty: Negotiating lesbian looks in everyday life. Journal of Lesbian Studies, 3(4), 55-63. https://doi.org/10.1300/J155v03n04_07.

Hartman, J. E. (2013). Creating a bisexual display: Making bisexuality visible. Journal of Bisexuality, 13(1), 39-62. https://doi.org/10.1080/15299716.2013.755727.

Hartman-Linck, J. E. (2014). Keeping bisexuality alive: Maintaining bisexual visibility in monogamous relationships. Journal of Bisexuality, 14(2), 177-193. https://doi.org/10.1080/15299716.2014.903220.

Hayfield, N. J. (2011). Bisexual women's visual identities: A feminist mixed-methods exploration. [Unpublished doctoral dissertation]. Bristol: University of the West of England.

Hayfield, N., Clarke, V., Halliwell, E., \& Malson, H. (2013). Visible lesbians and invisible bisexuals: Appearance and visual identities among bisexual women. Women's Studies International Forum, 40(8), 172-182. https://doi.org/ 10.1016/i.wsif.2013.07.015. 
Hemmings, C. (1999). Out of sight, out of mind? Theorizing femme narrative. Sexualities, 2(4), 451-464. https://doi.org/10.1177/136346099002004005.

Hillman, B. (2015). Dressing for the culture wars: Style and the politics of self-presentation in the 1960s and 1970s. Lincoln: University of Nebraska Press.

Holliday, R. (1999). The comfort of identity. Sexualities, 2(4), 475-491. https://doi.org/10.1177/ 136346099002004007.

Horton, B. A. (2020). Fashioning fabulation: Dress, gesture and the queer aesthetics of Mumbai Pride. South Asia: Journal of South Asian Studies, 43(2), 294-307. https://doi.org/10.1080/00856401.2020.1716288.

Humphries, M. (1985). Gay machismo. In A. Metcalf \& M. Humphries (Eds.), The sexuality of men (pp. 70-85). London: Pluto.

Huxley, C., Clarke, V., \& Halliwell, E. (2014). Resisting and conforming to the "lesbian look": The importance of appearance norms for lesbian and bisexual women. Journal of Community \& Applied Social Psychology, 24(3), 205-219. https://doi.org/10.1002/casp.2161.

Kaiser, S. B. (2012). Fashion and cultural studies. London: Bloomsbury.

Lane-Steele, L. (2011). Studs and protest-hypermasculinity: The tomboyism within Black lesbian female masculinity. Journal of Lesbian Studies, 15(4), 480-492. https://doi.org/10.1080/10894160.2011.532033.

Levitt, H. M., Gerrish, E. A., \& Hiestand, K. R. (2003). The misunderstood gender: A model of modern femme identity. Sex Roles, 48(3/4), 99-113. https://doi.org/10.1023/A:1022453304384.

Levitt, H. M., \& Hiestand, K. R. (2004). A quest for authenticity: Contemporary butch gender. Sex Roles, 50(9/10), 605-621. https://doi.org/10.1023/b:sers.0000027565.59109.80.

Levitt, H. M., \& Horne, S. G. (2002). Explorations of lesbian-queer genders. Journal of Lesbian Studies, 6(2), 25-39. https://doi.org/10.1300/J155v06n02 05.

Maltry, M., \& Tucker, K. (2002). Female fem(me)ininities. Journal of Lesbian Studies, 6(2), 89-102. https://doi.org/ $10.1300 / J 155 v 06 n 0212$.

McLean, K. (2008). Silences and stereotypes: The impact of (mis)constructions of bisexuality on Australian bisexual men and women. Gay and Lesbian Issues and Psychology Review, 4(3), 158-165.

Mead, G. H. (1934). Mind, self, and society. Chicago: University of Chicago Press.

moore, m. (2020). Critical mascara: On fabulousness, creativity and the end of gender. In A. Reilly \& B. Barry (Eds.), Crossing boundaries: Fashion to deconstruct and reimagine gender (pp. 192-200). Bristol, UK: Intellect Books.

Mosher, C. M., Levitt, H. M., \& Manley, E. (2006). Layers of leather: The identity formation of leather men as a process of transforming meanings of masculinity. Journal of Homosexuality, 51(3), 93-123. https://doi.org/ 10.1300/J082v51n03_06.

Reddy-Best, K. L. (2017). Miki Vargas: Queer fashion photographer and The Handsome Revolution. Clothing Cultures, 4(2), 153-170. https://doi.org/10.1386/cc.4.2.153_1. 
Reddy-Best, K. L. (2020). The politicization of fashion in virtual queer spaces: A case study of Saint Harridan, one of the pioneering queer fashion brands in the twenty-first century. In A. Reilly \& B. Barry (Eds.), Crossing boundaries: Fashion to deconstruct and reimagine gender (pp. 91-108). London: Bloomsbury.

Reddy-Best, K. L., \& Jones, K. B. (2020). Is this what a lesbian looks like? Lesbian fashion and the fashionable lesbian in the United States press, 1960s to 2010s. Journal of Lesbian Studies, 24(2), 159-171. https://doi.org/ $\underline{10.1080 / 10894160.2019 .1685816 .}$.

Reddy-Best, K. L., \& Goodin, D. (2018). Queercrip fashion in the 21st century: Sky Cubacub and the queercrip dress reform. Clothing Cultures, 5(3), 333-357. https://doi.org/10.1386/cc.5.3.333 1.

Reddy-Best, K. L., \& Goodin, D. (2020). Queer fashion and style: Stories from the Heartland-Authentic Midwestern queer voices through a museum exhibition. Dress: The Journal of the Costume Society of America, 46(2), 115-140. https://doi.org/10.1080/03612112.2019.1686875.

Reddy-Best, K. L., Goodin, D., \& Streck, K. (2020). 21st century queer fashion brands: Oral history project. Ames: lowa State University Digital Press. https://iastate.pressbooks.pub/queerfashionbrands/.

Reddy-Best, K. L., \& Pedersen, E. L. (2014). The relationship of gender expression, sexual identity, distress, appearance, and clothing choices for queer women. International Journal of Fashion Design, Technology, and Education, 8(1), 54-65. https://doi.org/10.1080/17543266.2014.958576.

Reddy-Best, K. L., \& Pedersen, E. L. (2015). Queer women's experiences purchasing clothing and looking for clothing styles. Clothing \& Textile Research Journal, 33(4), 265-279. https://doi.org/10.1177/ $0887302 \times 15585165$.

Reilly, A. (2010). Gay, lesbian, bisexual, and transgendered persons. In J. B. Eicher \& P. G. Tortora (Eds.), Berg encyclopedia of world dress and fashion: The United States and Canada (pp. 508-513). Oxford: Berg.

Reilly, A. (in press). The rise of the bottom: Counterdiscourse to challenge heteronormativity within the gay community. In V. Karaminas \& A. Geczy (Eds.), Millennial masculinities: Queers, pimp daddies, and lumbersexuals. New Brunswick, NJ: Rutgers University Press.

Roach-Higgins, M. E., \& Eicher, J. B. (1992). Dress and identity. Clothing and Textiles Research Journal, 10(4), 1-8. https://doi.org/10.1177/0887302X9201000401.

Rossiter, H. (2016). She's always a woman: Butch lesbian trans women in the lesbian community. Journal of Lesbian Studies, 20(1), 87-96. https://doi.org/10.1080/10894160.2015.1076236.

Rothblum, E. (1994). Lesbians and physical appearance: Which model applies? In B. Greene \& G. M. Herek (Eds.), Lesbian and gay psychology: Theory, research, and clinical applications (pp. 84-97). London: Sage.

Rothblum, E. (2010). The complexity of butch and femme among sexual minority women in the 21st century. Psychology of Sexualities Review, 1(1), 29-42.

Scott, D. T. (2011). Contested kicks: Sneakers and gay masculinity, 1964-2008. Communication and Critical/ Cultural Studies, 8(2), 146-164. https://doi.org/10.1080/14791420.2011.566275. 
Steele, V. (2013). A queer history of fashion: From the closet to the catwalk. In V. Steele (Ed.), A queer history of fashion: From the closet to the catwalk (pp. 7-75). New Haven: Yale University Press.

Stephenson, A. (2016). "Our jolly marin wear": The queer fashionability of the sailor uniform in interwar France and Britain. Fashion, Style \& Popular Culture, 3(2), 157-172. https://doi.org/10.1386/fspc.3.2.157_1.

Tabatabai, A., \& Linders, A. (2011). Vanishing act: Non-straight identity narratives of women in relationships with women and men. Qualitative Sociology, 34(4), 583-599. https://doi.org/10.1007/s11133-011-9202-4.

Tan, C. K. K. (2019). Taipei gay "bear" culture as sexual field; Or, why did Nanbu bear fail? Journal of Contemporary Ethnography, 48(4), 563-585. https://doi.org/10.1177/0891241617742191.

Taub, J. (2003). What should I wear? A qualitative look at the impact of feminism and women's communities on bisexual women's appearance. Journal of Bisexuality, 3(1), 9-22. https://doi.org/10.1300/J159v03n01 02.

Taylor, Y. (2007). "If your face doesn't fit ..." The misrecognition of working-class lesbians in scene space. Leisure Studies, 26(2), 161-178. https://doi.org/10.1080/02614360600661211.

Walker, L. M. (1993). How to recognize a lesbian: The cultural politics of looking like what you are. Signs, 18(4), 866-890. https://www.jstor.org/stable/3174910.

Wilson, E. (2013). What does a lesbian look like? In V. Steele (Ed.), A queer history of fashion: From the closet to the catwalk (pp.167-192). New Haven: Yale University Press.

Worsley, H. (2011). 100 ideas that changed fashion. London: Laurence King. 


\section{Sexuality Case Study}

\section{Step One: Become familiar with the case study.}

1. The case study attached below is a Word document and can be downloaded. It includes the task, evaluation, and template for the case study:

Sexuality Case Study [DOC]

Step Two: Submit your complete assignment on Canvas.

1. Format your document.

2. Remember to check the submission against the rubric. 


\section{0. \\ BEAUTY AND ATTRACTIVENESS}

\section{Module Learning Objectives (MLO)}

In this chapter, you will

- MLO 10.1 Identify foundational concepts related to beauty, attractiveness, identity, appearance, and dress. [CLO 1]

- MLO 10.2 Identify the ways beauty and perceptions of attractiveness influence people's experiences. [CLO 1]

- MLO 10.3 Identify the aspects of facial appearance that contribute to perceptions of attractiveness. [CLO 1]

- MLO 10.4 Identify how people alter their bodies when they do not think they are attractive or meet cultural beauty ideals. [CLO 1]

- MLO 10.5 Identify factors that influence why people alter their bodies when they do not think they are attractive or meet a specific beauty ideal. [CLO 1]

- MLO 10.6 Identify people's experiences related to meeting the ideals of beauty or perceptions of attractiveness. [CLO 2]

- MLO 10.7 Examine social justice issues related to dress, appearance, and interpretations of beauty and attractiveness in the United States. [CLO 3]

- MLO 10.8 Analyze how dress, appearance, and concepts of beauty and attractiveness in the United States are represented in the fashion system (e.g., advertisements or retailers). [CLO 3]

- MLO 10.9 Deconstruct your own perspectives and approaches to understanding dress, appearance, beauty, and attractiveness in the United States. [CLO 4]

- MLO 10.10 Identify the driving forces of transformative social justice change in the fashion system related to beauty and attractiveness in the United States. [CLO 5]

\section{“Beauty Is Good” Stereotype}

In US society, as well as in many other cultures, attractive people are assumed to be

- sociable 
- likable

- intelligent

- likely to succeed in a job

- likely to succeed in relationships

(Dion, Berscheid, \& Walster, 1972).

Physical attractiveness seems to have a halo effect that influences perceivers to assume that an attractive person holds a network of positive qualities. In this case, a positive stereotype is applied. Research indicates that this positive halo for attractiveness is pervasive, or held throughout US society. Traits that are considered physically unattractive, such as obesity is currently defined, act as a stigma to elicit a stereotype of negative qualities. For example, research indicates that obese individuals are more likely to be perceived as

- lazy

- lacking in self-control

- not intelligent

and a host of other negative things (Jasper \& Klassen, 1990). However, these qualities are not actually found to a greater extent in obese individuals. 


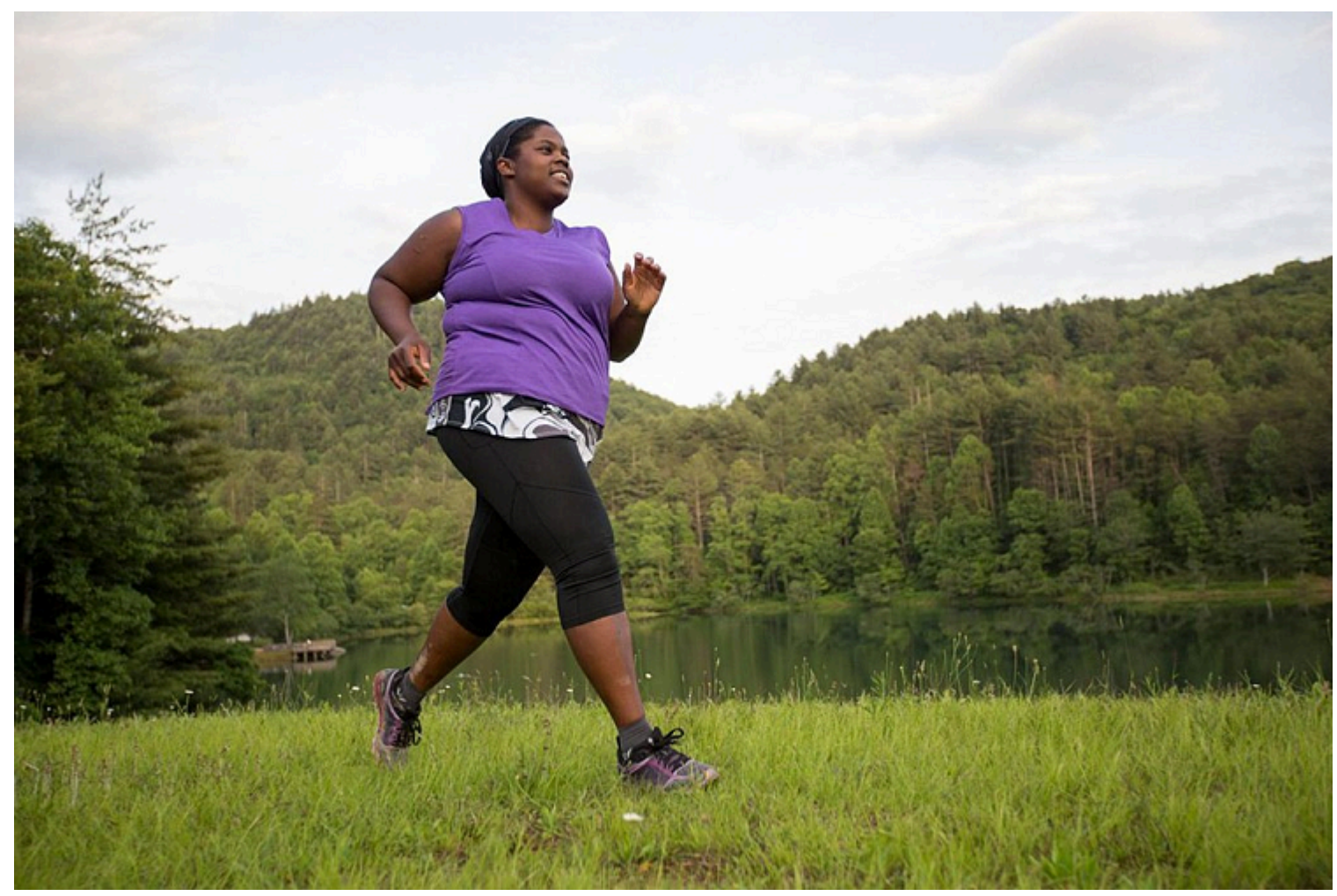

Mirna Valerio, National Geographic Adventurer of the Year for 2018, is an ultramarathon runner. Image Source: Jenny Nicholas \& Sarah Menzies, CC BY SA 4.0

According to Aronson (1965), the halo effect for attractiveness happens when

\section{Beauty is a reward because it}

- is aesthetically pleasing.

- is desirable to "possess." Attractive women, in particular, are seen as rewards or trophies for successful men.

- reflects positively on associates or friends of an attractive person. Research finds that if an attractive person is willing to hang out with someone, the halo effect rubs off a little on the partner or friend of the attractive person-especially in cases in which a man is romantically connected with a beautiful woman: he is seen as more powerful or effective if he can attract such a woman.

\section{Beauty lends power because it}

- attracts.

- holds attention, though not always to what someone is saying.

- opens doors of Attractive people get invited places so that others can have the rewarding or aesthetic experience of being around them. 


\section{Beauty is possibly a self-fulfilling prophecy}

- Positive reinforcement from others throughout society affects attractive people's self-concept and esteem positively over time. It is helpful to one's self-confidence to get so much positive feedback and validation of.

- There is some evidence that attractive people actually tend to be more sociable and outgoing and more self-confident than the average person.

- This does not mean that less attractive people cannot be self-confident and sociable. However, highly attractive people are given such positive responses by others that it may be easier for them to develop these traits.

\section{Symbolic Interaction Process and Body Satisfaction}

The people in our lives influence how we feel about our bodies. One study found that among older married couples, each spouses had a substantial impact on how the cother felt about their own attractiveness.

Oh and Damhorst (2009) studied 94 heterosexual married couples 60 years and older who lived in Florida. A good predictor of a man or woman's body satisfaction was what he or she believed his or her spouse thought about his or her attractiveness. But the best predictor of the older men's and women's body satisfaction was what the spouse actually thought about his or her attractiveness. 


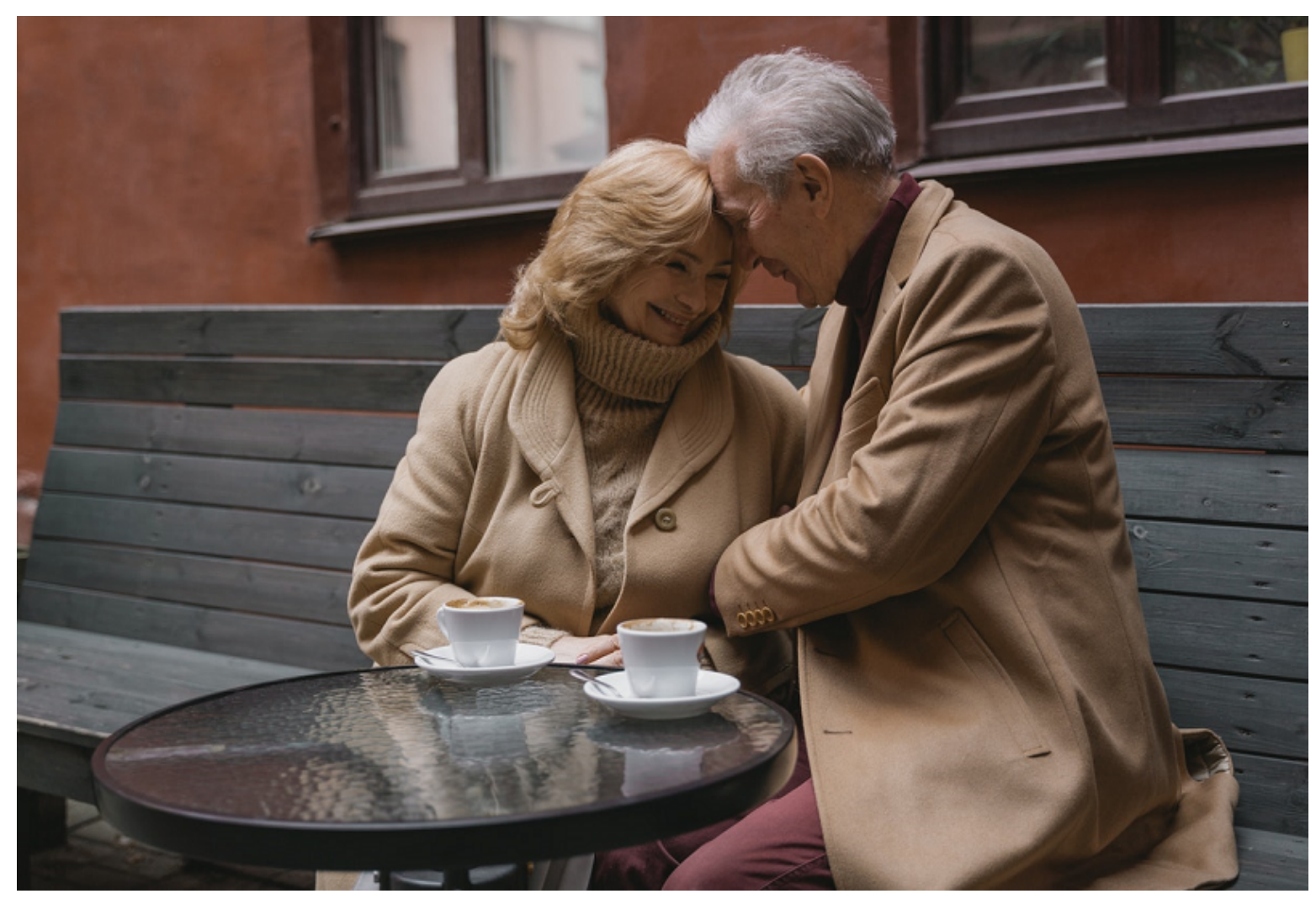

Image Source: Tima Miroshnichenko

Clearly, when someone takes on the role of the other to interpret how that other might think about the self, the interpretations can influence how one assesses or appraises the self. In a close relationship such as a long-term marriage, spouses serve as mirrors for each other to define, to some extent, the self. But even when a person is not totally aware of what the other thinks, the way a spouse acts nonverbally and verbally toward his or her mate over time has a profound influence on feelings of attractiveness and body satisfaction.

\section{Cultural Influences on How We Think About the Body}

Cheng (2000) studied 209 immigrant Chinese Americans living throughout the United States for body satisfaction and perceptions of attractiveness. In many Asian cultures, the spiritual and abstract qualities of personality and physical functioning are as important as or more important than appearance characteristics in assessing attractiveness. In the United States, emphasis on thinness for women and muscle development for men, as well as facial characteristics, are highly important standards for physical attractiveness. We emphasize surface qualities over internal qualities. As people acculturate to a new culture, they may adopt ways of thinking about attractiveness from the new culture. 


\section{Faces and Attraction}

Faces convey a significant amount of information about a person, including their various identities, such as sex, gender, ethnicity, race, and mood or emotion. The face is also one avenue through which judgements are made. That is, we have first impression of people based on their faces, and we make these judgements within seconds of meeting a person. Based on our impression of someone, we change our attitude and behavior toward this person (Lennon, Johnson, \& Rudd, 2017).

Overall, individuals perceived as attractive receive unearned advantages. And, conversely, unattractive people experience significant discrimination due to the sizes and shapes of their facial features. This result has been found repeatedly in numerous peer-reviewed studies. That is, attractive people are given more awards; make more money; are perceived as smarter, more competent, be more social-able, happier; are given more attention; are more likely to be elected to office; and generally have more positive interactions than those who aren't seen as markedly attractive (Lennon, Johnson, \& Rudd, 2017).

\section{Theories of Attraction}

The first theory of attraction is sexual dimorphism, which refers to the physical features that are determined to be associated with men or women or masculinity or femininity. In numerous studies, researchers found that women who have more feminine features are judged to be more attractive and men who have more masculine features (a hard jawline, for instance) are rated as more attractive (Rhode, 2006).

The second theory is the theory of average faces. In this theory, researchers found that those faces that are more average are judged to be more attractive. You can view an example of face that are more average on the Face Research website (Faceresearch.org).

The last theory refers to facial symmetry: those faces that are more symmetrical are rated as more attractive (Lennon, Johnson, \& Rudd, 2017).

\section{Attraction and the Beauty Industry}

There is a significant amount of bias against people who do not meet the appearance attractiveness standard.

The bias toward appearing attractive, being treated better simply because the size and shape of one's facial features, has created a multi-billion-dollar beauty industry. The cosmetic and plastic surgery industries have contributed to and upheld ideal beauty standards (American Society of Plastic Surgeons, 2017; Rhode, 2010; Ridder, 2021 ). It is no surprise, then, that the fashion industry is aware of the advantage and has employed attractive models, as these models sell more products. 

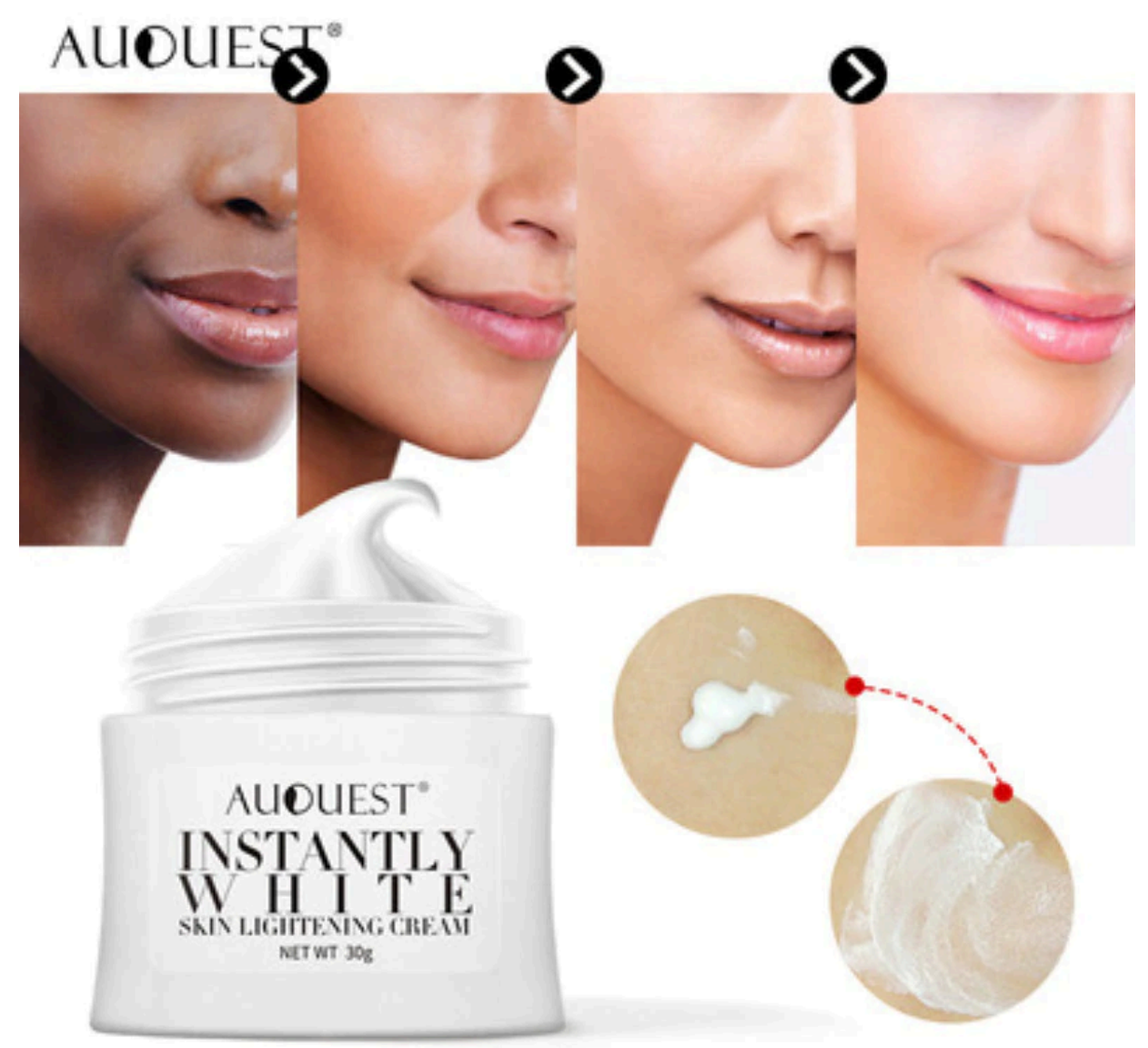

AuQuest “Instantly White” skin lightening cream (Image used under fair use for demonstrative purposes)

\section{Abercrombie \& Fitch}

Abercrombie \& Fitch is a fashion company that began in the 19th century (Abercrombie \& Fitch, 2021). It sells products in numerous categories, including menswear, womenswear, and childrenswear. The company has frequently, in the recent 21st century, been in the news for a variety of issues, including its risqué print catalog, which featured models in sexualized positions. Additionally, it has a history of discriminatory hiring practices (Walters, 2016).

In 2006, Mike Jeffries, the company's CEO, stated publicly, “A lot of people don't belong [in our clothes]. ... That's why we hire good-looking people in our stores Good-looking people attract other good-looking people, and we want to market to cool, good-looking people. We don't market to anyone other than that" (The Fashion Law, 2018). Jeffries was hired to overhaul the brand after company went bankrupt in 1992. His tactics of hiring "beautiful" people were to help revamp the company ad increase sales. His strategy was a success; it increased sales and profit. 
The company also instituted a looks policy; it regulated employees' appearances, including length and color of hair, women's makeup, and fingernail length. In other words, the company hired retail employees as it would models; it put employees in its retail stores based on their appearance rather than their ability to perform job functions. Any person of color (Asian, Black, and/or Latinx) was confined to the stockroom and not out on the selling floor, because they did not have a particular look. This issue is a complex one, and while we read the example in the facial attractiveness module, other intersecting identities certainly experiencing discrimination here, such as race and body size.

One or more interactive elements has been excluded from this version of the text. You can view them online here:
https://iastate.pressbooks.pub/dressappearancediversity/?p=26\#oembed-1

To view a transcript for the video above, download this file: 60 MIN Abercrombie \& Fitch Racism Lookism Controversy Video Transcript [DOC] 


\section{References}

Aronson, E. (1965). The social animal (2nd ed.). San Francisco: W. H. Freeman.

Cheng, C.-Y. (2000). Acculturation and cultural value orientations of immigrant Chinese Americans: Effects on body image, aesthetics for appearance, and involvement in dress. Unpublished doctoral dissertation, lowa State University, Ames.

Dion, K., Berscheid, E., \& Walster, E. (1972). What is beautiful is good. Journal of Personality and Social Psychology, 24, 285-290.

Fisher, S. (1968). Body image. In D. Sills (Ed.), International encyclopedia of the social sciences (Vol. 2). New York: Macmillan.

Giddon, D. B. (1985). Ethical considerations for the fashion industry. In M. R. Solomon (Ed.), The Psychology of Fashion (pp. 225-232). Lexington, MA: Lexington Books.

Goffman, E, (1968). Stigma Notes on the management of social identity. Harmondsworth: Penguin.

Jasper, C. R., \& Klassen. M. L. (1990). Stereotypical beliefs about appearance: Implications for retailing and consumer issues. Perceptual and Motor Skills, 71, 519-528.

Lennon, S., Johnson, K. K. P., \& Rudd, N. (2017). Social psychology of dress. London: Bloomsbury.

Ogle, J. P., \& Damhorst, M. L. (2004). Constructing and deconstructing the body malleable through mother-daughter interactions. Sociological Inquiry, 74(2), 180-209.

Oh, K., \& Damhorst, M. L. (2009). Coorientation of body image among older married couples. Body Image, 6, 43-47. Rhode, D. L. (2010). The beauty bias: The injustice of appearance in life and law. Oxford: Oxford University Press.

Rhode, G. (2006). The evolutionary psychology of facial beauty. Annual Review Psychology, 57, 199-226. 


\section{Beauty and Attractiveness Case Study}

Step One: Become familiar with the case study.

1. The case study attached below is a Word document and can be downloaded. It includes the task, evaluation, and template for the case study:

Beauty and Attractiveness Case Study [DOC]

Step Two: Submit your complete assignment on Canvas.

1. Format your document.

2. Remember to check the submission against the rubric. 


\section{1. \\ DISABILITY}

\section{Module Learning Objectives (MLO)}

In this chapter, you will

- MLO 11.1 Identify foundational concepts related to disability, fashion, identity, appearance, and dress. [CLO 1]

- MLO 11.2 Identify different types of dress worn by people with disabilities in the United States. [CLO 1]

- MLO 11.3 Identify the experiences of people with disabilities in the United States wearing different dress objects reflecting their disability identities. [CLO 2]

- MLO 11.4 Identify different fashion brands that produce and sell dress objects for people with disabilities in the United States. [CLO 2]

- MLO 11.5 Explain the role of dress and appearance in the development of one's disability identity. [CLO 2]

- MLO 11.6 Examine how dress and appearance of people with disabilities in the United States are represented in the fashion system (e.g., advertisements or retailers). [CLO 3]

- MLO 11.7 Examine social justice issues related to dress and appearance for people with disabilities in the United States. [CLO 3]

- MLO 11.8 Deconstruct your own perspectives and approach to understanding the dress and appearance of people with disabilities in the United States. [CLO 4]

- MLO 11.9 Identify the driving forces of transformative social justice change in the fashion system related to disabilities in the United States. [CLO 5]

A disability is any condition of the body or mind that makes it more difficult for a person to do certain activities and interact with the world around them. Disabilities may affect a person's vision, movement, thought, memory, learning, communication, hearing, mental health, and social relationships. Disabilities generally have three dimensions:

1. impairment in a person's body structure of function, or mental functioning, such as loss of a limb, loss of vision, or memory loss.

2. activity limitation, for example, causing difficulty seeing, hearing, walking, or problem-solving.

3. participation restrictions: affecting daily activities such as working, engaging in social and recreational 
activities, and obtaining health care and preventive services.

Disabilities can be present from birth, develop over time, be caused by injury, be long-standing conditions, or be progressive.

Required reading

Centers for Disease Control and Prevention. (n.d.). Disability and Health Overview. Retrieved from https://www.cdc.gov/ncbddd/disabilityandhealth/disability.html

\section{History of the Disabilities Rights Movement}

Individuals with disabilities have unique needs that historically have not been met. In addition to needing support, funding, and services, individuals with disabilities have also found themselves discriminated against and stigmatized by individuals, businesses, and potential employers. This led to the rise of a movement advocating for change in the latter 20th century.

Watch this video to learn more about the disability rights movement:

In 1990, the Americans with Disabilities Act (ADA) was passed to help support individuals with disabilities living in the United States. This act was revised in 2006 to account for the accessibility issues that had become apparent with the popular use and integration of the Internet into individuals' daily lives. There are five major sections within the act:

- Title I created equal employment rights for people with disabilities to remedy barriers at all stages of employment, including the fairness in the hiring process and reasonable accommodations throughout employment, training, and promotion.

- Title II requires public entities to provide equal access to all government programs and services.

- Title III requires equal access to businesses, including hotels, schools, museums, live theaters, restaurants, stores, and more.

- Title IV requires that telecommunications access be provided.

- Title $\mathbf{V}$ includes a variety of other provisions, including protection from retaliation when individuals assert 
these rights.

According to US Census data, nearly $19 \%$ of individuals in the United States are living with a disability (US Census Bureau, 2021). This includes, among others,

- 2 million people who are blind

- 7.6 million people who have difficulty hearing

- 9.4 million people who have difficulty grasping or lifting objects

- 30.6 million people who have mobility difficulties (difficult walking, necessitating the use of a wheelchair, cane, crutches, or walker)

With these disabilities comes the need for accommodations, not just through legal means like the affordances provided through the ADA but also through accessories and clothing that support or at least do not actively harmn an individual with a disability.

\section{Hearing Devices}

Individuals experience various degrees of hearing loss, from mild cases to more severe ones. A breakdown of degrees of hearing loss is provided below:

- mild: has some difficulty keeping up with conversations.

- moderate: has difficulty keeping up with conversations when not using a hearing aid.

- severe: benefits from powerful hearing aids but often relies on lip-reading; some use sign language.

- profound: is very hard of hearing; relies mostly on lip-reading and/or sign language.

Hearing aids are electroacoustic devices designed to amplify sound, with the goal of making speech audible for people with varying levels of hearing loss. The invention of the telephone inspired the development of the first electronic hearing aid in 1898.

The first hearing devices were speaking tubes, trumpets, and cups, devices with conical or wider openings that funneled sound into a smaller pipe and into the ear of the user. As technology developed, body-worn hearing aids came into popular use, making it easier for individuals to bring their hearing aids "on the go." 
Smaller hearing aids worn behind or in the ear were developed in the first half of the 20th century. These hearing aids, still in use today, continue to be improved. The most recent development in hearing devices is the cochlear implant. First developed in 1972, the cochlear implant consists of an internal device that is surgically implanted, with an external component worn near the ear.

\section{Aesthetics of hearing devices}

The design of hearing aids varies widely, from functionally basic designs to stealthier jewelry-based designs meant to blend in with one's hair or clothing, like the glasses featured below:

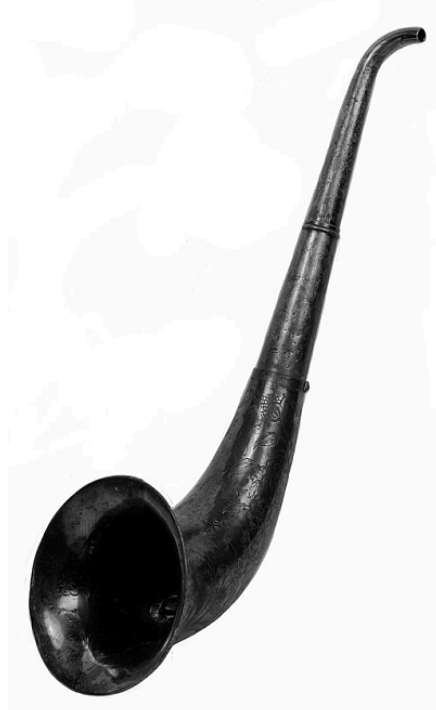

Image Source: 19 th century ear trumpet, via Wellcome Trust, CC BY 4.0

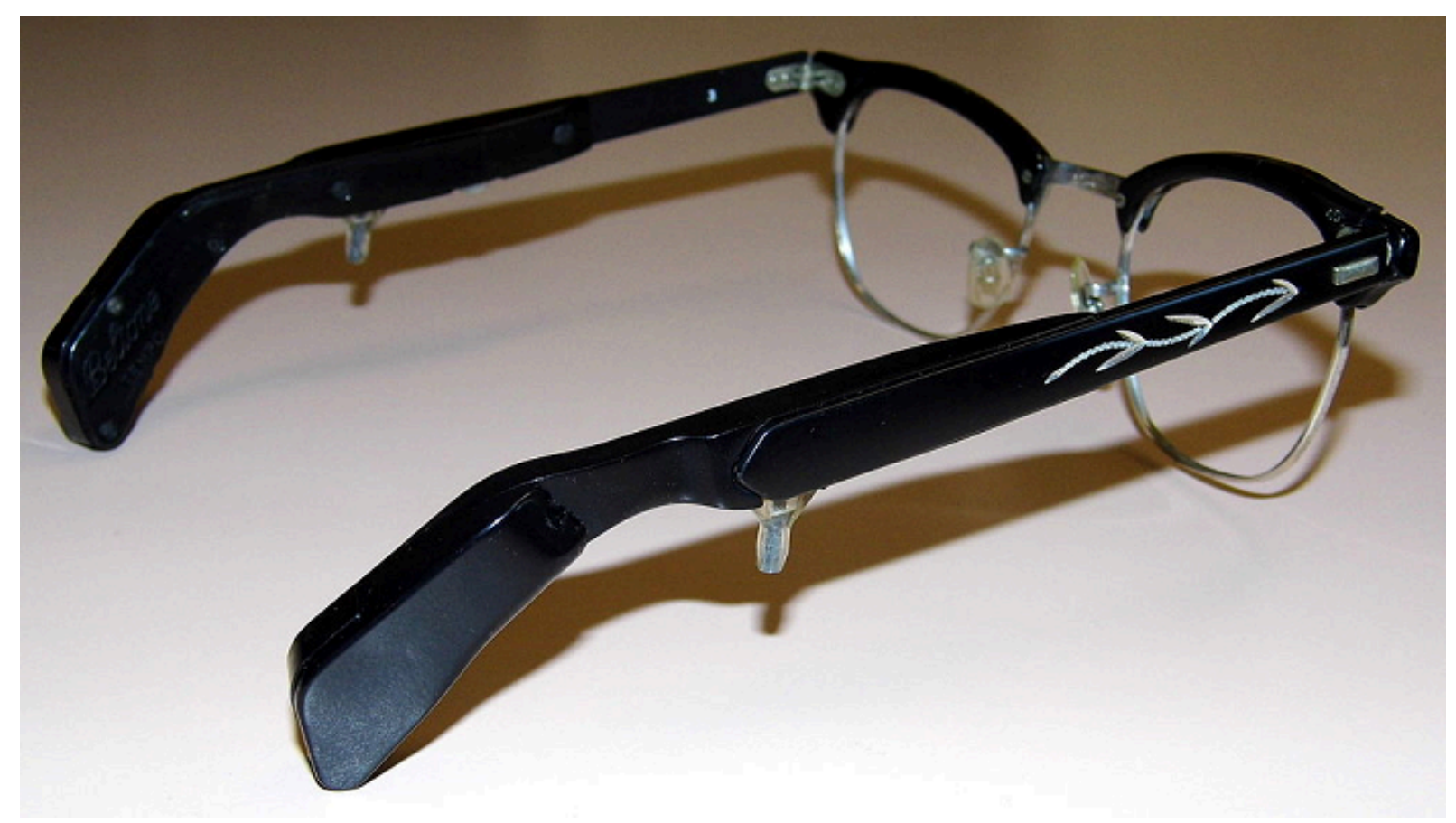

Image Source: Beltone Transistor Eyeglass Hearing Aid, ca. 1967, CC BY SA 2.0

Some hearing aid users have an interest in their devices' aesthetics. In contrast to the designs meant to "blend in," some behind-the-ear hearing aids are created with bright, fun patterns or in humorous shapes to draw attention to the device as a part of the user's dress, like these colorful hearing aids from Phonak (Phonak, 2021): 

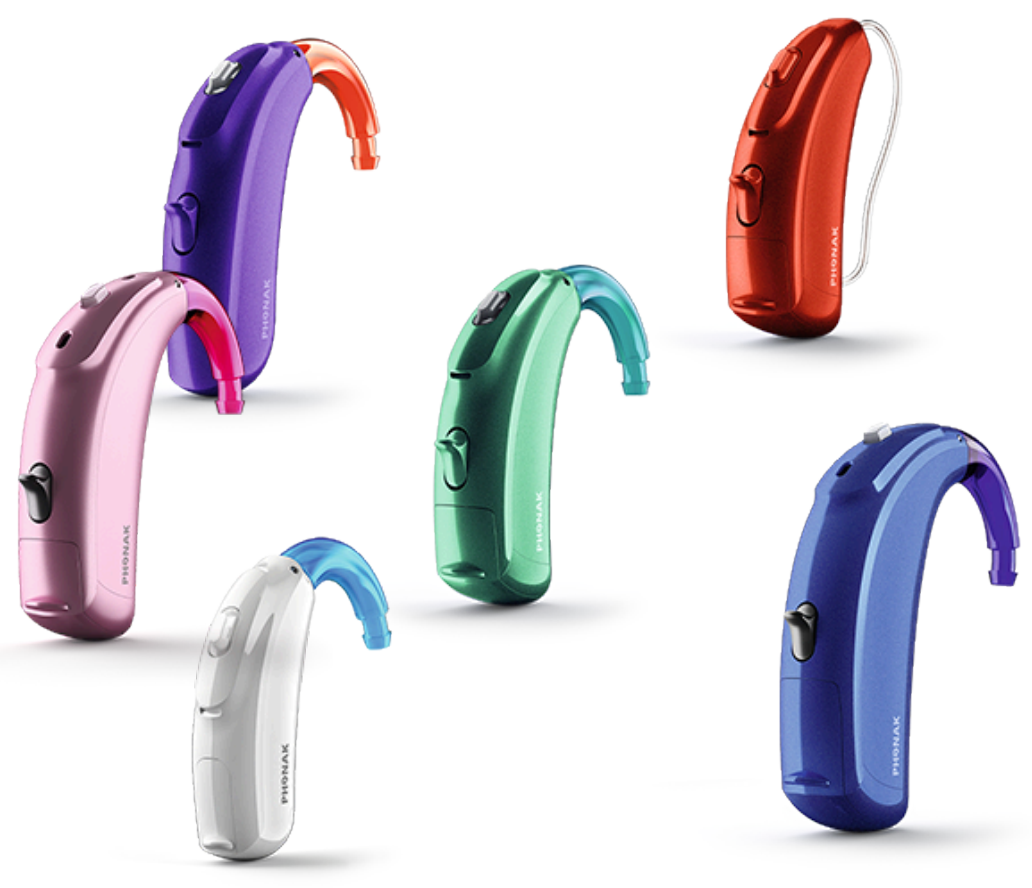

Image Source: Phonak, all rights reserved, used under fair use.

In a study that talked to a small group of adolescents about their perspectives on their hearing aids or cochlear implants, half of the participants reported medium to low self-esteem, with 5 of 8 total participants stating that when they met new people, they were treated as if they were stupid (Ellington \& Lim, 2015).

\section{Mobility Impairment and Dress}

Mobility impairment is a person's inability to use one or more of their extremities or a lack of strength to walk, grasp, or lift objects. Because the fashion industry has largely been built for able-bodied people, the needs of individuals with mobility impairment, who cannot easily grasp zippers or manipulate button closures, have been heavily affected by the clothing options available to them. Luckily, this has begun to change in the 2010 s as more adaptive clothing has entered the market. 


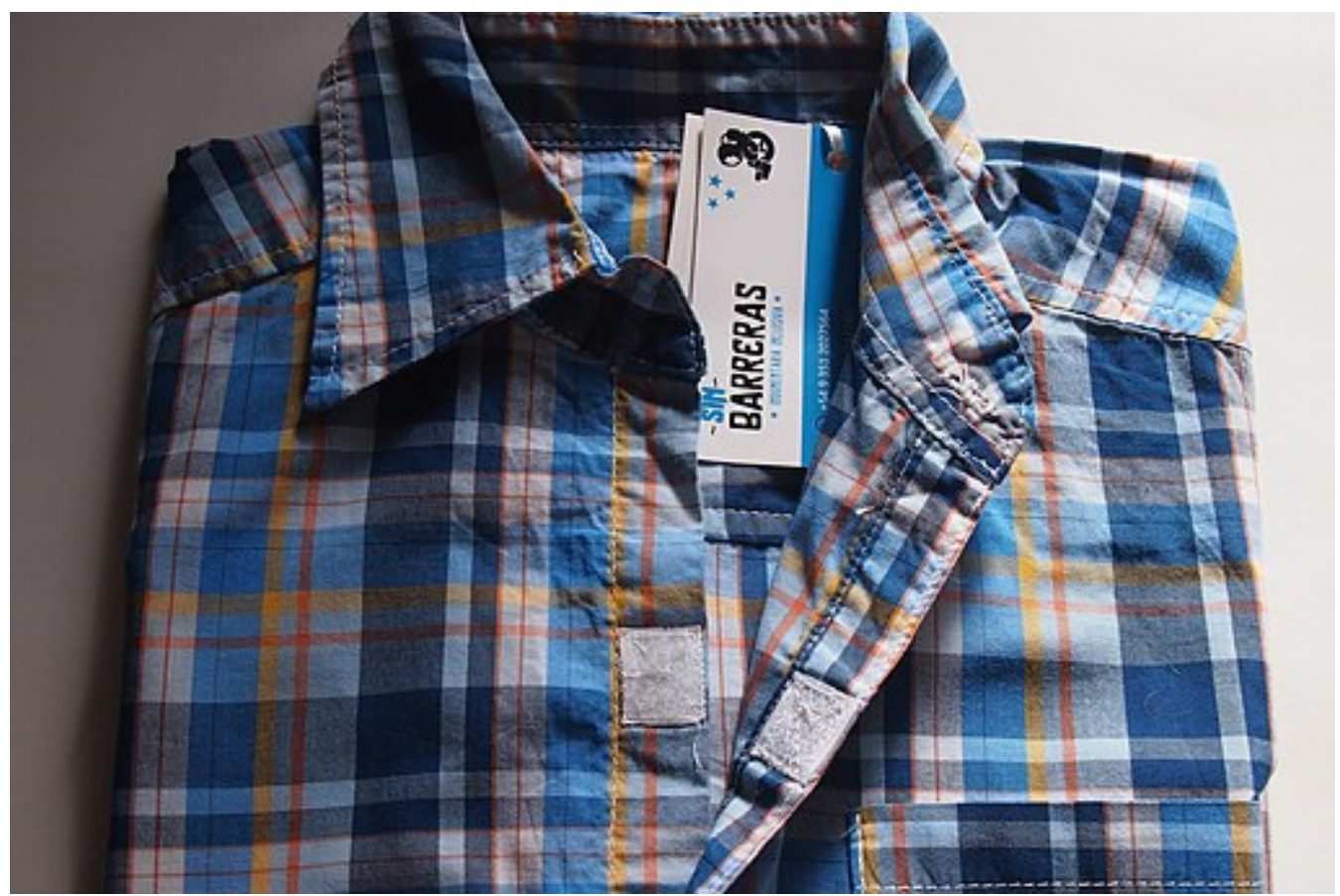

This shirt uses hook-and-loop fasteners instead of buttons for easier closure. Image source: Franpastrone, CC BY SA 4.0.

\section{Adaptive design}

Adaptive design refers to designs created for people with disabilities. The industry does not call its lines "ablebody designs," yet when companies label their clothes "adaptive designs," the nonadaptive designs labeled, for example, as "womenswear" are assumed to be for able-bodied people.

Numerous companies exist that create adaptive designs (Matchar, 2018). Some, such as Adaptions by Adrian, Buck \& Buck, and Silvert's Adaptive Clothing \& Footwear, are smaller and niche companies focusing just on adaptive designs. Other companies include Rebirth Garments, which focuses on designs aimed at gender nonconforming, trans, and disabled individuals.

Watch this short TedEd video to learn more about how adaptive clothing can support those who need it most: 
Even larger companies such as Target, Tommy Hilfiger, and Nike have incorporated adaptive lines into their already existing assortments (Pitman, 2017; Tommy Hilfiger, 2021; Nike, 2021).

\section{Prosthetics}

Prosthetics may be integrated into dress for individuals who are missing limbs. Prosthetics are artificial devices that replace missing body parts, which may have been lost through trauma, disease, or congenital conditions. These devices were originally designed in peg shapes for legs and hook shapes for hands. However, these prosthetics have considerably advanced in complexity. For example, arms have been refined first through the development of a harness that could open and close the hook or a facsimile hand in order to grasp objects. Today, hand prosthetics can be controlled by electrical signals from the muscles in the remaining portions of the arm, though these are very expensive.

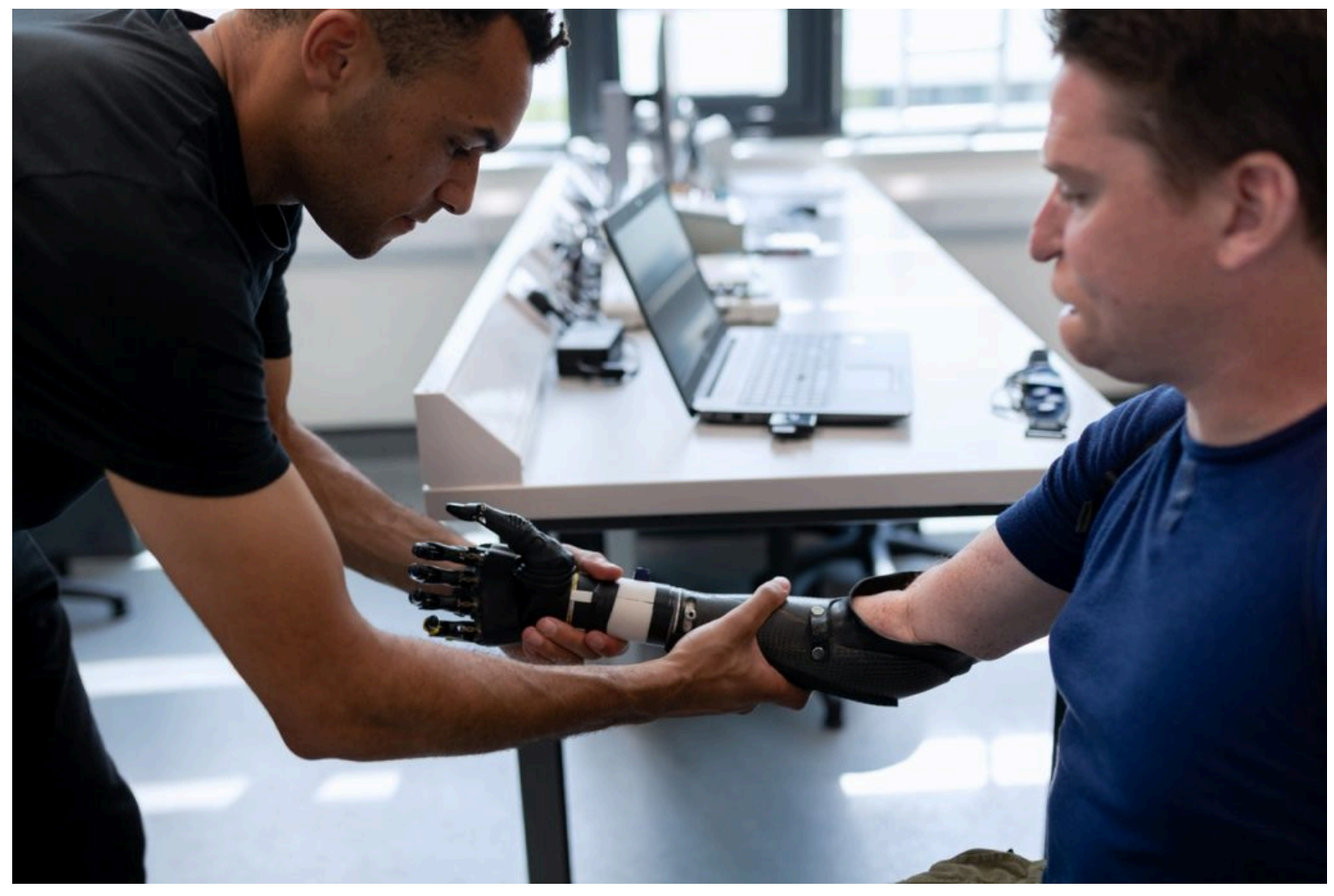

Image Source: This Is Engineering 
Similar to hearing aids, prosthetics can "blend in" with the rest of an individual's body, or they can be augmented through designs to make them stand out.

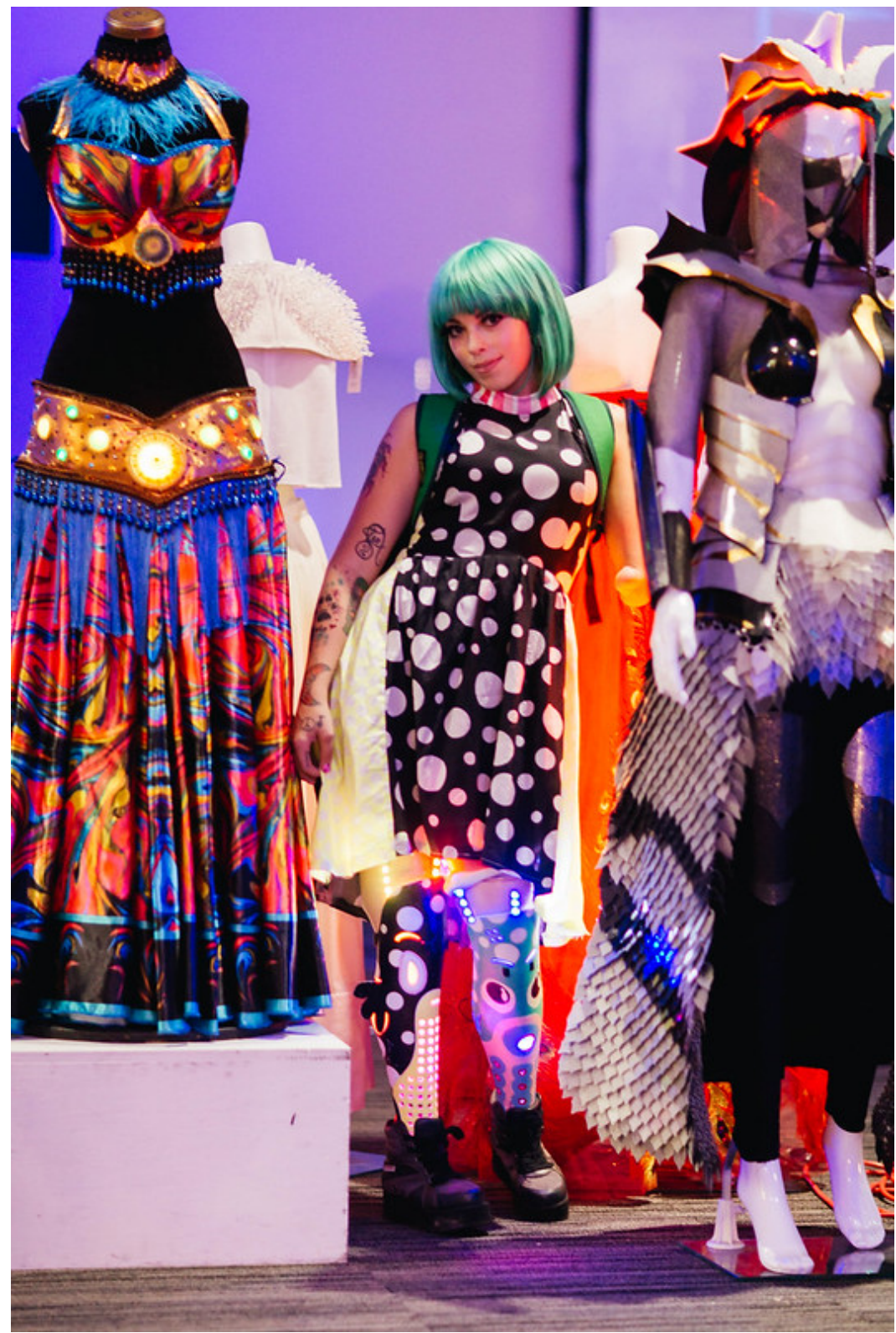

Calgary Mini Maker Faire at Telus Spark, September 2015. MakeFashion collection with Nadine wearing light-up prosthetic covers made by Alleles Design Studio. Image Source: Beakerhead. Photo by Kelly Hofer, CC BY NC ND 
Ellington, T., \& Lim, S. (2016). (dis)ABLED BEAUTY: The evolution of beauty, disability, and ability. https://oaks.kent.edu/ ksumuseum $/ 3$

\section{Disability Case Study}

ค. จ

\section{Step One: Become familiar with the case study.}

1. The case study attached below is a Word document and can be downloaded. It includes the task, evaluation, and template for the case study:

Disability Case Study [DOC]

\section{Step Two: Submit your complete assignment on Canvas.}

1. Format your document.

2. Remember to check the submission against the rubric. 


\section{2. \\ RELIGION}

\section{Module Learning Objectives (MLO)}

In this chapter, you will

- MLO 12.1 Identify foundational concepts related to religion, fashion, identity, appearance, and dress. [CLO 1]

- MLO 12.2 Identify different types of dress worn by people following different oppressed religions in the United States. [CLO 1]

- MLO 12.3 Identify people following different oppressed religions experiences in the United States wearing different dress objects reflecting their religious identities. [CLO 1]

- MLO 12.4 Identify different fashion brands that produce and sell dress objects for people following different oppressed religions in the United States. [CLO 2]

- MLO 12.5 Explain the role of dress and appearance in the development of one's religious identity in the United States. [CLO 2]

- MLO 12.6 Examine how dress and appearance of people following different oppressed religions in the United States are represented in the fashion system (e.g., advertisements or retailers). [CLO 3]

- MLO 12.7 Examine social justice issues related to dress and appearance for people following different oppressed religions in the United States. [CLO 3]

- MLO 12.8 Deconstruct your own perspectives and approach to understanding the dress and appearance of people following different oppressed religions in the United States. [CLO 4]

- MLO 12.9 Identify the driving forces of transformative social justice change in the fashion system related to oppressed religious groups in the United States. [CLO 5]

A religion is a set of beliefs, symbols, and practices based on the idea of the sacred (which people define as extraordinary, inspiring a sense of awe and reverence) and unites believers in a socioreligious community. There are over 4,000 religions worldwide, and more than $80 \%$ of the world's people are religiously affiliated. This includes

- 2.2 billion Christians (32\%)

- 1.6 billion Muslims (23\%) 
- 1 billion Hindus (15\%)

- 500 million Buddhists (7\%)

- 14 million Jews $(0.2 \%)$

In addition, more than 400 million people (6\%) practice various folk or traditional religions, including African traditional religions, Chinese folk religions, Native American religions, and Australian aboriginal religions. An estimated 58 million people-slightly less than $1 \%$ of the global population-belong to other religions, including, for example, the Baha'i faith, Jainism, Sikhism, Shintoism, Taoism, Tenrikyo, Wicca, and Zoroastrianism.

Among those living in the United States, $77 \%$ of adults identify with a religious faith. Even within a single religion, there are varying interpretations of dress. For example, Reform and Orthodox Jews have different customs or rules of dress, as do Mennonites (a Christian denomination) and Baptists (another Christian denomination).

\section{Muslim Dress}

There is a common misconception that all Arab people are Muslims, meaning they follow the religion of Islam. However, many Arabs follow Christian, Jewish, or other, less popular religions. After all, Arabs are simply people who speak Arabic as a native language. This encapsulates a wide swath of individuals from 22 different countries, from Morocco to Oman. (Further, Muslims are found around the world, with most Muslims residing in Asia and in Pacific regions, not the Middle East or Africa.)

The concept of modesty is central to Muslim dress for both men and women. That is, Muslim people often dress in clothing that does not reveal parts of the body. This might mean wears looser clothing or clothing that covers most of the skin. For example, a Muslim man might wear a thobe, a long, loose- fitting robe that is usually white in color. A Muslim man also might incorporate head coverings into his dress, such as a ghutra, a square or rectangular headscarf, with an igal, a cord that holds the ghutra in place. 


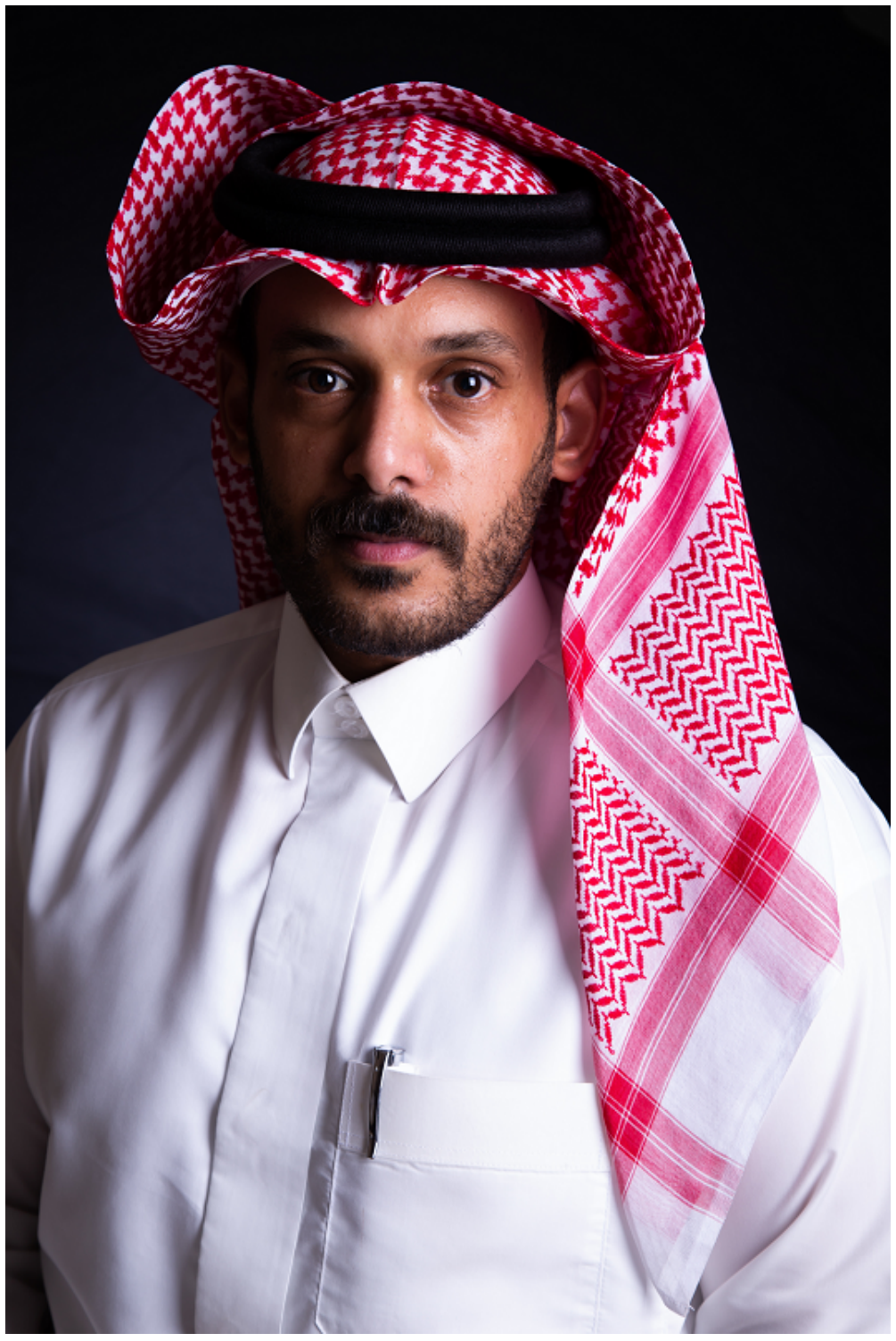

Image Source: Nasser Almutairi

Elements of Muslim women's dress include

- burka: a veil that covers the entire body and face, with mesh over the eyes that the wearer can see through.

- niqab: a veil that covers the head and face, but not the eyes. The niqab is usually worn paired with a long, loose black garment, called an abaya, that falls to cover the feet.

- chador: a cloak that covers the body from head to toe but leaves the face uncovered. The chador is popular among Iranian women.

- dupatta: a long scarf draped across the head and shoulders and often paired with matching garments. The dupatta is common in South Asian countries. 
- hijab: a general term meaning "to veil"; hijab commonly refers to a headscarf that covers the hair and neck of the wearer, but not the face.

\section{The Burkini: Design, History, and Controversies}

The burkini is a full-body swimsuit that includes long sleeves, long pants, and a hood, in an all-in-one design. Some, but not all Muslim women wear the burkini; there are different perspectives and interpretations of modesty within the Muslim community. There are a lot of different styles for the burkini, and numerous retailers sell them (Ahiida.com). The burkini is rather similar to a surfer's wet suit in design and overall look.

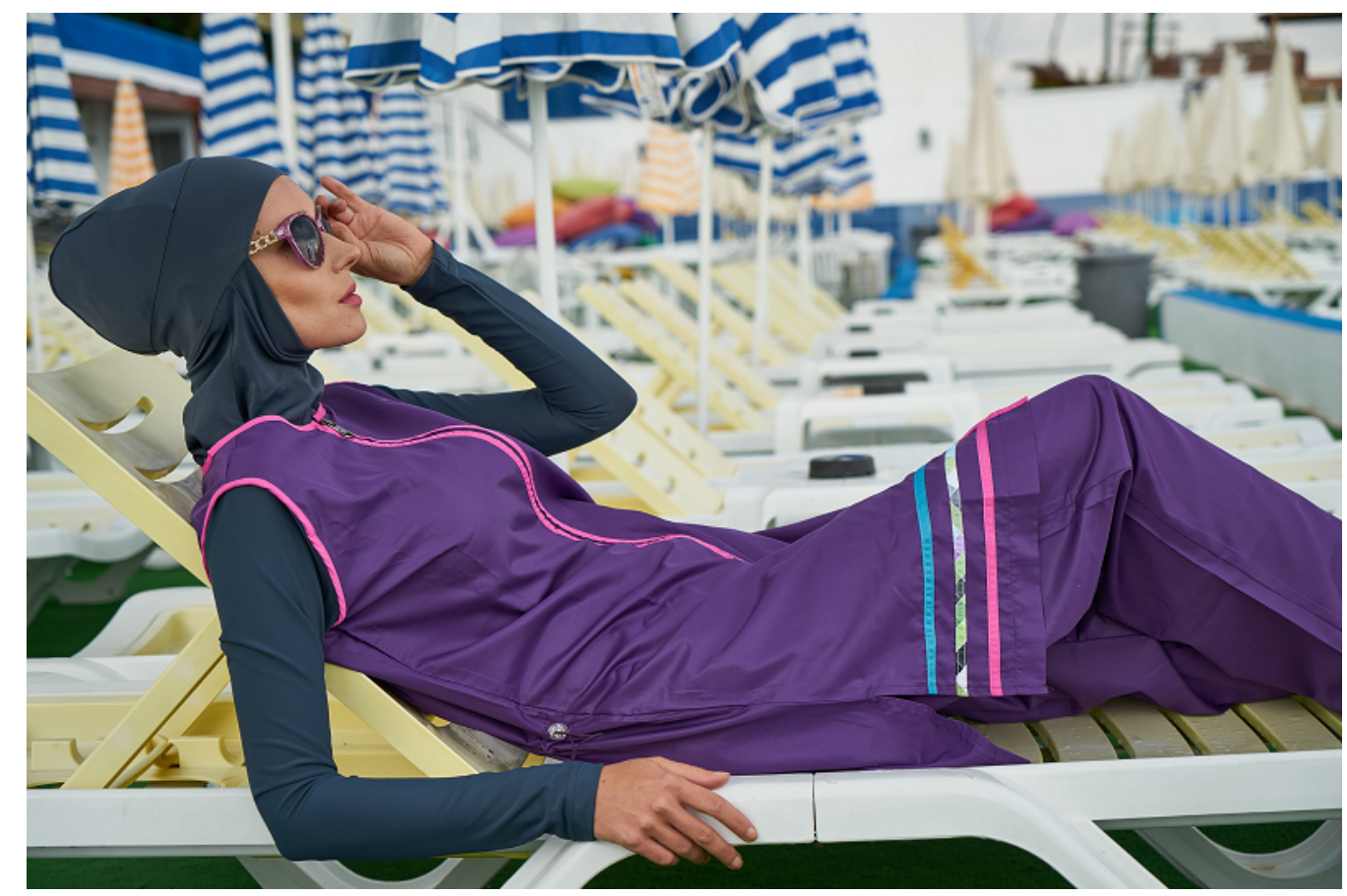

Image Source: Piqsels, $\underline{\mathrm{CCO}}$

The burkini was designed in 2006 by a Lebanese woman who lives in Australia, Ahiida Zanetti. It was originally made for lifeguards in Australia and has since spread and been worn by numerous Muslim women across the world (Akou, 2013). In 2019, Sports Illustrated featured the first model wearing a burkini. However, there was much controversy over whether a Muslim woman practicing modest dress should model in Sports Illustrated, a magazine that historically has featured women in sexualized and objectified poses (Sini, 2019).

The burkini is not the only sports-related dress to consider Muslim women and their religious needs. In 2017, Nike designed and introduced the Nike Pro Hijab for female Muslim athletes. Ibtihaj Muhammad, a champion fencer and Nike athlete, has described some of the issues she faced being a young Muslim girl and being active: "When I was in school, I always had to have a letter from a local imam that said that it was safe for me to wear 
my religious covering during sport. ... My coaches had to have that with them at all times" (Nike.com, 2017)." In a University of Minnesota research project, scholars worked with Muslim women and young girls and inquired about their design needs for athletic wear. The young Muslim girls codesigned the clothing with the researchers to meet their athletic and religious needs. There's a short video in the reference link at the end of the sentence that documented some of this process of this research project: "New Uniforms Score Points for Modesty for Muslim Girls (Satzinger, 2015)"

After the introduction of the burkini, some areas in France began banning the swimsuit for Muslim women (Dearden, 2016). Once the bans were in place, onsite security or police officers required some Muslim women to remove their burkini in public. The ban is related to France's overall move toward the separation of religion and state. France's secular principle introduced into law on March 15, 2004, prohibits any clothing or other religious attire being worn in schools (France Diplomacy, n.d.).

Controversy over modest swimwear was not limited to France. In 2016, in the United States, in New Jersey, Muslim women swimming in public spaces said they received stares of confusion, and another group of women was not admitted to a public pool because the pool officials stated the burkini was a safety hazard (Alex \& Alvarado, 2016).

Watch this short film about Muslim women's dress.

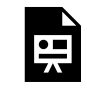

One or more interactive elements has been excluded from this version of the text. You can view them online here: https://iastate.pressbooks.pub/dressappearancediversity/?p=94\#oembed-1

Both Muslim men and women, however, engage varying degrees of modest dress. Some Muslim women might cover more of their bodies than others, and some might dress more modestly in public but not in the privacy of their own homes.

\section{Jewish dress}

Similar to Muslim dress, the dress of Jewish people can differ widely, from liberal to highly conservative presentations. Even Conservative Jews are less strict in their dress than Orthodox Jews, however.

Watch this short film about Judaism, Reform Jews, identity, and dress.

\section{国} One or more interactive elements has been excluded from this version of the text. You can view them online here: https://iastate.pressbooks.pub/dressappearancediversity/?p=94\#oembed -2 


\section{Orthodox Jewish Dress}

Orthodox Jews highly value modesty; some Jewish Orthodox women wear wigs, or sheitel, to ensure their modesty while allowing them to still fit into mainstream US culture. Orthodox Jewish men wear skullcaps, yarmulkes, or kippah to cover their heads. They do so is because the Talmud (the body of Jewish civil and ceremonial law) argues that because there is divine presence over one's head, you should cover your head to show respect to that divine presence, Hashem (God).

\section{Hasidic Jewish Dress}

Hasidic Jewish men might wear even more religion-specific garments, such as a fur hat (shtreimel), a curled lock of hair on each side of the head (payot), and a black prayer belt (gartel).

Watch this short film to learn more about Hasidic style.

To access a transcript for the video above, download this document: Hasidic Style Video Transcript [DOC]

\section{Mennonites (Christian)}

Mennonites follow the Anabaptist sect of the Christian faith, a group that rejected baptism of infants and insisted baptism should only occur when one is certain that they are a believer. This group often follows a conservative dress style, with a particular focus on women's modesty. For example, some women cover their hair with a starched cap, which represents the woman's humility to God and her resistance to worldly possessions. This cap also represents submissiveness to God, the woman's community, and her husband. 


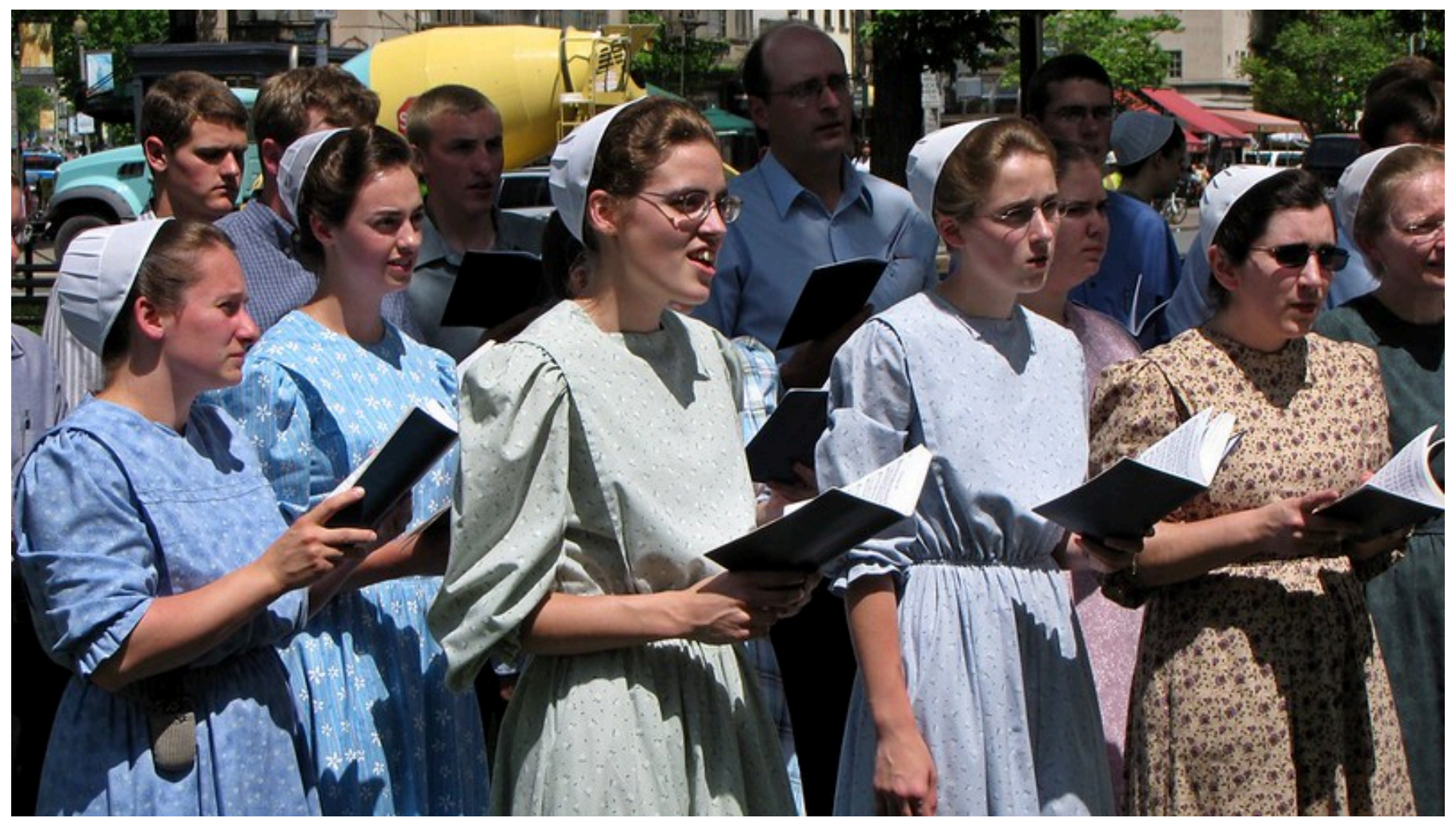

Mennonite choir in Dupont Circle, Washington, DC. Image Source: Ben Schumin, CC BY SA 2.0.

Watch this short video to see a 1960s Mennonite dress worn by a woman in lowa. The dress is part of the ISU Textiles and Clothing Museum permanent collection.

\section{Buddhist Dress}

Buddhism, Hinduism, Taoism, and Shintoism are all polytheistic religions (religions whose followers believe in many gods) represented in the United States. Their representatives follow particular manners of dress. In this section, we'll be reviewing Buddhist dress. 


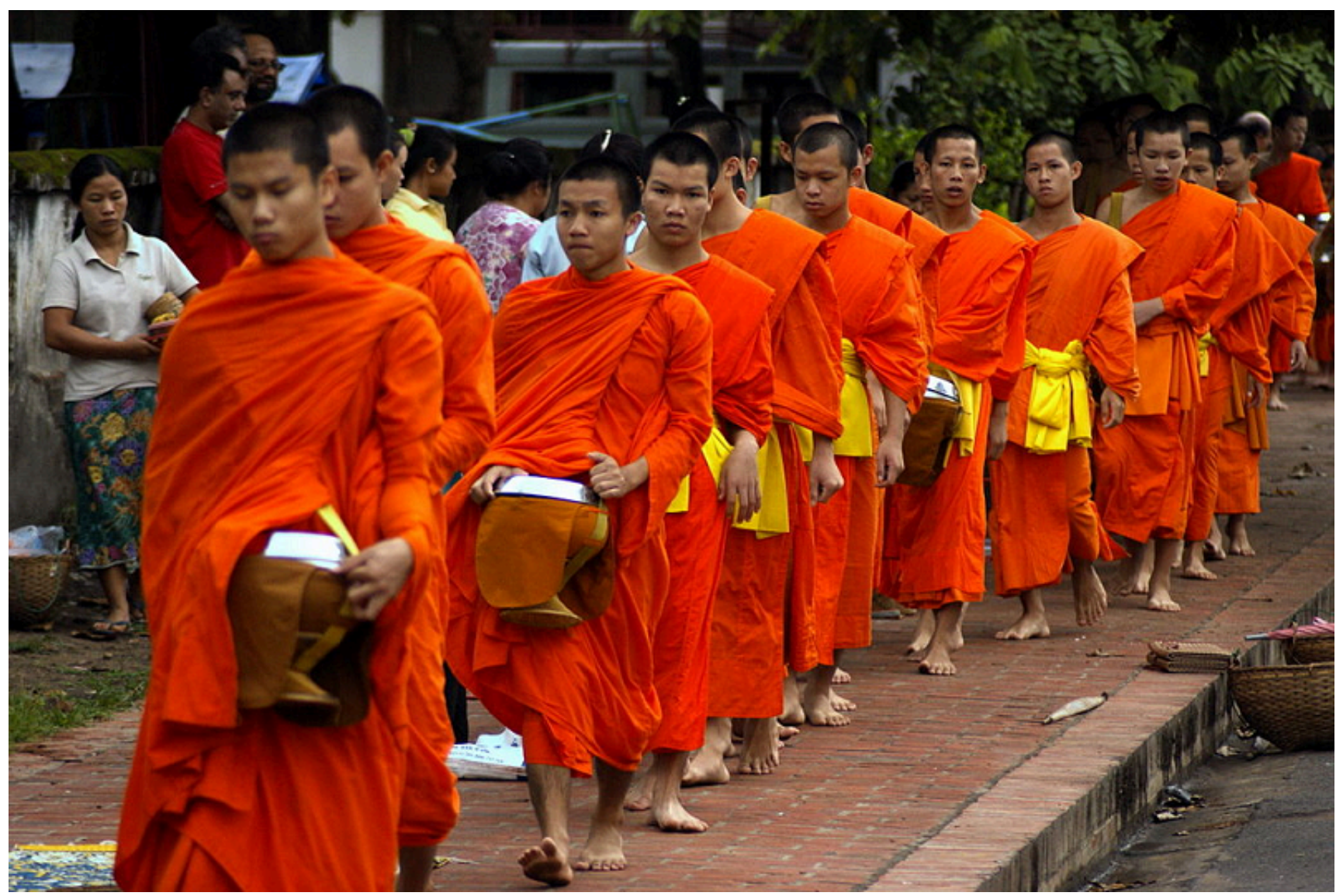

Image Source: Allie Caulfield, $\underline{\text { CC BY 2.0. }}$

Buddhism, which originates in India, stresses that material possessions do not bring happiness, but rather, true happiness comes from within oneself. Following this line of belief, fully ordained Buddhist monks wear robes, or kasayas, simple garments colored a bright orange with saffron. Today, 5-6 million Buddhists live in the United States.

\section{Sikh Turbans and Gucci}

Sikhism is a monotheistic religion that originated in India. Members of this religion are referred to as Sikhs. According to a 2012 Pew Research Center report, there are about 500,000 Sikhs living the United States (Rosentiel, 2012).

Rupinder Singh, who follows the Sikh religion discusses how his religion is reflected in his dress. Read about his experience in this article: "11 Things You Wanted to Know About My Turban but Were Too Afraid to Ask" (2021). The turban is one way that people who follow the Sikh religion symbolize their religion through their dress. 
After you read Rupinder's article, watch this short video : "How to Tie a Traditional Sikh Turban" (British Museum, 2011). It highlights one way a Sikh person can tie a turban.

In 2019, Gucci, an international high-fashion brand introduced a "fashionable turban" into its collection. The bright blue turban appeared to be styled very similarly to Sikh turbans. There was significant backlash against Gucci for producing and selling the $\$ 800$ turban. One Washington Post article discussed how the Gucci turban was an inappropriate form of cultural appropriation (Chiu, 2019).

The Sikh Coalition. (n.d.). Identity. Retrieved from https://www.sikhcoalition.org/about-sikhs/identity/

\section{Religion Case Study}

\section{Step One: Become familiar with the case study.}

1. The case study attached below is a Word document and can be downloaded. It includes the task, evaluation, and template for the case study:

Religion Case Study [DOC]

\section{Step Two: Submit your complete assignment on Canvas.}

1. Format your document.

2. Remember to check the submission against the rubric. 


\section{3. \\ RACE AND ETHNICITY}

\section{Module Learning Objectives (MLO)}

In this chapter, you will

- MLO 13.1 Identify foundational concepts related to race, ethnicity, fashion, identity, appearance, and dress. [CLO 1]

- MLO 13.2 Identify different types of dress worn by people of color in the United States. [CLO 1]

- MLO 13.3 Identify people of color's experiences wearing different dress object reflecting their race and/or ethnicity in the United States. [CLO 2]

- MLO 13.4 Identify different fashion brands that produce and sell dress objects for people of color in the United States. [CLO 2]

- MLO 13.5 Explain the role of dress and appearance in the development of one's racial and/or ethnic identity in the United States. [CLO 2]

- MLO 13.6 Examine how dress and appearance of people of color in the United States are represented in the fashion system (e.g., advertisements or retailers). [CLO 3]

- MLO 13.7 Examine social justice issues related to dress and appearance for people of color in the United States. [CLO 3]

- MLO 13.8 Deconstruct your own perspectives and approach to understanding the dress and appearance of people of color in the United States. [CLO 4]

- MLO 13.9 Identify the driving forces of transformative social justice change in the fashion system related to people of color in the United States. [CLO 5]

\section{Ethnicity versus Race}

Race refers to physical characteristics that separate individuals into groups. In contrast, ethnicity is culturally determined and may not be reflected physically. Both, however, are social constructions reinforced by society to classify human differences. These classifications are often based on skin color, hair texture, and facial features, as well as other arbitrary physical characteristics. The categories that have evolved to categorize 
groups are different depending on one's location and culture, and the meanings of these terms have shifted over time.

\section{“One-Drop Rule”}

In the United States, racial formation developed along an opposition between Black and White. Anyone with "one drop" of Blackness was identified as Black. So, if someone has a White mother and Black father, they will typically identify as Black (e.g., Barack Obama). This classification has roots in the system of slavery in the United States.

\section{Racial classification: South Africa during Apartheid}

Racial segregation was legal In South Africa from 1948 to 1994. An individual was considered Black if a pencil could stick in their hair and not fall out. If it fell, the individual was "white." This is clearly a flawed system, but it was not meant to be exact or accurate; it was only meant to reinforce the existing perceptions and classifications of race within that culture.

\section{What's in a Name?}

There are various names for different ethnic groups in the United States; these have differed over time and with a growing understanding of the various cultures represented in US society. It is important to develop a sensitivity to the terms marginalized groups prefer for themselves.

\section{African American vs. Black}

African Americans or Black people prefer different terms for various reasons, from generational differences to political or social differences. Not all African Americans identify as Black, and not all Black people identify as African American. This is particularly true of Black people who live in America but were born in, for example, England, Kenya, or Mexico.

\section{Native American vs. Indian}

Similarly, different Native American groups use different names to refer to themselves; some use Indigenous peoples or First Nations. Although the term Indian has often received pushback, since the people did not originate in India, some Native Americans do use the term American Indian to refer to themselves. 


\section{Hispanic American vs. Latino}

Hispanic and Latino/a/x do not necessarily refer to the same thing. Hispanic refers to individuals with heritage in a Spanish-speaking country, whereas Latino/a/x refers to someone from Latin America. While there is some overlap in these definitions, they are not interchangeable! It is often more accurate to refer to someone by their nation of origin rather than a broad category. For example, Mexican, Chilean, Puerto Rican, and other more specific classifications might be used to distinguish an individual rather than the term Latino.

\section{Oriental vs. Asian American}

Finally, some terms used to refer to a group of people are still used despite being derogatory. Oriental is one such term that is no longer in accepted use. Instead of calling someone "an Oriental," you could refer to them as Asian American. However, similar to Latino/a/x individuals, it's often best to refer to Asian people living in the United States based on their preferred term, which might be their ethnicity of origin (Korean, Taiwanese, Chinese, Hawaiian, for example), or a more specific Americanized term (e.g., Chinese American).

\section{Roots of Ethnicity}

Ethnicity is a learned cultural heritage typified by national origin, ideology, style of dress, dietary habits, and, often, language. While a foreign-exchange student from China and a Chinese person whose family has lived in the United States for three generations might share a race, they will have differences in ethnicity based on the different ways Chinese American culture has evolved to have its own style of dress, dietary habits, and ideology.

Watch this short film about Chinese culture, appearance, and fashion.

One or more interactive elements has been excluded from this version of the text. You can view them online here:

https://iastate.pressbooks.pub/dressappearancediversity/?p=96\#oembed-1

\section{Inequalities of Power}

Historically, people of color (POC), ethnic minorities, have faced racism and exclusion from mainstream US society. Those in power in the United States are White people with European heritage. Achieving economic and social equality with White individuals has been difficult for people of color. This power difference is referred to as hegemony.

Racial equity is when equal regard is offered to all races. It is the elimination of policies, practices, attitudes, and cultural messages that reinforce differential outcomes by race or that fail to eliminate them. 
This inequality is reflected in unequal representation within fashion magazines. Research has shown that fashion magazines lack racial diversity, despite improvement over time. Jackson \& Ervin (1991) studied racial representation in Cosmopolitan, Glamour, and Vogue between 1986 and 1988. 97\% of the models represented were White. POC representation consisted of 2.4\% Black individuals, $0.5 \%$ Asian individuals, and virtually no Hispanic individuals. Building on this work, Mayo et al. (2005). studied racial representation in Vogue between 1993 and 1997. They found a slight increase in Black representation (6.9\%), though the vast majority of models were still White. Finally, Fowler \& Carlson (2015) studied 2011 issues of Elle, Cosmopolitan, Harper's Bazaar, Vogue, and Marie Claire and found that the representation were $83 \%$ white, 1.9\& Asian, 5.2\% Hispanic, and only 3.7\% Black.

Fashion media, also highlights unequal representation; see, for example, this article by Gemma Kim, published on Fashionista.com:

DEC 1, 2015

\section{DIVERSITY ON MAGAZINE COVERS DID NOT IMPROVE IN 2015}

We took a look at 136 covers from 10 leading U.S. fashion publications, and while some did better than others, the results were not encouraging.

GEMMA KIM
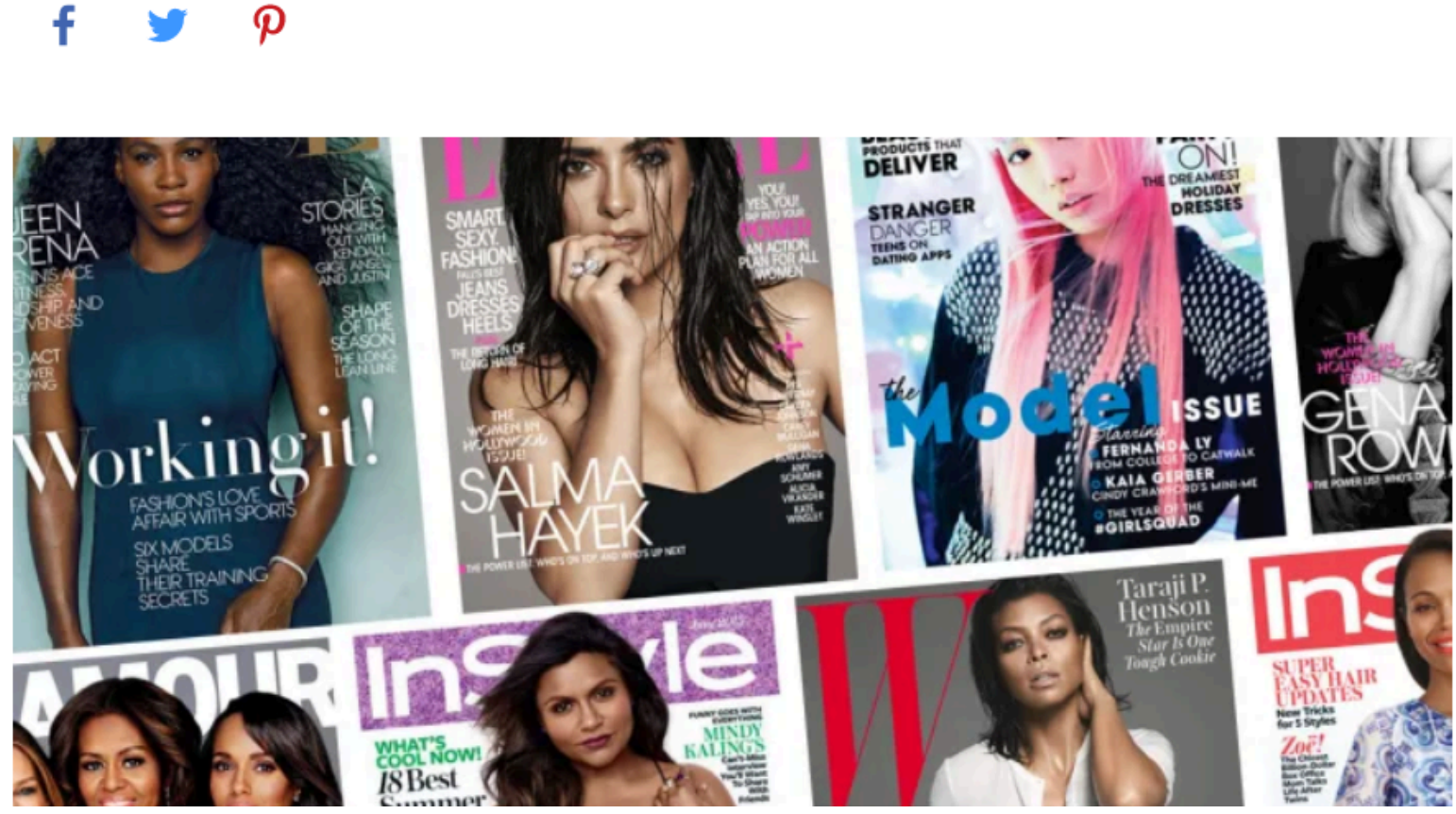

Image: Fashionista, December 2015 


\section{What is Colorism?}

Colorism is "interracial discrimination based on skin color stratification. Typically, lighter skin is preferred, along with facial and physical featuresmore closely associated with Caucasian standards of beauty" (Hunter, 2005). Since slavery, there has been evidence of discrimination based on skin color. Lighter-skinned Black slaves were more likely to be given indoor work, while darker-skinned Black slaves were more likely to be given field work. This is typified in the "paper-bag test," which was used to compare a person's complexion to a paper bag in order to exclude darker-skinned African Americans from clubs, schools, and churches (Russell, Wilson, \& Hall, 1992)

\section{Colorism in Hollywood}

Lupita Nyong'o, a Hollywood actor and fashion icon, spoke out in 2014 about her experience with colorism in the fashion industry. Watch Nyong'o's "Black Women in Hollywood" speech, posted by Essence.com (Essence, 2020). This quote from the clip highlights why diversity must be represented:

"And then Alek Wek came on the international scene. A celebrated model, she was dark as night, she was on all of the runways and in every magazine and everyone was talking about how beautiful she was. ... When I saw Alek I inadvertently saw a reflection of myself that I could not deny." (Lupita Nyong'o, 2014)

To access a full transcript of Lupita's speech, download this document: Lupita Nyongo Speech Video Transcript [DOC]

This isn't just anecdotally common, either: studies have looked into colorism in the fashion industry just as they have racial representation. Even within Ebony magazine, which focuses on and features Black people in the United States, light-skinned models and those with more European facial features dominated the magazine from the 1950s to the 1990s (Leslie, 1995; Keenan, 1996). 


\section{Example: Hair Straightening}

African Americans have used hair straightening as one strategy to fit into the dominant White society after slavery was abolished (Byrd \& Tharps, 2001). Hierarchies that privilege straight hair and finer hair textures still exist today. Robinson (2011) studied what Black women perceived as "good hair" and "bad hair" based on the society in which they live, and the women in the study stated that "good hair does not need straightening" (Robinson, 2011, 368).

Watch this short film about Black women, hair, and style.

One or more interactive elements has been excluded from this version of the text. You can view them online here:
https://iastate.pressbooks.pub/dressappearancediversity/?p=96\#oembed-2

The fashion industry reinforces the effects of colorism by offering skin-bleaching creams and hairstraightening techniques (Averhart \& Bigler, 1997; Brooks, Brown, \& Hampton, 2008; Porter, 1991; YoungHyman, Schlundt, Herman-Wenderoth, \& Bozylinski, 2003).

\section{Colorism in Korean Fashion Media}

The use of imagery that reinforces colorism by the fashion industry has become particularly pervasive in South and East Asian culture, particularly among media aimed at young Korean women. At lowa State University, graduate student Eunji Choi, in their MS thesis, "Korean fashion media, beauty ideals, and colorism: Examining the prominence of Whiteness between 2013 and 2017 in Céci magazine," analyzed images presented withine Céci (2018). They chose this magazine since it is produced in and for Korea and widely circulated. Choi coded the images within the magazine based on race (Black, Asian, White, Other Person of Color, or Indistinguishable), facial features (White-appearing, Black-appearing, Asian-appearing), and hairstyle (straight, curly, tied, no hair). They found that the most common race represented was Asian, followed by White, and that most of the Asian women presented in the magazine had White-leaning facial features and unnaturally dyed and styled hair to reflect the hairstyles popular among White women (curly, lighter hair).

Watch this short film about Korean culture, women, identity, and dress. 
Watch this short film about Indian culture, women, dress, and identity.

Watch this short film about Comanche identity, fashion, and dress.

One or more interactive elements has been excluded from this version of the text. You can view them online here: https://iastate.pressbooks.pub/dressappearancediversity/?p=96\#oembed-4

One or more interactive elements has been excluded from this version of the text. You can view them online here: https://iastate.pressbooks.pub/dressappearancediversity/?p=96\#oembed -5

\section{Race and Ethnicity Case Study}

\section{Step One: Become familiar with the case study.}

1. The case study attached below is a Word document and can be downloaded. It includes the task, evaluation, and template for the case study:

$\underline{\text { Race and Ethnicity Case Study [DOC] }}$

Step Two: Submit your complete assignment on Canvas.

1. Format your document.

2. Remember to check the submission against the rubric. 


\section{FINAL STUDENT REFLECTION}

\section{Course Learning Objectives (CLO)}

At the end of this course, you should be able to

- CLO 1 Analyze foundational concepts and theories related to dress, identity, fashion, and culture and how they intersect with sex, gender, sexuality, beauty, attractiveness, disability, religion, race, and ethnicity, with heightened attention to marginalized communities in the United States.

- CLO 2: Analyze the experiences and the role of fashion, clothing, dress, and/or accessories for identity development, with heightened attention to marginalized communities within social contexts in the United States.

- CLO 3: Critique social justice issues within the fashion system in the United States for marginalized communities.

- CLO 4: Deconstruct one's personal values and positionalities in relation to fashion, clothing, dress, and/or accessories with heightened attention to marginalized communities in the United States society to be able to live in and collaborate with others in the United States.

- CLO 5: Identify the driving forces of transformative social justice change in the fashion system.

- CLO 6: Analyze what academic honesty means, your experiences with academic honesty, and your related goals. 


\section{Final Student Reflection}

Step One: Become familiar with the final student reflection.

1. The final student reflection attached below is a Word document and can be downloaded. It includes the task, evaluation, and template for the final student reflection:

Final Student Reflection [DOC]

Step Two: Submit your complete assignment on Canvas.

1. Format your document.

2. Reminder to check the submission against the rubric.

\section{Fashion Culture, History, and Social Justice Minor}

If the content in AMD 165 was of much interest to you, you might want to explore the Fashion, Culture, History, and Social Justice minor in the Apparel, Merchandising, and Design program at lowa State University (Apparel, Merchandising, and Design, 2021).

The minor consists of three parts:

- the 3-credit course AMD 165 Dress, Appearance, and Diversity in Society

- 6 credits from a list of core classes in area of history, social psychology, and/or cultural studies related to fashion. These courses have an entire focus on social justice perspectives, or at least $25 \%$ of the curriculum has a focus on social justice perspectives.

- AMD 354 History of European and North American Dress

- AMD 356 History of 20th-Century Fashion

- AMD 366 History of Menswear

- AMD 458 Queer Fashions, Styles, and Bodies

- $A$ AESHM 462 Black Lives Matter: Fashion, Liberation, and the Fight for Freedom

- 6 credits from a list of electives that complement the core of the minor. These 6 credits may not specifically look at issues of power, privilege, and social inequity, yet the content does focus on historically marginalized communities (e.g., African Americans, Native Americans, women, queer community) or 
related topics. Many of courses in this option do focus on power and privilege, which is great for the minor.

Select from African and African American Studies coursework:

- AF AM 201: Introduction to African American Studies

- AF AM/ANTHR 325: Peoples and Cultures of Africa

- AF AM/HIST 311: African under Colonial Rule

- AF AM/SOC 330: Ethnic and Race Relations

- AF AM/RELIG 334: African American Religious Experience

- AF AM/ENGL 347: Studies in African American Literature

- AF AM/WGS 350: Women of Color in the United States

- AF AM/HIST 353: History of African Americans I

- AF AM/HIST 354: History of African Americans II

- AF AM/HIST 473: Civil Rights and Ethnic Power

Select from American Indian Studies coursework:

- AM IN 201: Native People in American Culture

- AM IN 205: American Indians in the Movies

- AM IN 210: Introduction to American Indian Studies

- AM IN/AHTHR 225: American Indians of lowa

- AM IN 310: Topic in American Indian Studies

- AM IN/ANTHR 322: Peoples and Cultures of Native North America

- AM IN/RELIG 328: American Indian Religions

- $A^{*}$ M IN/AHTHR 332: Current Issues in Native North America

- AM IN/ENGL 346: American Indian Literature

Select from Anthropology coursework:

- AM IN/AHTHR 225: American Indians of lowa

- ANTHR/AM IN 322: Peoples and Cultures of Native North America

- AF AM/ANTHR 325: Peoples and Cultures of Africa

- AHTHR/AM IN 332: Current Issues in Native North America

- ANTHR/WGS 444: Sex and Gender in Cross-cultural Perspectives

Select from American Sign Language coursework:

- ASL 107: Introduction to the Deaf World

- ASL 275: Topics in Deaf Culture

- ASL 325: Deaf Peoples: Pre-World War II 
Select from Apparel, Merchandising, and Design coursework:

- A M D 362: Cultural Perspectives of Dress

Select from Arabic coursework:

- ARABC 375: Arab Culture

Select from Architecture coursework:

- ARCH 426: Topics in Native American Architecture

Select from Art History coursework:

- ART H 382: Art and Architecture of Asia

- ART H 384: Art of Islam

- ART H/WGS: 494 Women/Gender in Art

Select from Chinese coursework:

- CHIN 272: Introduction to Chinese Culture

- CHIN 370: Chinese Literature in English Translation

- CHIN 375: China Today

- CHIN 378: Chinese Film and Society

- CHIN 403: Seminar in Chinese Language and Culture

Select from Classical Studies coursework:

- CL ST/HIST/WGS 374: Sex, Gender, and Culture in the Ancient Mediterranean World

Select from Economics coursework:

- ECON/WGS 321: Economics of Discrimination

Select from English coursework:

- ENGL/WGS 340: Women's Literature

- ENGL/ US LS 344: U.S. Latino/a Literature

- ENGL/AM IN 346: American Indian Literature

- ENGL/AF AM 347: Studies in African American Literature

- ENGL/WGS 352: Gay and Lesbian Literature 
Select from History coursework:

- HIST 207: Chinese Civilizations

- HIST 225: Introduction to Asian American Studies

- HIST 331: History of the Islamic World to 1800

- HIST 336: History of Modern China I

- HIST 337: History of Modern China II

- HIST 338: Modern Japanese History

- HIST 340: History of Latin America I

- HIST 341: History of Latin America II

- HIST/AF AM 353: History of American Americans I

- HIST/AF AM 354: History of American Americans II

- HIST/US LS 371: Mexican American History

- HIST/US LS 372: Latina/o History

- HIST/CL ST/WGS 374 Sex, Gender, and Culture in the Ancient Mediterranean World

- HIST/WGS 380 History of Women in Science, Technology, and Medicine

- HIST/WGS 386 History of Women in America

- HIST 410: The Holocaust in History

- HIST 435: History of the Modern Middle East

- HIST 441: History of Modern Mexico and Central America

- HIST/WGS 457: History of American Sexualities

- HIST 465: The American West

- HIST/AF AM/US LS 473: Civil Rights and Ethnic Power

Select from Leadership Studies coursework:

- LD ST/WGS 333: Women and Leadership

- LD ST/WGS 488: Research on Women in Leadership

Select from Philosophy coursework:

- PHIL 235: Ethical Issues in a Diverse Society

- PHIL/WGS 338: Feminist Philosophy

Select from Political Science coursework:

- POL S/WGS 385: Women in Politics

Select from Psychology coursework:

- PSYCH/WGS 346: Psychology of Women 
- PSYCH/US LS 347: US Latino/a Psychology

Select from Religious Studies coursework:

- RELIG 210: Religion in America

- RELIG/AM IN 328: American Indian Religions

- RELIG 333: Introduction to Judaism

- RELIG/AF AM 334: African American Religious Experience

- RELIG/WGS 336: Women and Religion

- RELIG/US LS 342: Religion and U.S. Latino/a Literature

- RELIG/WLC 352: Religious Traditions of India

- RELIG/WLC 358: Introduction to Islam

Select from Sociology coursework:

- SOC 235: Social Problems and American Values

- SOC 327/WGS327: Sex and Gender in Society

- SOC/AF AM 330: Ethnic and Race Relations

- SOC 331: Social Class and Inequality

- SOC 332: The Latino/Latina Experience in U.S. Society

- SOC 350: Women in Agriculture and the Food System

Select from U.S. Latino/a Studies coursework:

- US LS 211: Introduction to U.S. Latino/a Studies

- US LS 323/ANTHR 323: Topics in Latin American Anthropology

- US LS/ANTHR 323A: Latin American Anthropology: Violence and Memory

- US LS/ANTHR 323B: Latin American Anthropology: Social Movements and Democracy

- US LS/ANTHR 323C: Latin American Anthropology: Race, Class and Gender

- US LS/ANTHR 323D: Latin American Anthropology: Regional Focus

- US LS/ANTHR 323E: Latin American Anthropology: Culture and Sport

- US LS/RELIG 342: Religion and U.S. Latino/a Literature

- US LS/POL S 343: Latin American Government and Politics

- US LS/ PSYCH 347: U.S. Latino/a Psychology

- US LS/HIST 371: Mexican American History

- US LS /HIST 372: Latina/o History

- US LS/AF AM/HIST 473: Civil Rights and Ethnic Power

Select from Women's and Gender Studies coursework:

- WGS 201: Introduction to Women's and Gender Studies 
- WGS 203: Introduction to Lesbian Studies

- WGS 205: Introduction to Queer Studies

- WGS 210: Gender and Sexuality in American Pop Culture

- WGS 301: International Perspective on Women and Gender

- WGS/ENV S: 320: Ecofeminism

- WGS/ECON 321: Economics of Discrimination

- WGS 323: Gender and Communication

- WGS 325: Portrayals of Gender and Sexualities in the Media

- WGS/SOC 327: Sex and Gender in Society

- WGS/ LD ST 333: Women and Leadership

- WGS/RELIG 336: Women and Religion

- WGS/PHIL 338: Feminist Philosophy

- WGS/ENGL 340: Women's Literature

- WGS/PSYCH 346: Psychology of Women

- WGS/AF AM 350: Women of Color in the United States

- WGS/ENGL 352: Gay and Lesbian Literature

- WGS/HIST/CL ST 374: Sex, Gender, and Culture in the Ancient Mediterranean World

- WGS/HIST 380: History of Women in Science, Technology, and Medicine

- WGS/POL S 385: Women in Politics

- WGS/HIST 386: History of Women in America

- WGS 435: Gender, Globalization and Development

- WGS/ANTHR 444: Sex and Gender in Cross-cultural Perspectives

- WGS/HIST 457: History of American Sexualities

- WGS/LD ST 488: Research on Women in Leadership

- WGS/ART H 494: Women/Gender in Art

Select from World Languages and Cultures coursework:

- WLC/RELIG 352: Religious Traditions of India

- WLC/RELIG 358: Introduction to Islam 


\title{
BOOK CONTRIBUTORS
}

\section{Author}

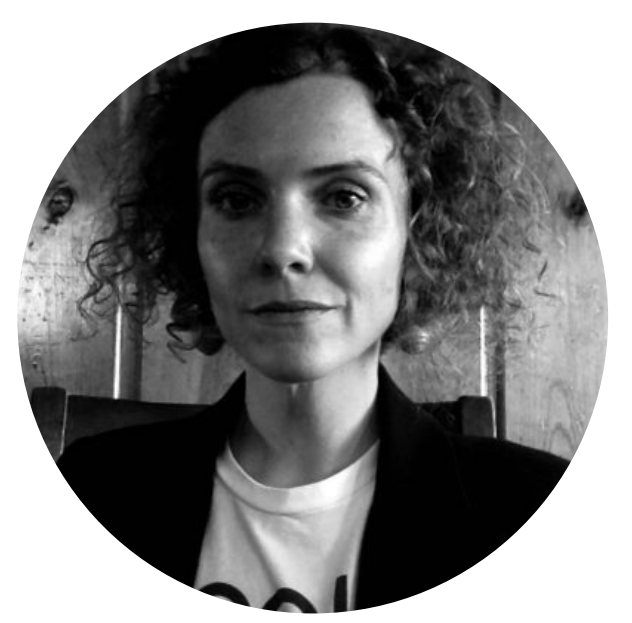

\author{
Kelly L. Reddy-Best \\ IOWA STATE UNIVERSITY \\ http://www.kellyreddy-best.com/
}

Kelly L. Reddy-Best is an associate professor in Apparel, Merchandising, and Design at lowa State University and the curator and director of ISU's Textiles and Clothing Museum. In her research, she examines the interrelationships of dress, identity, consumption, regulation, and the fashion system. All of her work is rooted in a social justice lens. She has taught courses across the apparel curriculum in design, product development, merchandising, culture, and history.

She has taught Dress Appearance and Diversity in US Society every semester since starting at lowa State in 2016, including winter and summer sessions. The course enrollment averages 280 students, and she has delivered the course in-person and online.

\section{Contributors}

\section{Abbey K. Elder \\ IOWA STATE UNIVERSITY \\ https://twitter.com/OpenAccessElder}

Abbey K. Elder is the Open Access and Scholarly Communication Librarian for lowa State University. She provides support for authors developing open textbooks and other open educational resources (OER) at lowa State. 
BOOK CONTRIBUTORS | 142

\section{Lesya Hassall}

IOWA STATE UNIVERSITY

Lesya leads technical and pedagogical support of audience response technology. Her primary duties revolve around the design, development and implementation of faculty training opportunities for meaningful and effective applications of instructional technologies, including audience response technology. 